\title{
Criticality Experiments to Provide Benchmark Data on Neutron Flux Traps
}

\author{
S. R. Bierman
}

June 1988

Prepared for the U.S. Department of Energy under Contract DE-AC06-76RLO 1830

Pacific Northwest Laboratory

Operated for the U.S. Department of Energy by Battelle Memorial Institute 


\section{DISCLAIMER}

This report was prepared as an account of work sponsored by an agency of the United States Government. Neither the United States Government nor any agency thereof, nor Battelle Memorial Institute, nor any or their employees, makes any warranty, expressed or implied, or assumes any legal liability or responsibility for the accuracy, completeness, or usefulness of any information, apparatus, product, or process disclosed, or represents that its use would not infringe privately owned rights. Reference herein to any specific commercial product, process, or service by trade name, trademark, manufacturer, or otherwise does not necessarily constitute or imply its endorsement, recommendation, or favoring by the United States Government or any agency thereof, or Battelle Memorial Institute. The views and opinions of authors expressed herein do not necessarily state or reflect those of the United States Government or any agency thereof, or Battelle Memorial Institute.

\section{PACIFIC NORTHWEST LABORATORY operated by BATTELLE MEMORIAL INSTITUTE for the UNITED STATES DEPARTMENT OF ENERGY under Contract DE-AC06-76RLO 1830}

Printed in the United States of America
Available from
National Technical Information Service
United States Department of Commerce
5285 Port Royal Road
Springfield, Virginia 22161
NTIS Price Codes
Microfiche A01
Printed Copy
Pages
$001-025$
$026-050$


CRITICALITY EXPERIMENTS

TO PROVIDE BENCHMARK DATA

ON NEUTRON FLUX TRAPS

S. R. Bierman

June 1983

Prepared for

the U. S. Department of Energy under Contract DE-AC06-76RLO 1830

Pacific Northwest Laboratory

Richland, Washington 99352 


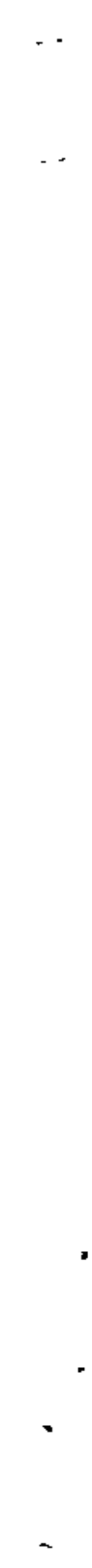




\section{SUMMARY}

A research program was initiated by the Sandia National Laboratories in 1982 to provide benchmark type experimental criticality data in support of the design and safe operations of nuclear fuel transportation systems. The overall objective of the program is to identify and provide the experimental data needed to form a consistent, firm, and complete data base for verifying calculational models used in the criticality analyses of nuclear transport and related systems. The results obtained from the initial series of experiments in this program are presented in this report along with a complete description of the experiments.

The experimental measurements covered by this report were designed to provide benchmark type data on water moderated LWR type fuel arrays containing neutron flux traps. The experiments were performed at the U. S. Department of Energy Hanford critical Mass Laboratory, operated by Pacific Northwest Laboratory. The experimental assemblies consisted of $2 \times 2$ arrays of $4.31 \mathrm{wt} \%{ }^{235} \mathrm{U}$ enriched $\mathrm{UO}_{2}$ fuel rods, uniformly arranged in water on a $1.891 \mathrm{~cm}$ square center-to-center spacing. Neutron flux traps were created between the fuel units using metal plates containing varying amounts of boron. Measurements were made to determine the effect that boron loading and distance between the fuel and flux trap had on the amount of fuel required for criticality. Also, measurements were made, using the pulse neutron source technique, to determine the effect of boron loading on the effective neutron multiplication constant. On two assemblies, reaction rate measurements were made using solid state track recorders to determine absolute fission rates in ${ }^{235} \mathrm{U}$ and ${ }^{238} \mathrm{u}$.

Benchmark type data were obtained on the :

- Effect on boron concentration on critical size

- Effect of water gap between fuel and neutron flux trap on critical size

- Effectiveness of boron concentration to reduce keff 
In general these data indicate that the effectiveness of neutron flux traps for criticality control is relatively insensitive to boron loadings above about $0.1 \mathrm{~g} \mathrm{~B} / \mathrm{cm}^{2}$ and are essentially ineffective when separated from the fuel unit by more than $6 \mathrm{~cm}$ of water. Also the ${ }^{235} \mathrm{U}$ and ${ }^{238} \mathrm{U}$ fission rates observed indicate that the boron loading primarily affects the neutron intensity but not the neutron spectrum in a flux trap region. 
CONTENTS

SUMMARY ..........................

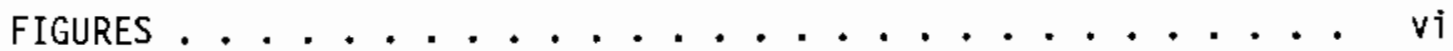

TABLES ............................. vii

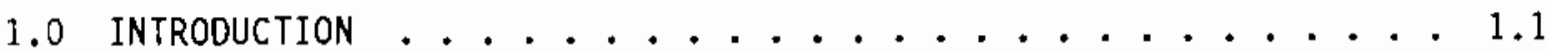

2.0 DESCRIPTION OF EXPERIMENTAL ASSEMBLIES .......... 2.1

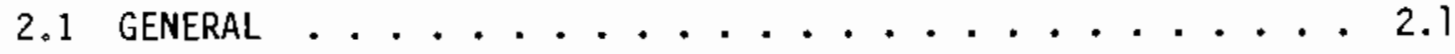

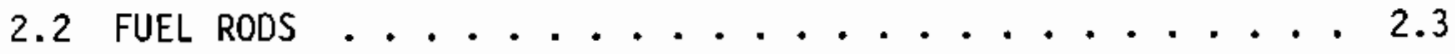

2.3 MODERATOR - REFLECTOR . . . . . . . . . . 2.6

2.4 LATTICE PLATES AND SUPPORTS . . . . . . . . 2.6

2.5 FLUX TRAP PLATES . . . . . . . . . . . . 2.6

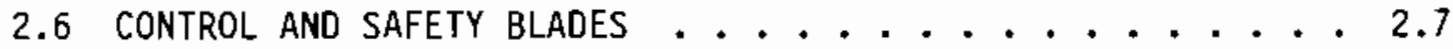

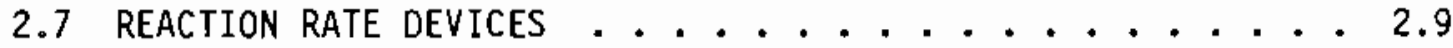

3.0 EXPERIMENTAL MEASUREMENTS AND RESULTS ............... 3.1

3.1 EFFECT OF BORON CONCENTRATION

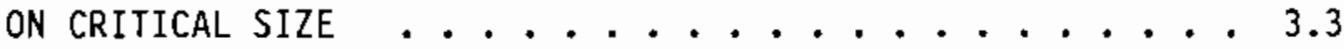

3.2 EFFECT OF WATER GAP BETWEEN FUEL

AND NEUTRON FLUX TRAP ON CRITICAL SIZE ........ 3.3

3.3 EFFECTIVENESS OF BORON CONCENTRATION

TO REDUCE $\mathrm{K}_{\mathrm{eff}} \ldots \ldots \ldots \ldots \ldots \ldots \ldots . \ldots \ldots$

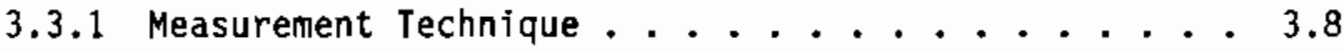

3.3.2 Description of Pulse Neutron System . . . . . 3.12

3.3.3 Experimental Measurements and Results . . . . . 3.12

3.4 FISSION RATES IN ${ }^{235} \mathrm{U}$ AND ${ }^{238} \mathrm{U} \ldots \ldots . \ldots . \ldots . \ldots . . \ldots 38$

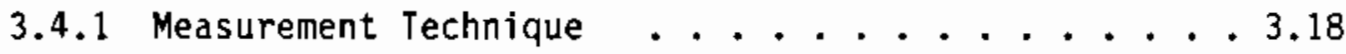

3.4.2 Experimental Measurements \& Results . . . . . 3.22

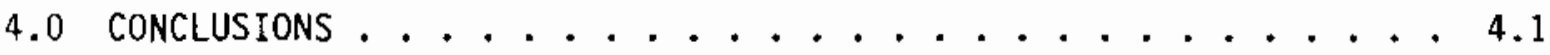

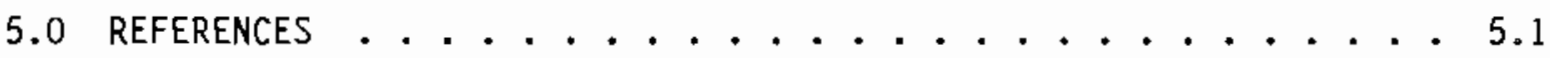




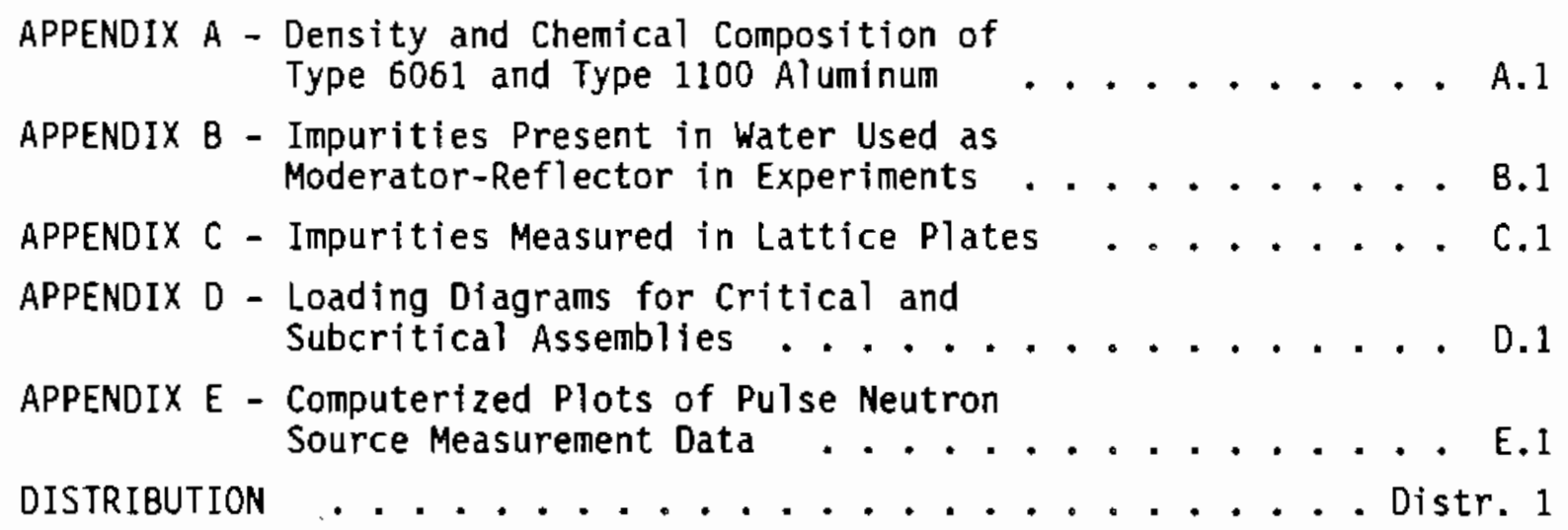




\section{FIGURES}

1.1 Typical Experimental Assembly . . . . . . . . . 1.3

2.1 Experimental System Modified for use in Experiments . . . . . 2.2

2.2 Description of 4.31 wt\% ${ }^{235}$ Enriched $\mathrm{UO}_{2}$ Fuel Rods . . . . . 2.4

2.3 Experimental Assembly Elevations . . . . . . . . . . 2.5

3.1 Critical Number of Fuel Rods as a Function of Boron Concentration In Neutron Flux Traps . . . . . . . . . 3.4

3.2 Critical Number of Fuel Rods As Function of Separation Between Fuel and Neutron Flux Trap ............ 3.7

3.3 Pulse Neutron Source and Data Acquisition System . . . . . . 3.13

3.4 Average $k_{\text {eff }}$ Values As a Function of Boron Loading in Flux Trap . . . . . . . . . . . 3.16

3.5 Prompt Neutron Decay Rate As Function of Assembly Fuel Loading and Boron Creating the Neutron Flux Trap . . . . . 3.17

3.6 Layout of Experimental Assembly 230 Showing Fuel Rod Loading and SSTR for Irradiation . . . . . . . . . . 3.19

3.7 Layout of Experimental Assembly 231 Showing Fuel Rod Loading and SSTR for Irradiation . . . . . . . 3.20

3.8 Typical SSTR Geometrical Configuration . . . . . . . . 3.21 


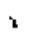

, 


\section{$\underline{\text { TABLES }}$}

2.1 Description of Neutron Flux Trap Plates . . . . . . . . 2.8

2.2 Boron Carbide Particle Distribution . . . . . . . . . . 2.7

3.1 Experimental Results - Delayed Critical $2 \times 2$ Lattice Assemblies of $4.31 \mathrm{wt} \%{ }^{235} \mathrm{U}$ Enriched $\mathrm{UO}_{2}$ Fuel Rods in Water Separated by Neutron Flux Traps Containing

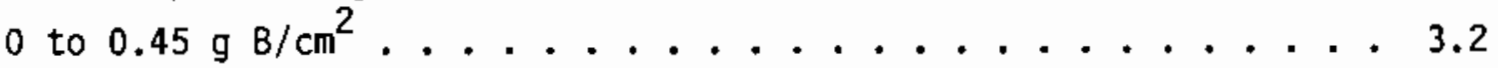

3.2 Experimental Results - Delayed Critical $2 \times 2$ Lattice Assemblies of $4.31 \mathrm{wt} \%{ }^{235} \mathrm{U}$ Enriched $\mathrm{UO}_{2}$ Fuel Rods in Water at Various Distances from a $3.73 \mathrm{~cm}$ Wide Neutron Flux Trap Created by $0.36 \mathrm{~g} \mathrm{~B} / \mathrm{cm}^{2}$ Boral . . . . . . . . 3.6

3.3 Experimental Results - Average keff and Prompt Neutron Decay Constants in $2 \times 2$ Lattice Assemblies of $4.31 \mathrm{wt} \%{ }^{235} \mathrm{U}$ Enriched $\mathrm{UO}_{2}$ Fuel Rods in Water Separated by Neutron Flux Traps Containing 0 to $0.45 \mathrm{~g} \mathrm{~B}^{\mathrm{cm}} \mathrm{cm}^{2}$............. 3.14

3.4 Power-Time History for SSTR Irradiations . . . . . . . . . 3.23

3.5 Fission Rates in $0.05 \mathrm{~g} \mathrm{~B} / \mathrm{cm}^{2}$ and $0.45 \mathrm{~g} \mathrm{~B} / \mathrm{cm}^{2} \mathrm{Flux}$ Trap Assemblies ................. . . . 3.24 



\section{CRITICALITY EXPERIMENTS TO PROVIDE \\ BENCHMARK DATA ON NEUTRON FLUX TRAPS}

\subsection{INTRODUCTION}

A research program was initiated for the U.S. Department of Energy (DOE) Sandia National Laboratories Transportation Systems Development Department in 1982 to provide benchmark type experimental criticality data in support of the design and safe operations of nuclear fuel transportation system. The overall objective of the program is to identify and provide the experimental data needed to form a consistent, firm, and complete data base for verifying calculational models used in the criticality analyses of nuclear transport and related systems.

As an initial effort under this program, the existing experimental data suitable for validating neutronic calculations on fuel transportation and storage systems were identified (Bierman, 1983). In addition to identifying the existing data, areas in which additional data were needed to from a complete data base were also identified by the study. One area in which the study indicated additional data was particularly needed involved systems containing neutron flux traps. Such flux traps are created in transportation systems and high density fuel storage racks by the practice of using sleeves or canisters containing strong thermal neutron absorbers around the fuel elements for criticality control. These arrangements create very effective neutron flux traps in which non-thermal neutrons escaping the absorber sleeve are thermalized and thus "trapped" outside the sleeves enclosing the fuel elements. The effectiveness of these flux traps to maintain a given degree of subcriticality is very sensitive to the amount of water between the absorber sleeves, the amount of absorber and the location of the flux trap. A recently completed multi-national exercise (CSNI Working Group, 1982) by the Organization for Economic Cooperation and Development's Nuclear Energy Agency (OECD-NEA) revealed an inability for calculational models to 
adequately agree on the effectiveness of neutron flux traps in such systems. Consequently, the first in a series of criticality experiments to be performed under this research program were designed to provide data on systems containing neutron flux traps. The experiments and the results obtained are presented in this report.

The experiments were performed at the U. S. Department of Energy Hanford Critical Mass Laboratory, operated by Pacific Northwest Laboratory of Battelle Memorial Institute. The experimental measurements are described in detail in the sections that follow. Briefly, however, the experimental assemblies consisted of $2 \times 2$ arrays of $4.31 \mathrm{wt} \%{ }^{235} \mathrm{U}$ enriched $\mathrm{UO}_{2}$ fuel rods, uniformly arranged in water on a $1.891 \mathrm{~cm}$ square center-to-center spacing. Neutron flux traps were created between the fuel units using metal plates (T6061 Al or Boral ${ }^{T M}$ ) containing varying amounts of boron. A photograph of one of the assemblies is shown in Figure 1.1. Measurements were made to determine the effect that boron loading and distance between the fuel and flux trap had on the amount of fuel required for criticality. Also, measurements were made, using the pulse neutron source technique, to determine the effect of boron loading on the effective neutron multiplication constant. On two assemblies, reaction rate measurements were made using solid state track recorders to determine absolute fission rates in ${ }^{235} U$ and $238_{U}$.

Boral is a trademark product of Brooks and Perkins, Inc. 


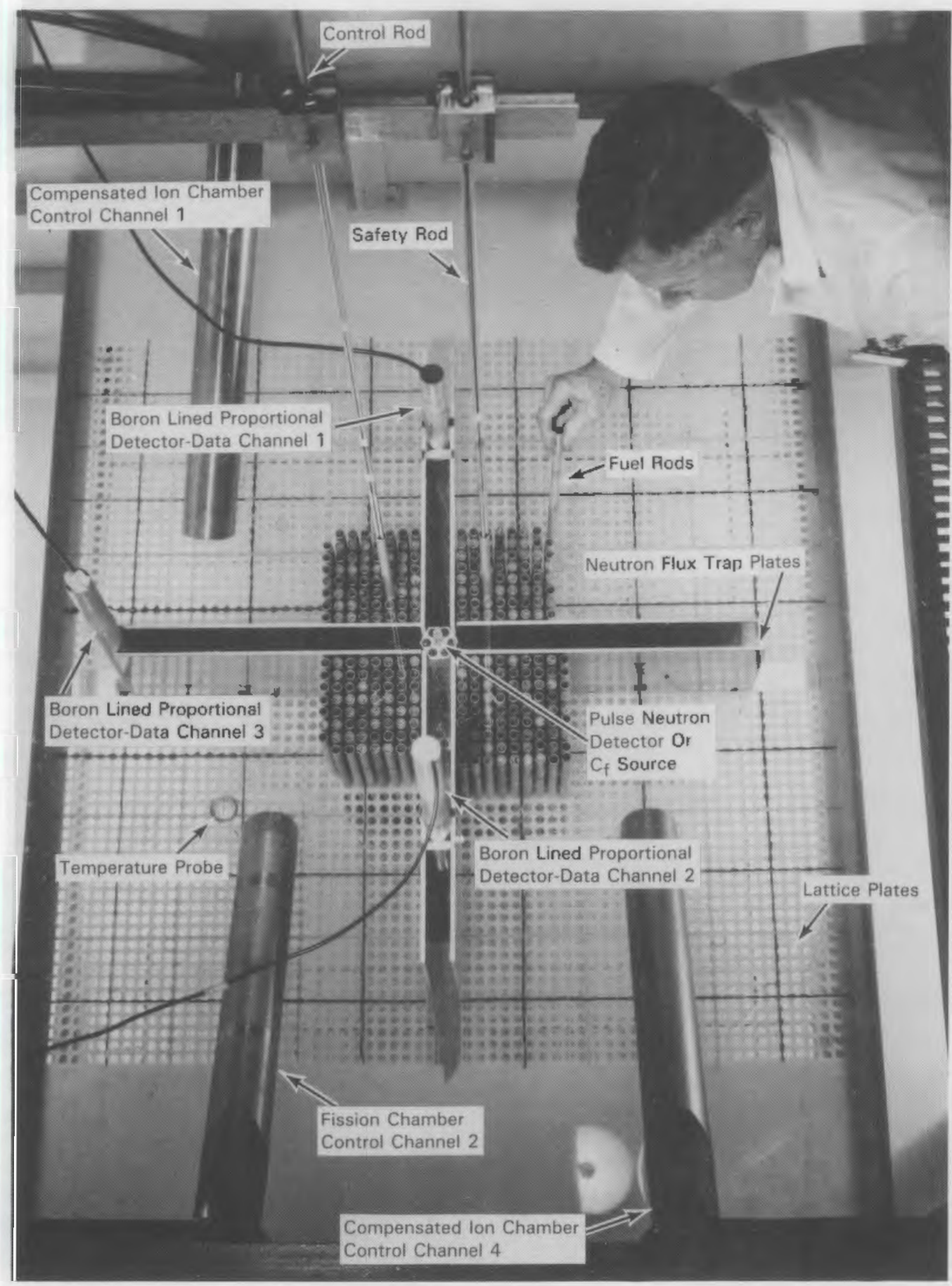

Figure 1.1 Typical Experimental Assembly 



\subsection{GENERAL DESCRIPTION OF EXPERIMENTAL ASSEMBLIES}

The experimental system and materials used in making the measurements covered by this report are described in this section.

\subsection{GENERAL}

An existing experimental system used previously in fuel element array studies at the Critical Mass Laboratory was used in performing the measurements covered in this report. This system, the Fuel Element Array System (FEAS), consists of a $1.8 \mathrm{~m} \times 3 \mathrm{~m} \times 2.1 \mathrm{~m}$ deep, open-top, carbon-steel tank provided with a moderator/reflector dump valve, a control blade drive, a safety blade drive, a water deionizer, and associated electronic detection and interlock devices. An overall photograph of the system is shown in Figure 2.1

The control and safety blade drive systems shown in Figure 2.1 were modified to permit replacing the blades with rod-type devices. Also, a set of lattice plates were positioned below the control and safety drives to permit assembling 2 $x 2$ arrays of fuel until separated by a neutron flux trap. A photograph of an experimental assembly is shown in Figure 1.1 as typical.

Data were obtained on water moderated assemblies of 4.31 wt\% ${ }^{235} U$ enriched $\mathrm{UO}_{2}$ fuel rods at constant center-to-center fuel rod spacing of $1.891 \mathrm{~cm}$ in a square arrangement. This lattice spacing results in a moderator-to-fuel volume ratio of 1.6, which approximates that found typically in Boiling Water Reactors (BWR) and in Pressurized Water Reactors (PWR). Each assembly consisted of four, near equally sized units of fuel rods separated by a neutron flux trap and varying amounts of moderator. Measurements were made with flux traps created by Boral plates of approximately equal thickness and containing $0.45 \mathrm{~g} \mathrm{~B} / \mathrm{cm}^{2}, 0.36 \mathrm{~g}$ $\mathrm{B} / \mathrm{cm}^{2}, 0.13 \mathrm{~g} \mathrm{~B} / \mathrm{cm}^{2}, 0.05 \mathrm{~g} \mathrm{~B}^{2} \mathrm{~cm}^{2}$, and no boron (aluminum plates). The width (thickness) of the flux traps was held approximately constant at $3.7 \mathrm{~cm}$ (previous experiments, Bierman and Clayton, 1981, provided data on the effectiveness of a flux trap to reduce a system subcritical as the distance between plates increased). 


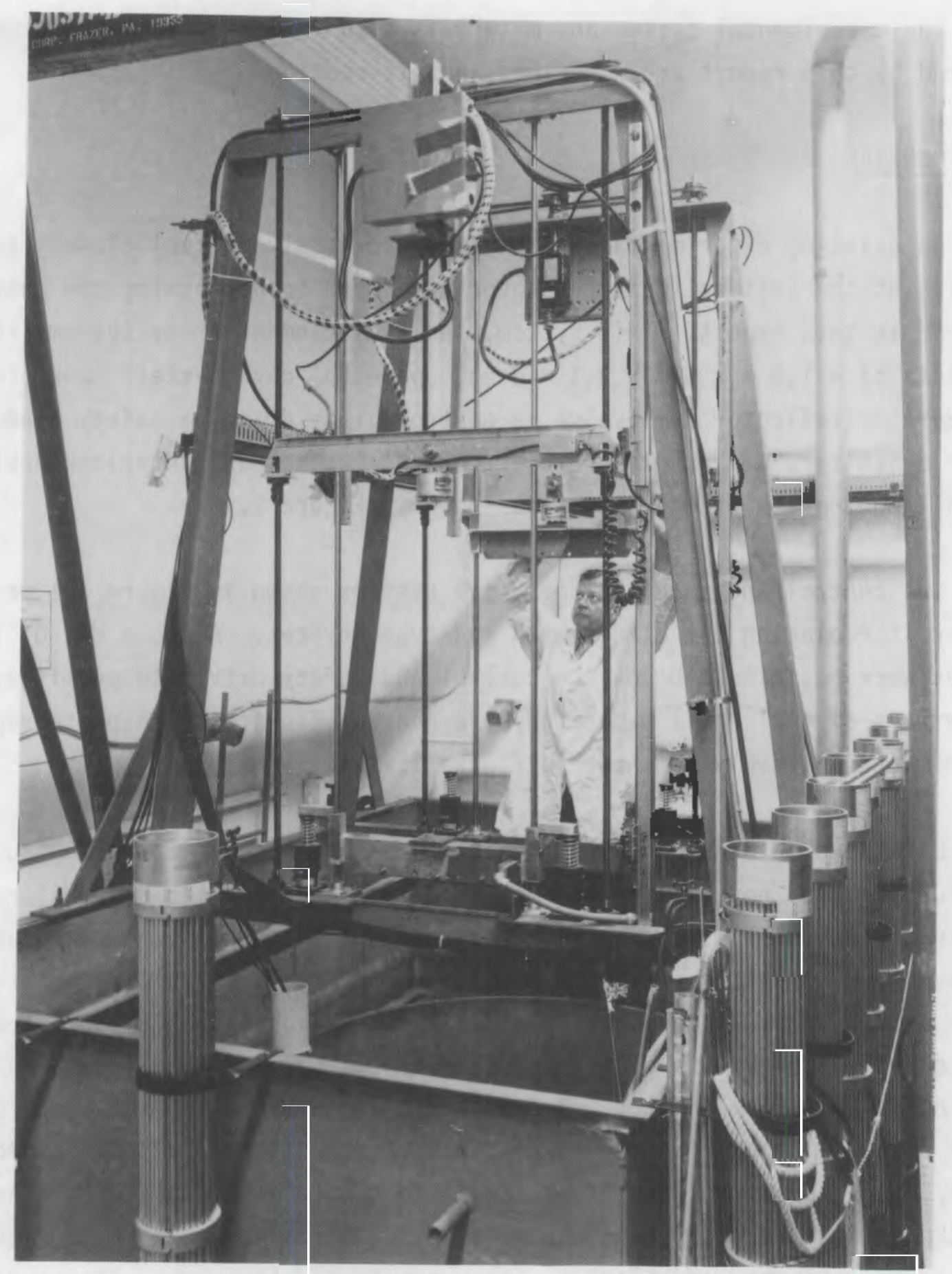

Figure 2.I Experimental System Modified for use in Experiments 
All of the assemblies were fully reflected by at least $15 \mathrm{~cm}$ of water on all sides and essentially free of any structural materials in the fuel and flux trap regions. All of the instrument thimbles were located outside the fuel area except in the subcritical pulse neutron source measurements. In these measurements the detector was located in the center of each assembly and the reactivity worth was measured in terms of assembly fuel loading. Except for the $1.2 \mathrm{~cm}$ diameter T6061 aluminum guide tubes for the safetycontrol rods and the 0.2 microgram ${ }^{252} \mathrm{Cf}$ source used in the critical approach measurements, all other material (lattice and base support plates) in the fuel-flux trap regions have neutronic properties similar to the water moderator. Consequently, each assembly can be considered as a fully water reflected and moderated assembly of fuel only, in which the fuel is separated by the specified flux trap and water gaps.

\subsection{FUEL RODS}

The fuel rods used to construct each experimental assembly were $4.31 \mathrm{wt} \%$ $235 \mathrm{U}$ enriched $\mathrm{UO}_{2}$ rods previously obtained by downloading stainless steel clad rods, originally fabricated for Core II of the N. S. Savannah (Katz 1969), and reloading the pellets into type 6061 aluminum tubes (see Appendix A for American Society for Testing Materials, T6061 Al Specifications). A complete description of these rods is given in Figure 2.2. The uranium assay $(1059.64 \pm 4.80 \mathrm{~g} / \mathrm{rod})$ and the ${ }^{235} \mathrm{U}$ enrichment $(4.306 \pm 0.013 \%)$ shown in Figure 2.2 for these rods are the average of six assays and six spectrographic analyses made on fuel pellets chosen at random during the reloading. The oxide density $\left(10.40 * 0.06 \mathrm{~g} \mathrm{vO}_{2} / \mathrm{cm}^{3}\right)$ given in Figure 2.2 is based on individual volume displacement measurements with 20 pellets selected at random during the reloading operations. The mass of $\mathrm{UO}_{2}$ per rod $(1203.38$ $\pm 4.12 \mathrm{~g}$ ) is the average mass of the 1865 rods of this type available for use in the experiments. The fuel diameter $(1.265 \neq 0.003 \mathrm{~cm})$ given in Figure 2.2 was checked repeatedly during the reloading operations and found to agree with that quoted in the document characterizing Core II of the N. S. Savannah (Katz 1969). The rubber end cap density $\left(1.321 \mathrm{~g} / \mathrm{cm}_{3}\right)$ quoted in Figure 2.2 


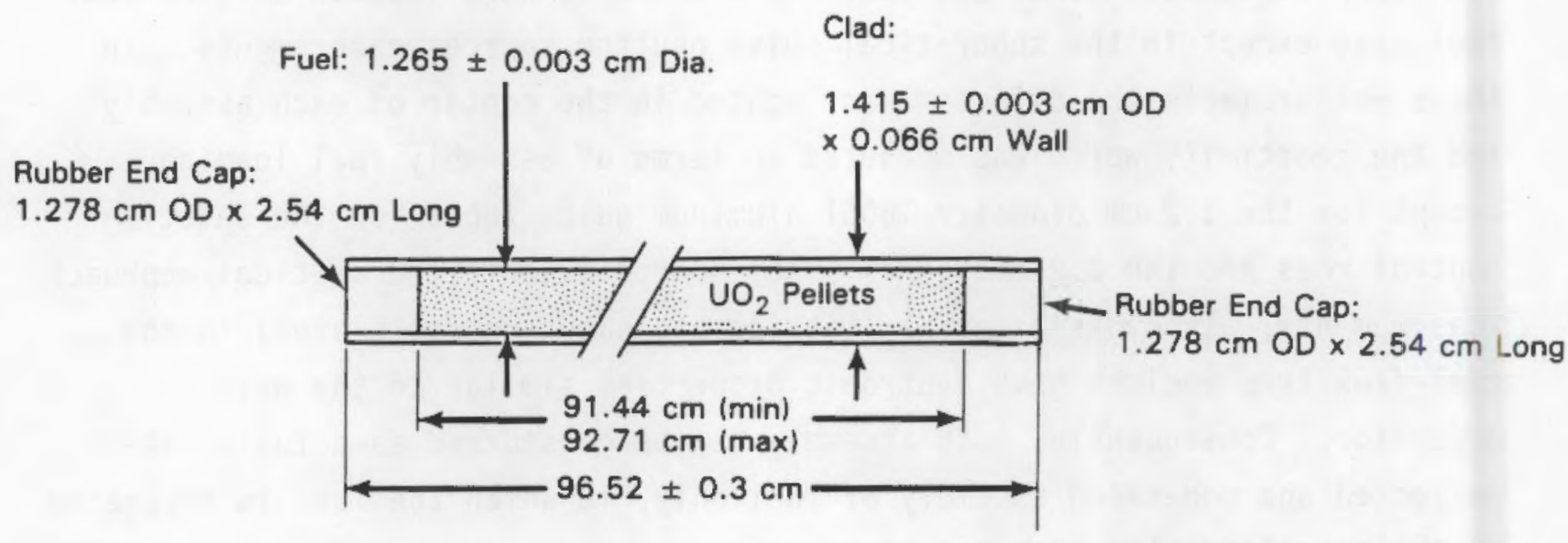

Cladding: 6061 Aluminum Tubing

Loading

Enrichment $-4.306 \pm 0.013 \% 235 \mathrm{U}$

Oxide Density - $10.40 \pm 0.06 \mathrm{~g} / \mathrm{cm}^{3}$

$\mathrm{UO}_{2}-1203.38 \pm 4.12 \mathrm{~g} / \mathrm{Rod}$

$\mathrm{U}-1059.64 \pm 4.80 \mathrm{~g} / \mathrm{Rod}$

Uranium Composition:

$$
\begin{aligned}
& 234 U-0.022 \pm 0.002 \\
& 235 U-4.306 \pm 0.013 \\
& 236 U-0.022 \pm 0.002 \\
& 238 U-95.650 \pm 0.017
\end{aligned}
$$

End Cap:

$$
\begin{array}{ll}
\mathrm{C}-58 \pm 1 w t \% & S-1.7 \pm 0.2 \text { wt } \% \\
H-6.5 \pm 0.3 w t \% & 0-22.1 \text { wt } \% \text { (Balance) } \\
\text { Ca-11.4 } \pm 1.8 w t \% & \text { Si- } 0.3 \pm 0.1 \text { wt } \%
\end{array}
$$

Notes:

1. Error limits are one standard deviation

2. End Cap Density is $1.321 \mathrm{~g} / \mathrm{cm}^{3}$

Figure 2.2 Description of $4.31 \mathrm{wt} \%{ }^{235}$ Enriched $\mathrm{UO}_{2}$ Fuel Rods 
for the $4.31 \mathrm{wt} \%{ }^{235} \mathrm{U}$ enriched fuel is the result of a single mass-volume measurement with six end caps selected at random. The composition of the end caps is the result of four analyses on randomly selected end caps.

\subsection{MODERATOR-REFLECTOR}

As indicated previously, each assembly was moderated and fully reflected with water. Impurities analyses of three water samples taken during the experiments are given in Appendix B.

\subsection{LATTICE PLATES AND SUPPORTS}

Three $1.23=0.01 \mathrm{~cm}$ thick, polypropylene lattice plates, having a $\mathrm{C}_{3} \mathrm{H}_{6}$ molecular structure and a density of $0.90 \mathrm{~g} / \mathrm{cm}^{3}$, were used to achieve and maintain uniform spacings between the fuel pins in each experimental assembly and between the fuel and the flux traps. Trace impurity levels for the lattice plates are given in Appendix $C$. Relative dimensions between flux trap materials and fuel positions in the lattice plates are given in each of the experimental assembly loading diagrams presented in Appendix $D$. These plates, which have neutronic properties similar to the water moderator, were the only structural materials in the fuel-moderator region of each assembly. The elevation of each lattice plate relative to other components in the experimental assemblies is shown in Figure 2.3.

In each assembly the fuel pins were supported on a $5.08 \mathrm{~cm}$ thick acrylic plate $\left(1.185 \mathrm{~g} / \mathrm{cm}^{3}\right.$ containing $8 \mathrm{wt} \% \mathrm{H}, 60 \mathrm{wt} \% \mathrm{C}$ and $\left.32 \mathrm{wt} \% 0\right)$ mounted off the FEAS tank walls. The elevation of the acrylic support plate, relative to components in the experimental assemblies is shown in Figure 2.3.

\subsection{FLUX TRAP PLATES}

The neutron flux traps between the fuel units were created by positioning parallel plates of Boral, separated by about $3.75 \mathrm{~cm}$ of water, between the fuel. The fuel units were not encased on all four sides since the measurements are concerned only with interaction between the units. 


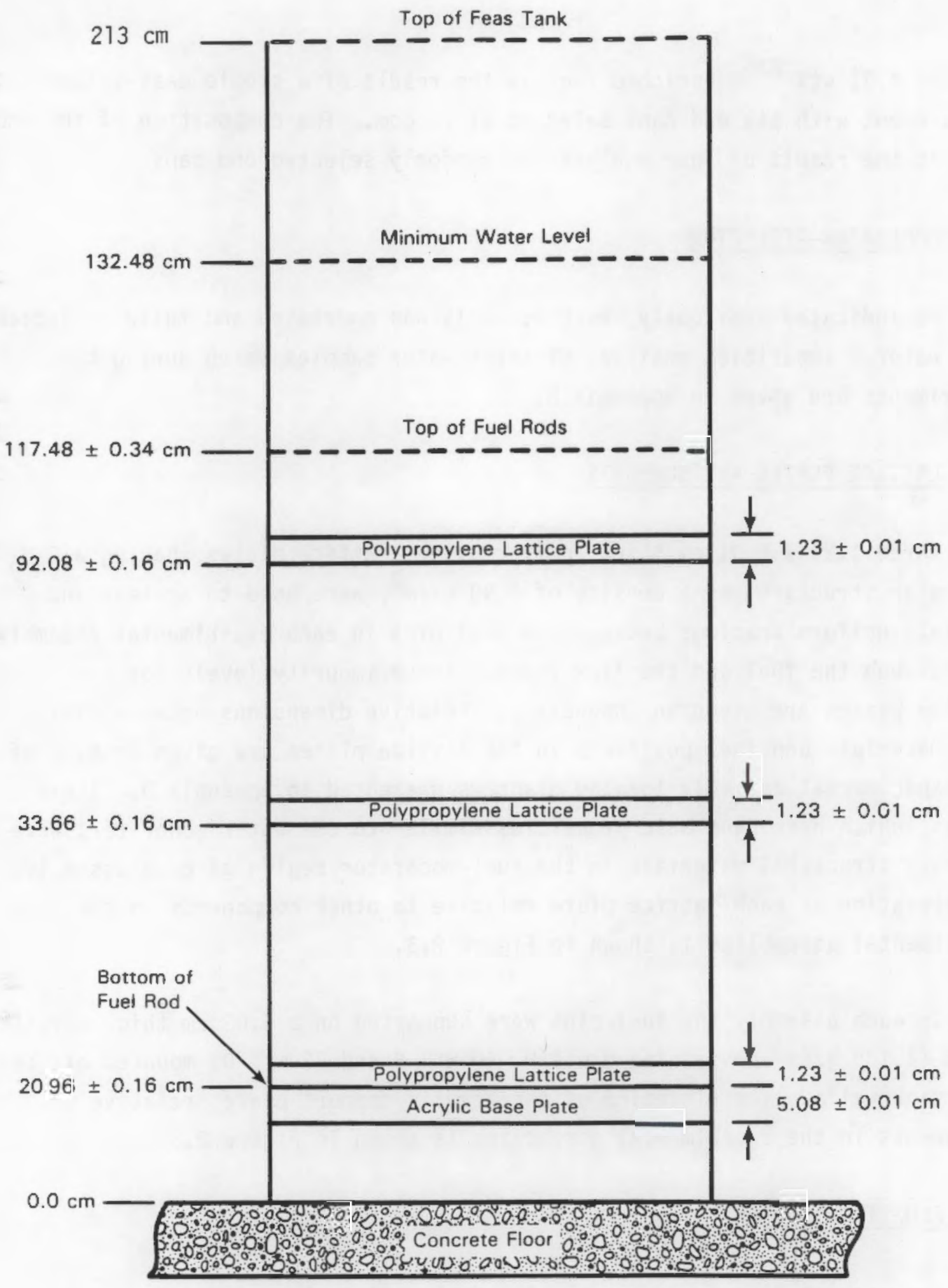

Figure 2.3 Experimental Assembly Elevations 
Also, not encasing the fuel on all sides permitted varying the size of the fuel units and the location of the fuel units relative to the flux trap region.

The plates consisted of a homogeneous matrix of aluminum and boron carbide particles sandwiched between two thin $(0.102 \mathrm{~cm})$ sheets of type 1100 A1. Plates containing boron loadings of $0.45 \mathrm{~g} \mathrm{~B} / \mathrm{cm}^{2}, 0.36 \mathrm{~g} \mathrm{~B} / \mathrm{cm}^{2}, 0.13 \mathrm{~g}$ $B / \mathrm{cm}^{2}$ and $0.05 \mathrm{~g} \mathrm{~B} / \mathrm{cm}^{2}$ were used in the measurements. The composition and the physical description of these plates are given in Table 2.1 The boron carbide particle size distribution is given in Table 2.2 and ASTM specifications for T1100 aluminum are given in Appendix A.

TABLE 2.2 Boron Carbide Particle Distribution

$\begin{array}{cc}\begin{array}{c}\text { Particle Size } \\ \mathrm{cm}\end{array} & \begin{array}{c}\text { Distribution } \\ \text { wt\% }\end{array} \\ >0.0300 & \\ >0.0180 & 0 \\ >0.0045 & 8.6 \\ \langle 0.0045 & 81.7 \\ & 9.7\end{array}$

As stated in a previous section, measurements were performed with a zero boron content in the flux trap plates. T6061 aluminum plates of approximately the same thickness and size as the Boral plates were used in these measurements. ASTM specifications for T6061 aluminum are given in Appendix A.

\subsection{CONTROL AND SAFETY BLADES}

The FEAS control and safety drives were provided with gadolinium rods such that each experimental assembly could be constructed in compliance with operating regulations and procedures. These rods and their associated Type 
TABLE 2.1 Description of Neutron Flux Trap Plates

\begin{tabular}{|c|c|c|c|c|c|}
\hline Element/Absorber & $\begin{array}{c}6061 \mathrm{AI} \\
(\mathrm{wt} \%)^{(a)(b)}\end{array}$ & $\begin{array}{c}0.05 \mathrm{gB} / \mathrm{cm}^{2} \text { Boral } \\
(w t \%)(a)(b)\end{array}$ & $\begin{array}{c}0.13 \mathrm{gB} / \mathrm{cm}^{2} \text { Boral } \\
(w t \%)^{(a)}(\mathrm{b})\end{array}$ & $\begin{array}{c}0.36 \mathrm{gB} / \mathrm{cm}^{2} \mathrm{Boral} \\
(w \mathrm{t} \%)^{(a)(\mathrm{b})}\end{array}$ & $\begin{array}{c}0.45 \mathrm{gB} / \mathrm{cm}^{2} \text { Boral } \\
(w t \%)^{(a)(b)}\end{array}$ \\
\hline Al & (c) & $94.56 \pm 0.61$ & $85.65 \pm 0.91$ & $62.54 \pm 2.43$ & $54.33 \pm 1.11$ \\
\hline 8 & 0 & $4.24 \pm 0.25$ & $11.20 \pm 0.64$ & $29.22 \pm 1.87$ & $35.63 \pm 0 . B 2$ \\
\hline c & 0 & $1.18 \pm 0.07$ & $3.12 \pm 0.48$ & $8.16 \pm 0.52$ & $9.95 \pm 0.19$ \\
\hline 0 & 0 & 0.01 & 0.02 & 0.06 & 0.07 \\
\hline $\mathrm{Fe}$ & (c) & 0.01 & 0.01 & 0.02 & 0.02 \\
\hline Core Density, $\mathrm{g} / \mathrm{cm}^{3}$ & $2.69 \pm 0.01$ & $2.64 \pm 0.01$ & $2.64 \pm 0.01$ & $2.64 \pm 0.01$ & $2.64 \pm 0.01$ \\
\hline Thickness, $\mathrm{cm}^{(\mathrm{d})}$ & $0.63 \pm 0.001$ & $0.663 \pm 0.003$ & $0.658 \pm 0.003$ & $0.673 \pm 0.003$ & $0.683 \pm 0.003$ \\
\hline Length, $\mathrm{cm}$ & 96 & 96 & 96 & 96 & 96 \\
\hline Width, cm & 45 & 45 & 45 & 45 & 45 \\
\hline
\end{tabular}

\footnotetext{
(a) Error limits are one standard deviation estimate

(b) Composition of $\mathrm{B}_{4} \mathrm{C}$-Al core material. Cladding is aluminum Type 1100 (Refer to Appendix A).

(c) Refer to Appendix A

(d) Includes $0.203 \mathrm{~cm}$ of Type 1100 aluminum clad
} 
6061 aluminum guides were located in the fuel regions of each experimental assembly such that the rods fall by gravity into the assembly should an outof-range condition exist in the control channels shown in Figure 1.1. The control and safety rods are not defined since all of the criticality and subcriticality data reported herein were obtained with these rods fully withdrawn from the experimental assemblies. ASTM specifications for the aluminum sleeves are given in Appendix $A$. The aluminum sleeves extended from the acrylic base plate shown in Figure 2.3 to above the top reflector level at locations shown in the loading diagrams for each assembly in Appendix D. The sleeves had a $1.283 \mathrm{~cm}$ inside diameter and a wall thickness of $0.066 \mathrm{~cm}$.

\subsection{REACTION RATE DEVICES}

In one experimental assembly, fission and capture rate measurements were made using solid state track recorders and foils. These devices and their locations in the measurements will be discussed with the measurement data in Section 3. The devices and holders were not present during the criticality and subcriticality measurements. 



\subsection{EXPERIMENTAL MEASUREMENTS AND RESULTS}

The experimental measurements performed and the results obtained are covered in this section.

\subsection{EFFECT OF BORON CONCENTRATION ON CRITICAL SIZE}

One series of experiments were performed to measure the effectiveness of a neutron flux trap to reduce a system subcritical as the boron content, of the plate creating the flux trap, was varied. In these series of experiments, the flux traps were created, as indicated in Figure 1.1, by using plates containing either $0.45 \mathrm{~g} \mathrm{~B} / \mathrm{cm}^{2}, 0.36 \mathrm{~g} \mathrm{~B} / \mathrm{cm}^{2}, 0.13 \mathrm{~g} \mathrm{B.} \mathrm{cm}^{2}, 0.05 \mathrm{~g} \mathrm{~B} / \mathrm{cm}^{2}$, or no boron. For each boron loading the number of fuel rods required for delayed criticality was determined by incremently adding fuel in the four fuel position areas immediately adjacent to the flux trap region. For comparison purposes, data were also obtained for two boron loadings $\left(0.45 \mathrm{~g} \mathrm{~B} / \mathrm{cm}^{2}\right.$ and $\left.0.13 \mathrm{~g} \mathrm{~B} / \mathrm{cm}^{2}\right)$ with the fuel rod units $5.97 \mathrm{~cm}$ from the flux trap plates. To the extent permitted by the delayed critical condition, fuel was distributed equally between the four fuel units in each assembly. Fuel loading diagrams for each experimental assembly are given in Appendix $D$.

The experimental results obtained from these series of measurements are given in Table 3.1. As shown in Table 2.1, the plates used to create the neutron flux trap in each assembly were of slightly different thicknesses. To maintain a constant water region between the plates and fuel units over a set of measurements, the flux trap width was allowed to vary with the variation in plate thickness between assemblies. For intracomparision purposes, these small variations $(3.71 \mathrm{~cm}$ to $3.81 \mathrm{~cm})$ in flux trap widths should have a negligible effect on the measurement results (Bierman and Clayton, 1981). Consequently, the delayed critical sizes, shown in Table 3.1, are plotted in Figure 3.1 as a function of boron loading only. The critical size of each experimental assembly identified in Table 3.1 was determined by the approach-to-critical method to obtain well defined, fully water reflected, neutron flux trap assemblies consisting of water moderated fuel only. In an approach-to-critical 
TABLE 3.1 Experimental Results - Delayed Critical $2 \times 2$ Lattice Assemblies of 4.31 wt\% $235 \mathrm{U}$ Enriched $\mathrm{UO}_{2}$ Fuel Rods in Water Separated by Neutron Flux Traps Containing 0 to $0.45 \mathrm{~g} \mathrm{~B} / \mathrm{cm}^{2}$

\begin{tabular}{|c|c|c|c|c|c|}
\hline $\begin{array}{c}\text { Experiment } \\
\text { Assembly } \\
\text { Number }\end{array}$ & $\begin{array}{c}\text { Lattice } \\
\text { Spacing(a) (b) } \\
\text { (cm) }\end{array}$ & $\begin{array}{l}\text { Flux Trap } \\
\text { Width(b)(c) } \\
(\mathrm{cm})\end{array}$ & $\begin{array}{c}\text { Boron Loading(b) } \\
\left(\mathrm{g} \mathrm{B} / \mathrm{cm}^{2}\right)\end{array}$ & $\begin{array}{l}\text { Critical Size } \\
\text { (b) (d) } \\
\text { (Total Rods) }\end{array}$ & $\begin{array}{l}\text { Flux Trap to Fuel } \\
\text { Separation (b) (e) } \\
\text { (cm) }\end{array}$ \\
\hline $231(f)$ & $1.891 \pm 0.001$ & $3.71 \pm 0.02$ & $0.45 \pm 0.01$ & $963 \pm 1$ & $0.295 \pm 0.040$ \\
\hline $214 R$ & $1.891 \pm 0.001$ & $3.73 \pm 0.02$ & $0.36 \pm 0.02$ & $952 \pm 2$ & $0.295 \pm 0.040$ \\
\hline 228 & $1.891 \pm 0.001$ & $3.76 \pm 0.02$ & $0.13 \pm 0.01$ & $910 \pm 1$ & $0.295 \pm 0.040$ \\
\hline $230(f)$ & $1.891 \pm 0.001$ & $3.75 \pm 0.02$ & $0.05 \pm 0.01$ & $855 \pm 2$ & $0.295 \pm 0.040$ \\
\hline 229 & $1.891 \pm 0.001$ & $3.81 \pm 0.02$ & $0.0-$ & $308 \pm 1$ & $0.295 \pm 0.040$ \\
\hline 226 & $1.891 \pm 0.001$ & $3.71 \pm 0.02$ & $0.45 \pm 0.01$ & $849 \pm 1$ & $5.967 \pm 0.040$ \\
\hline 227 & $1.891 \pm 0.001$ & $3.76 \pm 0.02$ & $0.13 \pm 0.01$ & $844 \pm 1$ & $5.967 \pm 0.040$ \\
\hline
\end{tabular}

(a) Center-to-center distance between fuel rods in a square array

(b) Error limits are one standard deviation estimates, limits on critical size include estimates on reproducibility

(c) Perpendicular distance between plates

(d) Total number of fuel rods in $2 \times 2$ unit assembly

(e) Water gap between fuel rods and flux trap plate

(f) $235 \mathrm{U}$ and ${ }^{238} \mathrm{U}$ fission rates measured in these assemblies 
measurement to determine the critical conditions for a system, neutron multiplication measurements are made as the parameter of interest is varied such that the system "approaches" criticality. By extrapolating subcritical data very near critical, a precise definition of the critical conditions for that system can be obtained with the parameter of interest being the only perturbing variable. In each of the experimental assemblies fuel was loaded into the lattice plates in increments that were neutronically symmetrical to each other. At each incremental fuel loading, neutron count rates were obtained using the three boron-lined proportional detectors identified as data channels in Figure 1.1. At the delayed critical condition the neutron count rate approaches infinity. Consequently the number of fuel pins required for criticality can be predicted by extrapolating a function of the inverse count rate to zero.

As can be seen in Figure 3.1, the effectiveness of a neutron flux trap for criticality control is relatively insensitive to boron loadings above about 0.1 $\mathrm{g} \mathrm{B} / \mathrm{cm}^{2}$. A decrease in boron content from about $0.5 \mathrm{~g} \mathrm{~B} / \mathrm{cm}^{2}$ to $0.1 \mathrm{~g} \mathrm{~B} / \mathrm{cm}^{2}$ in the neutron flux trap results in a decrease of only about $7 \%$ in the number of fuel rods required for criticality. Below about $0.1 \mathrm{~g} \mathrm{~B} / \mathrm{cm}^{2}$, the effectiveness of the neutron flux trap is very sensitive to the boron loading. As indicated in Figure 3.1, the number of fuel rods required for criticality in the experimental assembly decreases by about a factor of 3 as the boron content is decreased to zero.

\subsection{EFFECT OF WATER GAP BETWEEN FUEL AND NEUTRON FLUX TRAP ON CRITICAL SIZE}

In a second series of experiments, measurements were performed to determine the effectiveness of a neutron flux trap to reduce a system subcritical as the distance between fuel and the flux trap varied. In one set of measurements each of the four fuel units were positioned equal distances from a neutron flux trap containing a fixed amount of boron $\left(0.36 \mathrm{~g} \mathrm{~B} / \mathrm{cm}^{2}\right)$. At each separation distance, the delayed critical size of the assembly was determined. In another set of measurements, two fuel units were held stationary adjacent to the neutron flux trap. The remaining two units were 


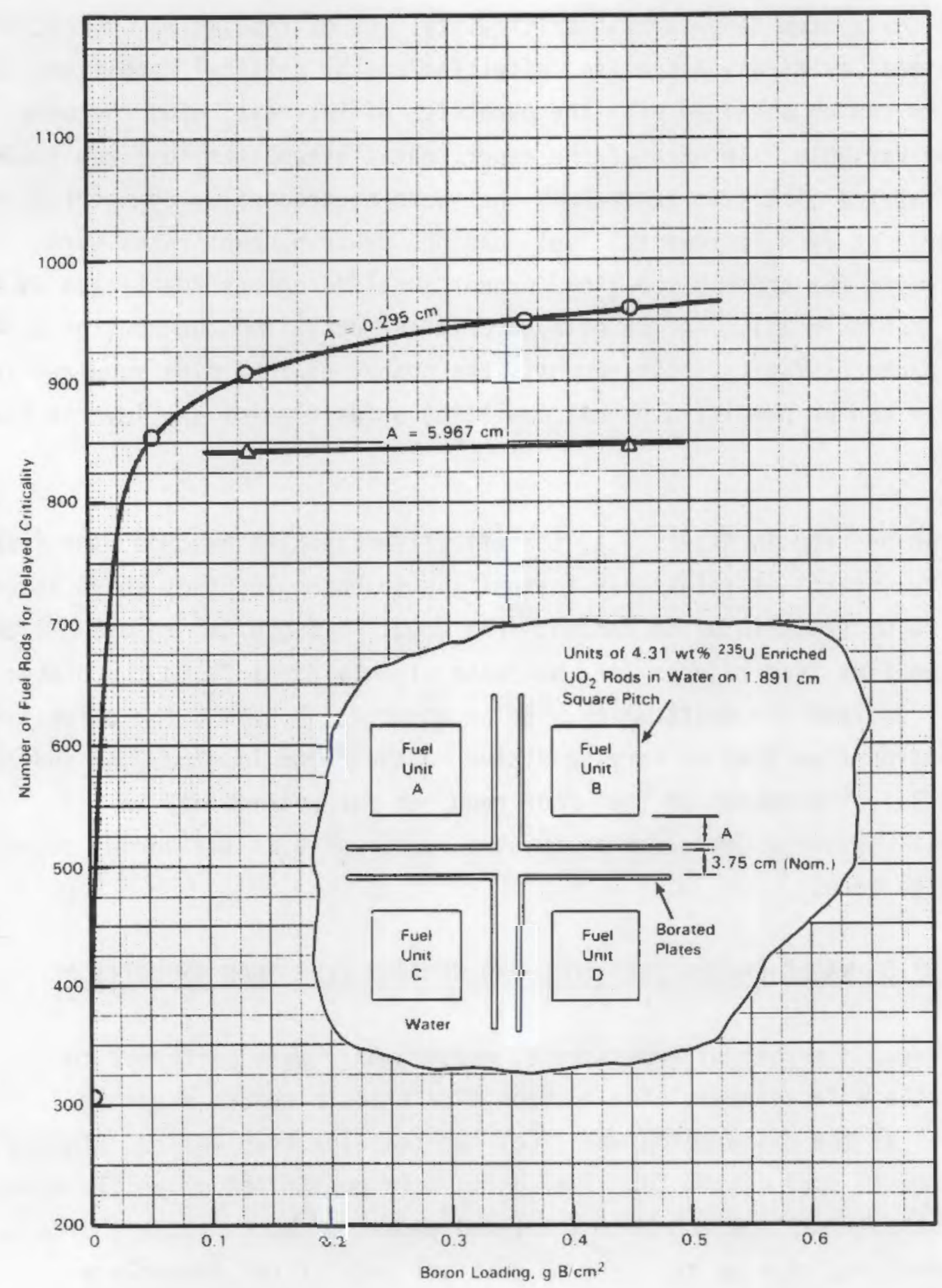

Figure 3.1 Critical Number of Fuel Rods as a Function of of Boron Concentration in Neutron Flux Traps 
moved, in equal increments, away from the opposing two stationary fuel units such that the water gap between the fuel and flux trap varied in one dimension only. At each of these separation distances, the delayed critical size of the assembly was determined. Both sets of measurements were performed with a neutron flux trap created with plates containing $0.36 \mathrm{~g} \mathrm{~B} / \mathrm{cm}^{2}$. As discussed in Section 3.1, the measurement results obtained at this concentration should be essentially insensitive to the estimated variation in boron $\left( \pm 0.02 \mathrm{~g} \mathrm{~B} / \mathrm{cm}^{2}\right)$. In both sets of measurements, fuel was incremently added to each of the four fuel units to determine the delayed critical condition, as discussed in Section 3.1, with essentially four equally sized fuel units. Fuel loading diagrams for each of the experimental assemblies are given in Appendix $D$. The measurement results and assembly descriptions are summarized in Table 3.2.

Plots of the data are shown in Figure 3.2 and indicate a minimum critical sized assembly at a fuel to flux trap separation of about $6 \mathrm{~cm}$ for both sets of data. As can be seen in Figure 3.2, the minimum for the four fuel units equal distance from the neutron flux trap is less than four critical units infinitely separated in water. Each fuel unit over this region contains less fuel than that required for delayed criticality in a single isolated unit (217 fuel rods). Consequently, some neutron interaction exists between the units for the experimental assemblies to be delayed critical over this minimum, i.e., optimum separation region.

\subsection{EFFECTIVENESS OF BORON CONCENTRATION TO REDUCE K $\mathrm{K}_{\text {eff }}$}

In a third series of experiments, measurements were performed to determine the effect of boron loading (creating a neutron flux trap) on the effective neutron multiplication constant $\left(k_{e f f}\right)$. In these series of experiments, pulse neutron source measurements were performed to determine $k_{\text {eff }}$ of neutron flux trap assemblies having multiple fuel loadings for each of the four boron

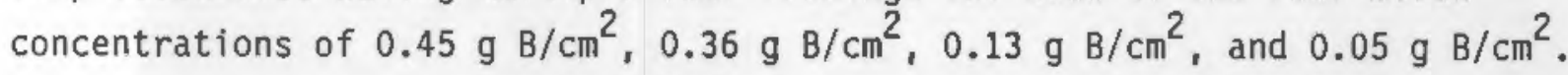
In each experimental assembly, the fuel rods were equally distributed among four units as indicated in Appendix D. Each fuel unit was located $0.295 \pm 0.40$ $\mathrm{cm}$ from the borated plates creating the neutron flux trap. 
TABLE 3.2 Experimental Results - Delayed Critical $2 \times 2$ Lattice Assemblies of 4.31 wt\% $235 \mathrm{U}$ Enriched $\mathrm{UO}_{2}$ Fuel Rods in Water at Various Distances from a $3.73 \mathrm{~cm}$ Wide Neutron Flux Trap Created by $0.36 \mathrm{~g} \mathrm{~B} / \mathrm{cm}^{2}$ Boral

\begin{tabular}{|c|c|c|c|}
\hline $\begin{array}{c}\text { Experiment } \\
\text { Assembly } \\
\text { Number }\end{array}$ & $\begin{array}{c}\text { Lattice } \\
\text { Spacing (a) (b) } \\
\text { (cm) }\end{array}$ & $\begin{array}{c}\text { Critical Size } \\
\text { (b) (c) } \\
\text { (Total Rods) }\end{array}$ & $\begin{array}{l}\text { Flux Trap to } \\
x \\
\text { (cm) }\end{array}$ \\
\hline $214 R$ & $1.891 \pm 0.001$ & $952 \pm 2$ & $0.295 \pm 0.040$ \\
\hline 224 & $1.891 \pm 0.001$ & $874 \pm 1$ & $2.186 \pm 0.040$ \\
\hline $223 R$ & $1.891 \pm 0.001$ & $858 \pm 3$ & $4.077 \pm 0.040$ \\
\hline $221 R$ & $1.891 \pm 0.001$ & $858 \pm 3$ & $7.859 \pm 0.040$ \\
\hline $220 R$ & $1.891 \pm 0.001$ & $860 \pm 1$ & $9.750 \pm 0.040$ \\
\hline 210 & $1.891 \pm 0.001$ & $864 \pm 2^{|e|}$ & $\infty$ \\
\hline 215 & $1.891 \pm 0.001$ & $923 \pm 3$ & $0.295 \pm 0.040$ \\
\hline 216 & $1.891 \pm 0.001$ & $910 \pm 1$ & $0.295 \pm 0.040$ \\
\hline 217 & $1.891 \pm 0.001$ & $906 \pm 3$ & $0.295 \pm 0.040$ \\
\hline 218 & $1.891 \pm 0.001$ & $907 \pm 2$ & $0.295 \pm 0.040$ \\
\hline 219 & $1.891 \pm 0.001$ & $909 \pm 1$ & $0.295 \pm 0.040$ \\
\hline 225 & $1.891 \pm 0.001$ & $975^{(t)}$ & $0.295 \pm 0.040$ \\
\hline
\end{tabular}

\begin{tabular}{c} 
Separation $(b)(d)$ \\
$Y$ \\
$(\mathrm{~cm})$ \\
\hline $0.295 \pm 0.040$ \\
$2.186 \pm 0.040$ \\
$4.077 \pm 0.040$ \\
$7.859 \pm 0.040$ \\
$9.750 \pm 0.040$ \\
$\infty \quad 0.040^{(g)}$ \\
$2.186 \pm 0.040^{(g)}$ \\
$4.077 \pm 0.079$ \\
$5.968 \pm 0.040^{(g)}$ \\
$7.859 \pm 0.040^{\prime g)}$ \\
$9.750 \pm 0.040^{(g)}$ \\
$\infty$
\end{tabular}

(a) Center-to-center distance between fuel rods in a square array

(b) Error limits are one standard deviation estimates. Limits on critical size include estimates on reproducibility

(c) Total number of fuel rods in $2 \times 2$ unit assembly

(d) Water gap between fuel rods and flux trap plates

(e) Four times the critical size $(216$ rods) of a single fuel unit 16 rods wide.

(f) Upper bound based partially on extrapolation of previously reported data (Bierman and Clayton, 1981)

(g) Fuel units $C$ and $D$ are stationary at $Y=0.295 \pm 0.040 \mathrm{~cm}$

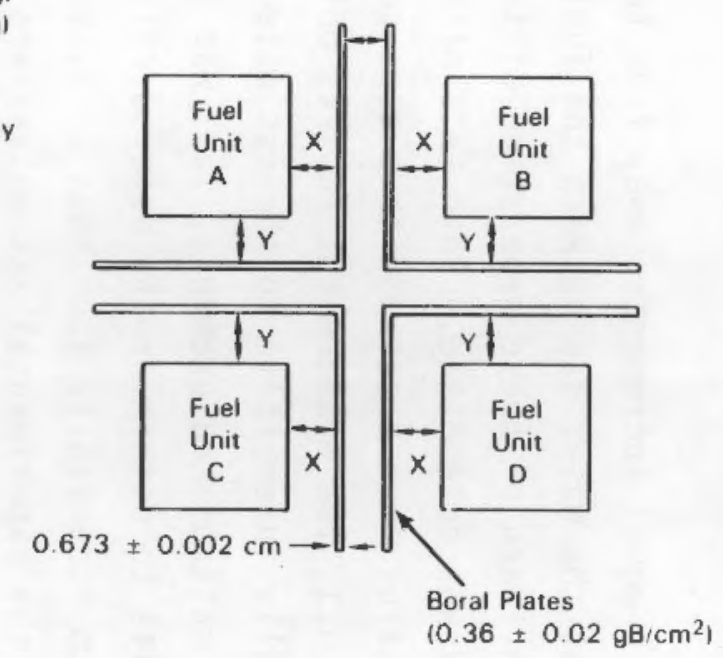




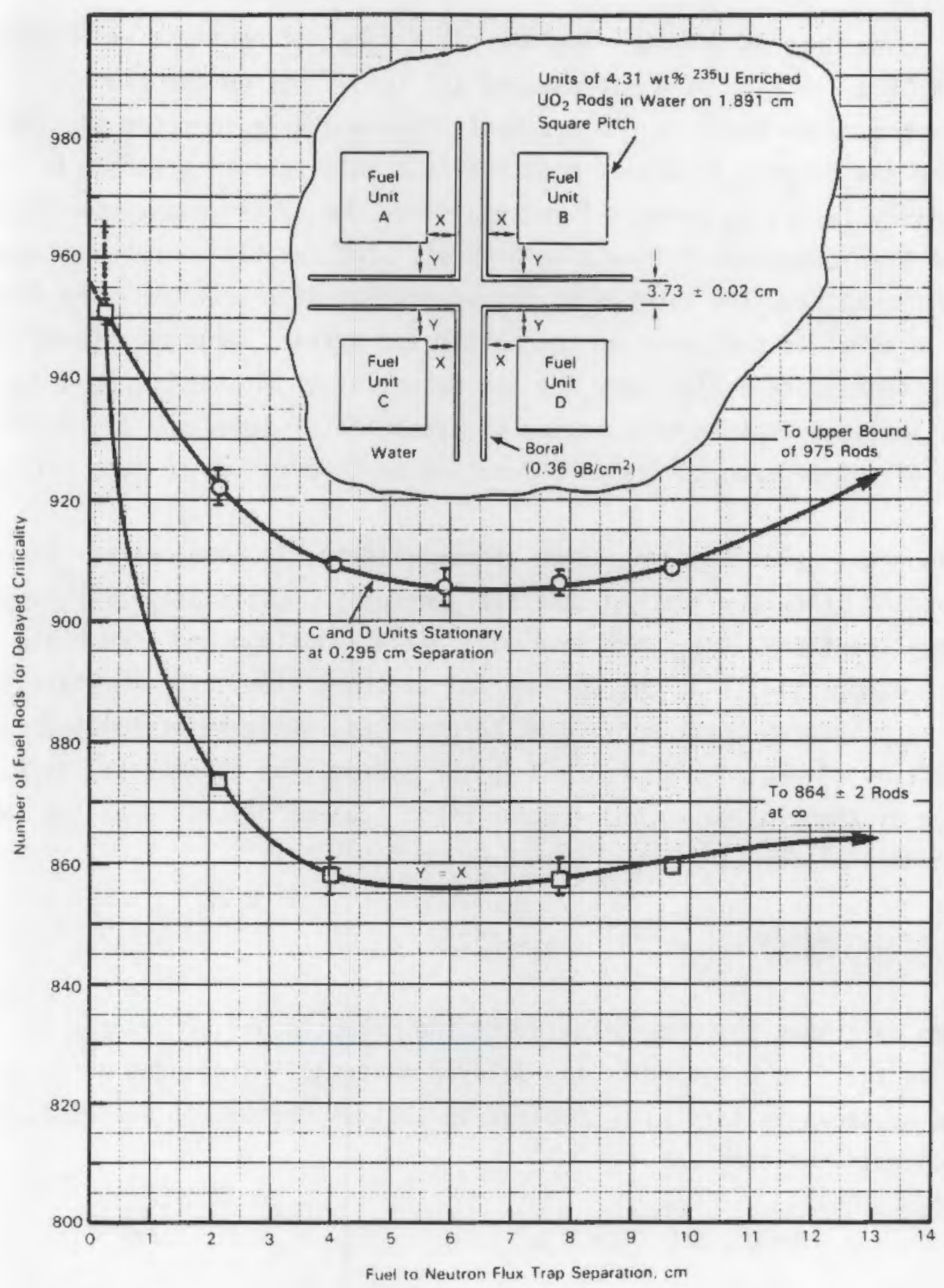

Figure 3.2 Critical Number of Fuel Rods as Function of of Separation Between Fuel and Neutron Flux Trap 


\subsubsection{Measurement Technique}

In pulse neutron source measurements, a burst of neutrons is injected into a system in a fraction of a microsecond and its effect on the neutron population at some point in the system is observed as a function of time following the burst. In actual practice, the measurements are made by repetitively injecting bursts of neutrons into the system and accumulating the observed time behavior following each burst. The repetition rate and number of neutron bursts required depends on the statistics of the accumulated data, which, in turn, is dependent on the particular system. A proportional counter or a $\mathrm{BF}_{3}$ tube is generally used for the detection of the neutrons, and a multichannel analyzer is used as a series of sequentially gaged scalers for the storage of the neutron counts as a function of time following each burst.

Since the pulse neutron source characteristically produces epi-thermal neutrons and since the neutron detector generally used is primarily sensitive to thermal neutrons, the count rate will reach a maximum and then begin to decrease exponentially as the epi-thermal neutrons slow down immediately following a neutron burst and become thermalized. Once an asymptotic distribution of neutrons is reached in the system, the count rate, as a function of time following the neutron burst, can be described as the sum of two exponential terms:

$$
n(t)=A_{1} e^{-\alpha_{1} t}+A_{2} e^{-\alpha_{2} t}
$$

One term describes the time behavior of the prompt neutrons and the other describes the time behavior of the delayed neutrons. Since the decay of the delayed neutrons is very slow compared to that of the prompt neutrons, Equation 1 is generally written as:

$$
n(t)=A_{1} e^{-\alpha_{1} t}+N_{D}
$$


where $N_{D}$ is a constant equal to the averaged delayed neutron contribution and

$$
A_{1} e^{-\alpha_{1} t}
$$

is the prompt neutron contribution decreasing exponentially with time at a rate $\alpha_{1}$.

After a period of time, the prompt neutron portion of the total population, that is due to the neutron burst, will approach the background level preceding the burst and only the delayed neutrons will remain. Since the prompt neutrons must all decay away before the delayed neutron contribution can be determined, the prompt neutron decay rate is a limiting factor in determining the pulse repetition rates and counting time intervals to be used. This rate of decay is dependent upon the system on which the measurements are being made. However, the faster the neutron spectrum, the faster the decay rate will be. Also, the further subcritical a system is, the faster the decay rate will be. Therefore it is possible to obtain the same decay rate for two different degrees of subcriticality. It is this ambiguous feature of the prompt neutron decay which prevents it being used as a direct measurement of reactivity, al though it is directly related to the reactivity of the given system. The rate of decay of the prompt neutrons can, however, be used to obtain an effective multiplication constant, $k_{\text {eff }}$, for the system by the following relationship:

$$
\alpha_{1}=\frac{1-k_{e f f}\left(1-\beta_{e f f}\right)}{\ell}
$$

where $\alpha_{1}$ is the decay rate, $\beta_{\text {eff }}$ the effective delayed neutron fraction, and $\ell$ the neutron lifetime in the system. However, this requires a knowledge of $\ell$ and $\beta_{\text {eff }}$ and $\ell$ is as difficult to calculate as $k_{\text {eff }}$. However, Equation 3 and the definition for reactivity,

$$
\rho \equiv \frac{k-1}{k}
$$


can be combined to obtain an expression for the reactivity of a system in units of $\beta$, i.e., dollars.

$$
\frac{\rho}{\beta}=-\frac{a_{1}-k \beta / \ell}{k \beta / \ell} \text {, }
$$

If the neutron generation time is assumed to be constant, Equation 5 can be reduced to:

$$
\frac{\rho}{\beta}=-\frac{\alpha_{1}-\alpha_{c}}{\alpha_{c}}
$$

where $\alpha_{c}$ is the prompt neutron decay rate at delayed critical $(k=1)$. However, the generation time does vary significantly with the degree of subcriticality. Also, $\alpha_{c}$ is a parameter not generally available for fuel transport or storage systems.

Three methods have been developed whereby the reactivity of a system can be determined directly from the pulse neutron measurements if the data can be obtained essentially free of energy and spatial effects. The earliest technique was suggested by Sjostrand (Sjostrand 1956) who simply separated the data into a prompt neutron component and delayed neutron component, as implied by Equations 1 and 2, and then approximated the reactivity by taking the ratio of the area under the prompt neutron curve to the area under the delayed neutron curve.

$$
\left(\frac{\rho}{\beta}\right)_{S J}=-\frac{\text { Prompt Neutron Area }}{\text { Delayed Neutron Area }}
$$


Gozani (Gozani, et. al., 1965) improved on this by extrapolating the prompt neutron fundamental mode of decay back to time zero following the burst of neutrons, and taking the reactivity essentially as:

$$
\left(\frac{\rho}{B}\right)_{G O}=-\frac{\text { Prompt Neutron Fundamental Mode Area }}{\text { Del ayed Neutron Area }}
$$

Garelis and Russell (Garelis and Russell 1963) developed a more rigorous theoretical model and showed that the prompt neutron count rates multiplied by a factor involving the reactivity of the system must equal the total area under the pulsed neutron source curve between time zero and $1 / R$ following the burst of neutrons.

$$
\int_{0}^{l / R} A_{1} e^{-\alpha} t_{1}^{\frac{k B}{l} t} d t=\int_{0}^{1 / R} A_{1} e^{-\alpha} t d t+\frac{N_{D}}{R}
$$

Where $A_{1} e^{-\alpha_{1} t}$ is the prompt neutron count rate at time $t$ following the burst, $N_{D}$ is the averaged delayed neutron count rate, and $R$ is the pulse repetition rate. All the information needed to solve Equation 9 for $k \beta / \ell$ is available in the data obtained from the pulse neutron source measurement. Consequently, all the data needed to solve Equation 5 for the reactivity of the system is provided by the pulse neutron source data in the Garelis-Russell model.

If energy-and space-independent kinetics data are not obtained in the measurements, correction factors must be applied to equation (7), (8), and (9) to account for any harmonic effect and kinetic distortion in the prompt neutron fundamental mode of decay. Although harmonic effects can be due to prompt, delayed, and other complicated forms of harmonics, prompt harmonics are generally the dominant harmonic factor (Gozani, 1972). Consequently the extrapolated area or Gozani, method of analysis (Eq. 8) is in general, least affected by harmonics. For this reason, and the fact that the Garelis-Russell (GR) and Gozani (GO) methods of analyses (Eq. 8 and 9) affect the obtained 
reactivities in opposite ways (Gozani, 1972, 1965), both the Gozani and the Garelis-Russell methods were used in analyzing each of the pulse neutron measurements covered in this report. In analyzing the data it was assumed that any kinetic distortion effects were negligible since the data were accumulated in the center of the experimental assemblies. However, it should be noted that the pulse neutron source was positioned just outside the core region in the reflector and may contribute some minor effects which may be of interest in any computational analysis of the data presented in this section.

\subsubsection{Description of Pulse Neutron System}

The pulse neutron source measurements were made with a Kaman A808 pulsed neutron source capable of being repetitively pulsed up to 50 pulses per second and having a neutron yield of about $10^{9} \mathrm{n} / \mathrm{sec}$. The source is encased in a sixinch diameter oil filled cylinder, 36 inches long, and can be moved about. In all of the measurements the source was located outside the lattice plates, at least $15 \mathrm{~cm}$ from the fuel rods as indicated in loading diagrams shown in Appendix 0 . The source was positioned such that its tritium target was located approximately at the horizontal midplane of the assembly fuel region. The pulse neutron source measurement data were accumulated with a boron line proportional detector using a nuclear data N066 channel analyzer operating in the time mode with 0.25 microsecond dead time between the counting channels. The neutron detector was centered at midplane in the center of the neutron flux trap as indicated in the loading diagrams shown in Appendix D. A diagram of the pulsed neutron source control and data acquisition system is shown in Figure 3.3

\subsubsection{Experimental Measurements and Results}

Measurements were performed at three assembly fuel loadings $(306,676$, and 855 fuel rods) as a function of boron loading in the plates creating the neutron flux trap. The measurement results obtained and the experimental assembly descriptions are summarized in Table 3.3 Delayed critical conditions 


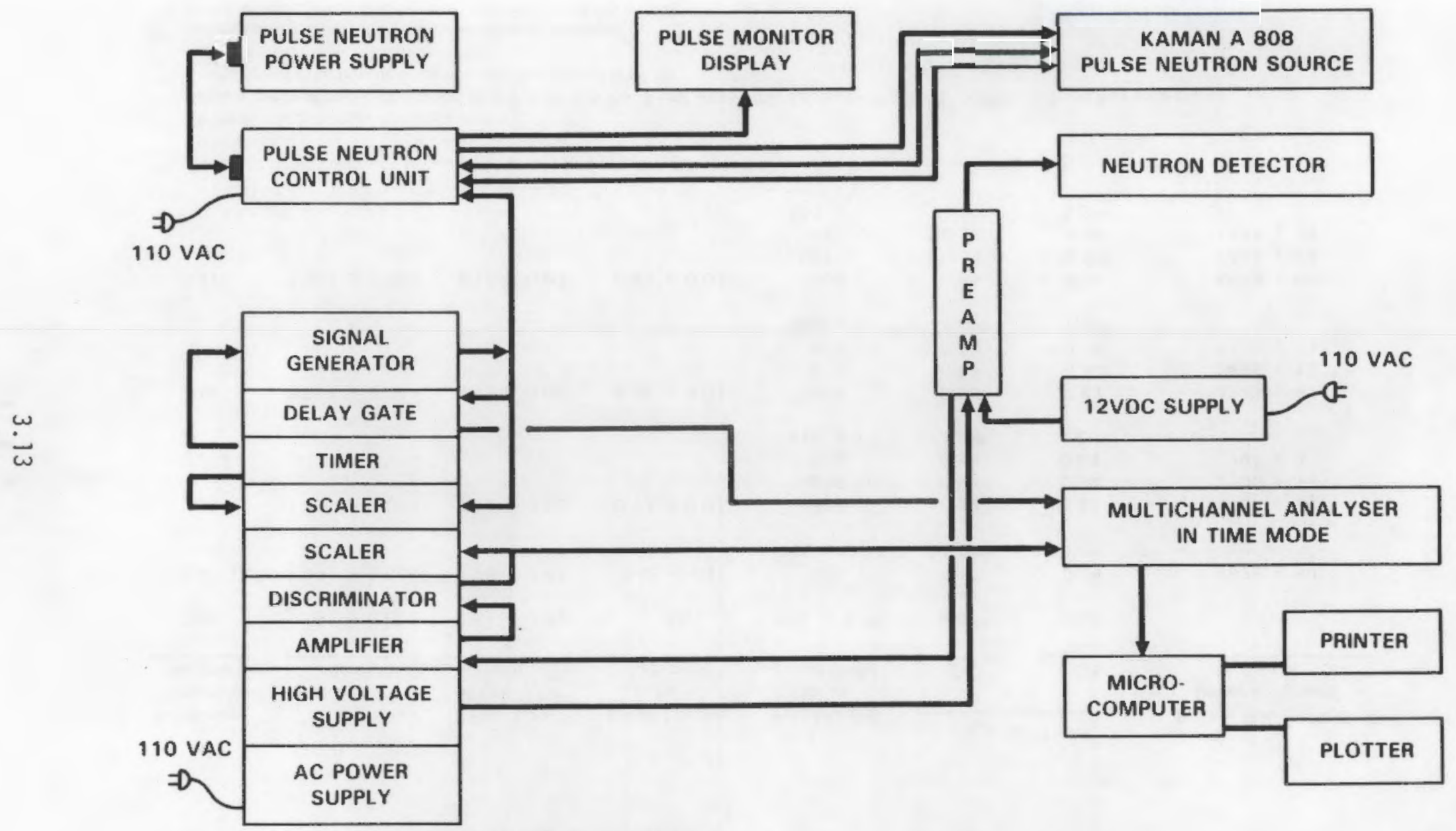

Figure 3.3 Pulse Neutron Source and Data Acquisition System 
TABLE 3.3 Experimental Results - Average $K_{\text {ff }}$ and Prompt Neutron Decay Constants in $2 \times 2$ Lattice Assembfies of $4.31 \mathrm{wt} \%{ }^{235} \mathrm{U}$ Enriched $\mathrm{UO}_{2}$ Fuel Rods in Water Separated by Neutron Flux Traps

Containing 0 to $0.45 \mathrm{~g} \mathrm{~B} / \mathrm{cm}^{2}$

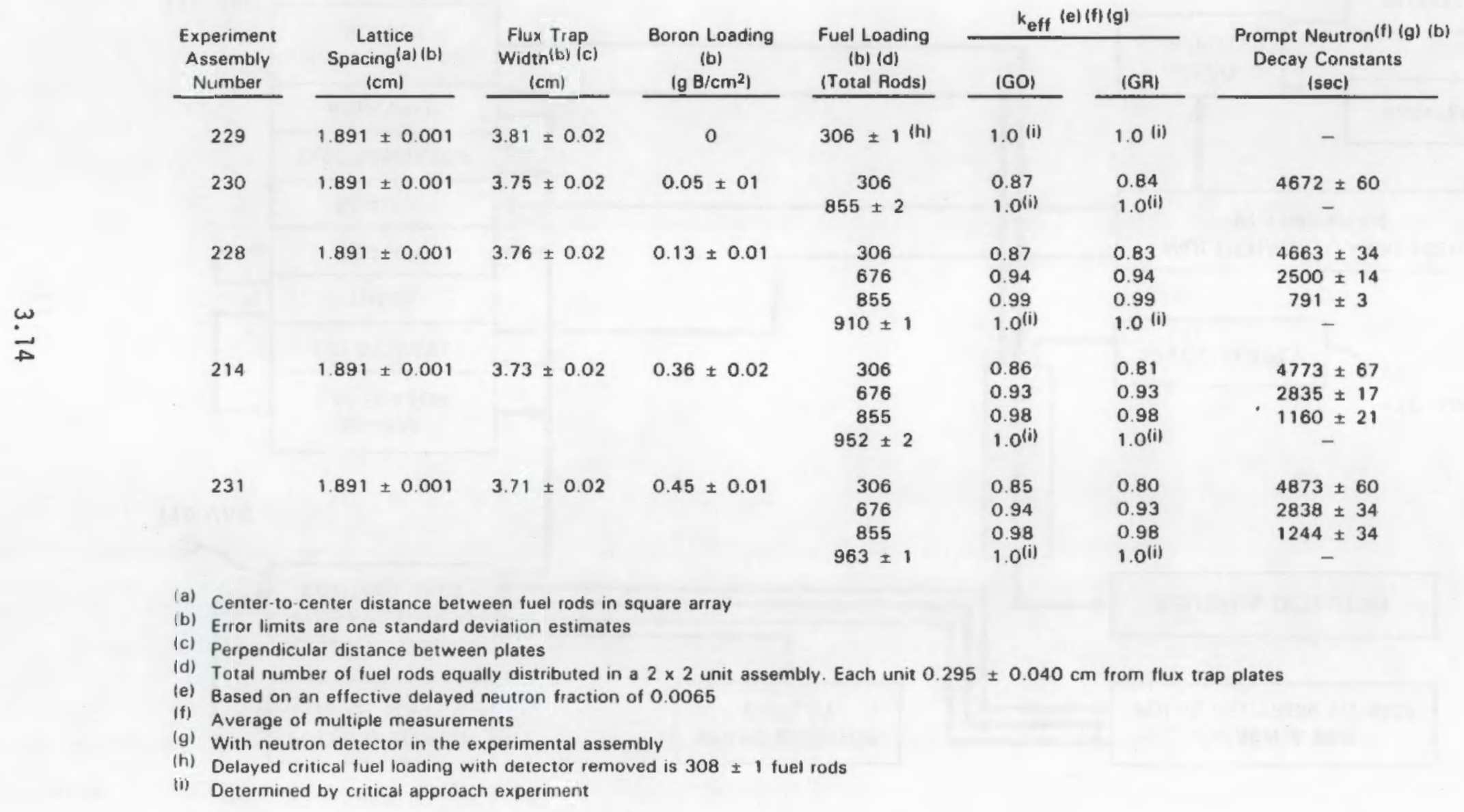


presented previously in Table 3.1 are shown in Table 3.3 also for ease of comparison with the subcritical $k_{\text {eff }}$ values. The $k_{\text {eff }}$ and prompt neutron decay constants reported in Table 3.3 for each assembly are averages obtained from multiple pulsed neutron measurements at the indicated assembly condition. Loading diagrams of each experimental assembly are provided in Appendix $D$. The data obtained from each of the multiple pulse neutron measurements are provided in Appendix E.

Both the Gozani and the Garelis-Russell methods of data analyses require that a fundamental mode of decay be established. To determine if a single mode of neutron decay eventually existed in each set of measurement data, a technique developed by Pfeiffer, Brown and Marshall (Pfeiffer, 1974) in a Fort St. Vrain startup test was used. The technique makes use of the standard deviation obtained on the fitted value for the prompt neutron decay rate, $\alpha$, and the random fluctuation of the fitted value for $\alpha$ within the standard deviation as measurement data immediately following the neutron burst is successively ignored in the fitting process. If it can be demonstrated that a decay rate, and the associated standard deviation, fluctuates within the standard deviation as data are deleted, it can be concluded that a single time rate of decay predominates and is the fundamental mode of neutron decay for that experimental assembly.

The measurements at an assembly loading of 306 fuel rods, equally distributed between four units, provide data on a flux trap system in which the boron content is being depleted to zero. The $k_{e f f}$ values obtained at this assembly loading are plotted in Figure 3.4. As can be seen in Figure $3.4, k_{\text {eff }}$ is essentially insensitive to boron content except at the very low boron loadings below $0.05 \mathrm{~g} \mathrm{~B} / \mathrm{cm}^{2}$. The data indicate that little if any increase in $k_{\text {eff }}$ would result from changes in boron loadings above $0.05 \mathrm{~g} \mathrm{~B} / \mathrm{cm}^{2}$ in this four unit interacting array.

To obtain more data near the critical condition, and thus more accurate data, the assembly loading was increased to 855 fuel rods and the measurements 


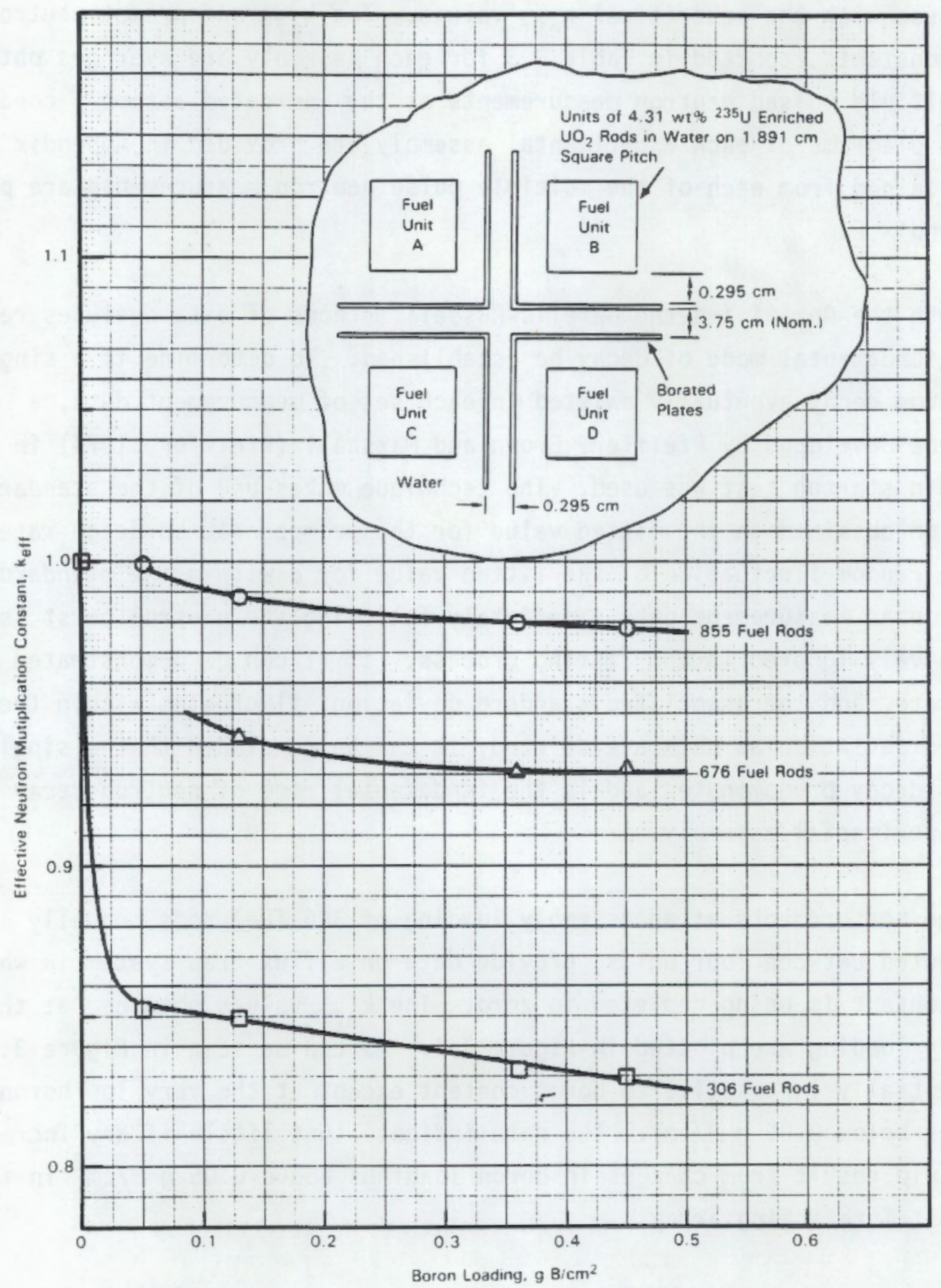

Figure 3.4 Average $\mathrm{K}_{\text {eff }}$ Values as a Function of Boron Loading in Flux Trap 
repeated to delayed criticality at a boron loading of $0.05 \mathrm{~g} \mathrm{~B} / \mathrm{cm}^{2}$. These data are also shown in Figure 3.4 and indicate the same general behavior in $k_{\text {eff }}$ with boron loading. The $k_{\text {eff }}$ data obtained at an intermediate assembly loading of 676 fuel rods is also presented graphically in Figure 3.4 .

Sufficient data were obtained for the $0.45 \mathrm{~g} \mathrm{~B} / \mathrm{cm}^{2}, 0.36 \mathrm{~g} \mathrm{~B} / \mathrm{cm}^{2}$, and 0.13 $\mathrm{g} \mathrm{B} / \mathrm{cm}^{2}$ loadings to permit determining a prompt critical fuel loading for each of these flux trap assemblies. By extrapolating the subcritical prompt neutron decay rates measured in each of these assemblies to a decay

rate of zero, their respective fuel loading for prompt criticality can be determined as shown in Figure 3.5. The prompt critical loading for the $0.45 \mathrm{~g}$ $\mathrm{B} / \mathrm{cm}^{2}, 0.36 \mathrm{~g} \mathrm{~B} / \mathrm{cm}^{2}$, and the $0.13 \mathrm{~g} \mathrm{~B}^{2} \mathrm{~cm}^{2}$ flux trap assemblies is estimated to be 970,960 , and 930 fuel rods respectively.

\subsection{Fission Rates in ${ }^{235} \mathrm{U}$ and ${ }^{238} \mathrm{U}$}

Absolute ${ }^{235} \mathrm{U}$ and ${ }^{238} \mathrm{U}$ fission rates were measured in the $0.45 \mathrm{~g} \mathrm{~B} / \mathrm{cm}^{2}$ and the $0.05 \mathrm{~g} \mathrm{~B} / \mathrm{cm}^{2}$ flux trap assemblies using solid state track recorders (SSTR). In each assembly these SSTR were centered, at midplane, in the flux trap region between two fuel units as indicated in Figures 3.6 and 3.7 . Fuel loading and critical assembly layout diagrams are also shown in Figures 3.6 and 3.7 .

\subsubsection{Measurement Technique}

The absolute fission rate measurements were made using solid state track recorders prepared and analyzed by the Irradiation and Environment Group of Westinghouse Hanford Company. The use of SSTR to measure absolute fission rates is extensively discussed in readily available publications (Gold, 1968, Lippincott, 1979, and Roberts 1968). Briefly, however, fission rate measurements with SSTR are carried out using isotopic deposits of a fissionable material in contact with a recorder material such as mica. A typical SSTR geometrical configuration is shown in Figure 3.8 for a single deposit. Fissions in the deposit produce fission fragments that create damage tracks in the mica. These tracks can be optically counted, after suitable etching, to determine the number of fissions per atom of deposit per unit time of 


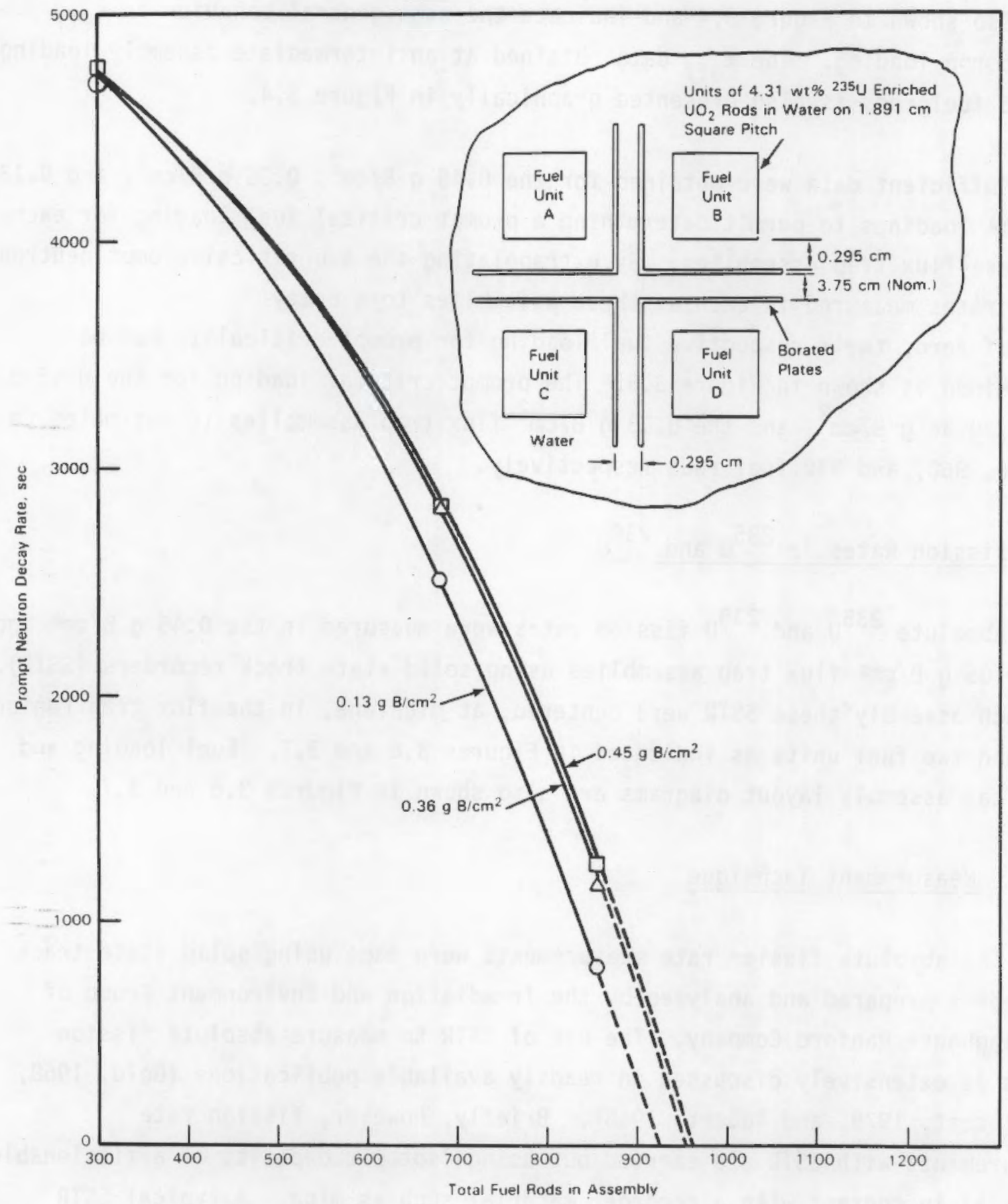

Figure 3.5 Prompt Neutron Decay Rate as Function of Assembly Fuel Loading and Boron Creating the Neutron Flux Trap 


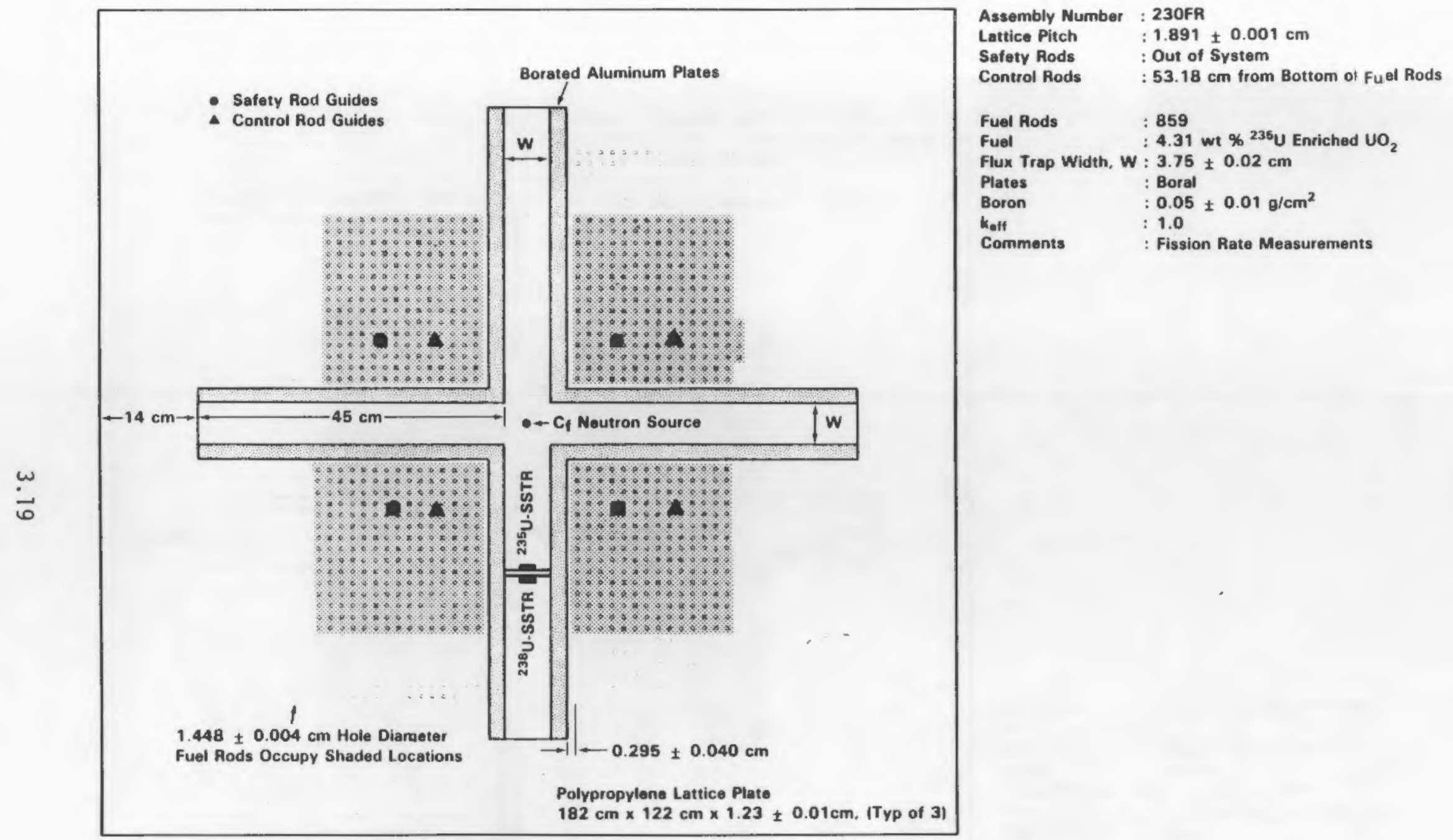

Figure 3.6 Layout of Experimental Assembly 230 Showing Fuel Rod Loading and SSTR for Irradiation 


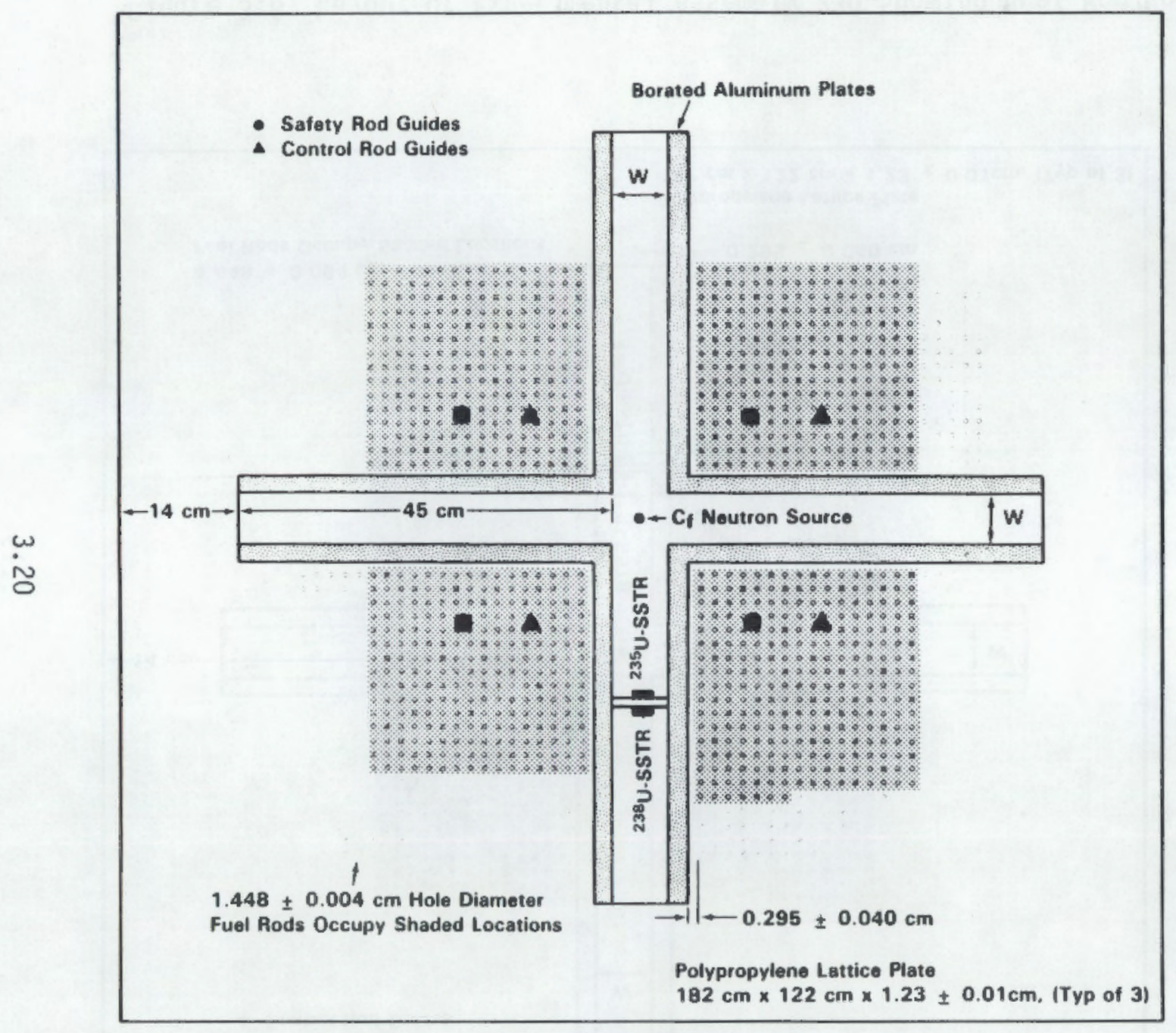
Assembly Number : 231FR
Lattice Pitch : $1.891 \pm 0.001 \mathrm{~cm}$
Safoty Rods : Out of System
Control Rods $\quad: 46.23 \mathrm{~cm}$ from Bottom of Fuel Rods
Fuel Rods $\quad: 967$
Fuel : 4.31 wt $\%{ }^{235} U$ Enriched Uo
Flux Trap Width, $W: 3.71 \pm 0.02 \mathrm{~cm}$
Plates $\quad:$ Boral
Boron $\quad: 0.45 \pm 0.01 \mathrm{~g} / \mathrm{cm}^{2}$
kalt : 1.0
Comments : Fission Rate Measurements

Figure 3.7 Layout of Experimental Assembly 231 Showing Fuel Rod Loading and SSTR for Irradiation 


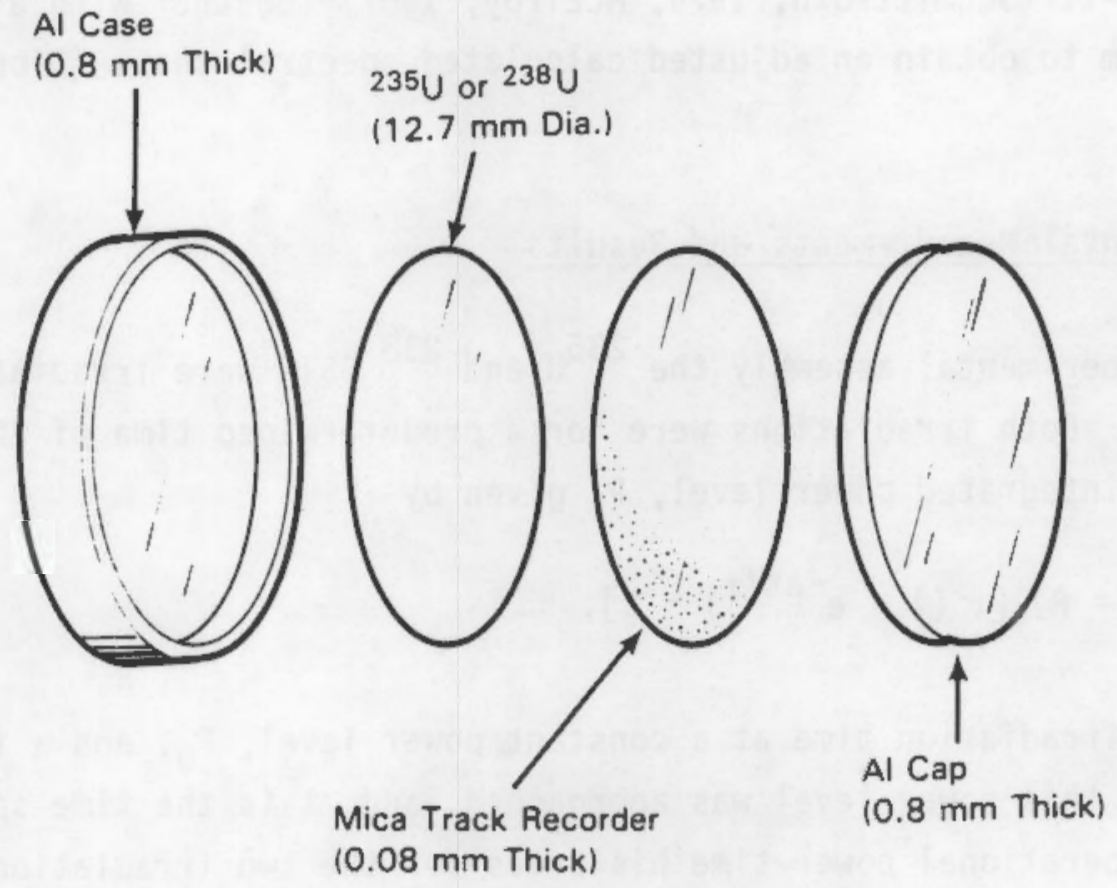

Figure 3.8 Typical SSTR Geometrical Configuration 
irradiation. These measured fission rates can be input to a computer code such a FERRET - SAND-II (Schmittroth, 1979, McEl roy, 1967) together with a starting neutron spectrum to obtain an adjusted calculated spectral shape (Lippincott, 1979).

\subsubsection{Experimental Measurements and Results}

In each experimental assembly the ${ }^{235} U$ and ${ }^{238}$ SSTR were irradiated simultaneously. Both irradiations were for a predetermined time of 200 seconds duration at an integrated power level, $P$, given by

$$
P=P_{0}\left[\tau\left(1-e^{-\Delta t / \tau}\right)+t\right] \text {, }
$$

where $t$ is the irradiation time at a constant power level, $P_{0}$, and $\tau$ is the period at which this power level was approached, and $\Delta t$ is the time spent on this period. Operational power-time histories for the two irradiations are given in Table 3.4. Power normalized fission rates measured in each assembly are given in Table 3.5 along with the deposit weights and track densities on which each fission rate is based. To obtained better counting statistics, the irradiations in the $0.45 \mathrm{~g} \mathrm{~B} / \mathrm{cm}^{2}$ flux trap assembly were performed at a higher power level (factor of about 3) than in the $0.05 \mathrm{~g} \mathrm{~B} / \mathrm{cm}^{2}$ assembly. Consequently, the fission rates measured in each assembly have been divided by the relative power levels, to provide the comparable fission rates shown in Table 3.5.

A1though a single spectral index is only indicative of spectral change, the data presented in Table 3.5 indicates that the change in boron loading primarily affects the neutron intensity but not the neutron spectrum in the flux trap region. The ratio of ${ }^{235} U$ and ${ }^{238} U$ fissions (i.e., essentially thermal to epithermal fissions) in each assembly differ by only about $10 \%$, which is within experimental error. However, the absolute fission rates differ by a factor of about 6 between the two assemblies. 


\section{TABLE 3.4 Power-Time History for SSTR Irradiations}

\begin{tabular}{|c|c|c|c|c|c|c|}
\hline $\begin{array}{c}\text { Experimental } \\
\text { Asseably } \\
\text { Number } \\
\end{array}$ & $\begin{array}{c}\text { Flux } \\
\left.\text { Vidth }(a)^{a} p_{b}\right) \\
\left(c_{a}\right) \\
\end{array}$ & 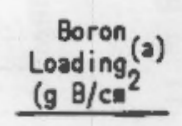 & $\begin{array}{c}\text { Irradiation } \\
\text { Tine } \\
\text { (sec) } \\
\end{array}$ & $\begin{array}{c}\text { Poriod } \\
\text { (sec) } \\
\end{array}$ & $\begin{array}{c}\text { Rolative } \\
\text { Porer } \\
\text { Level } \\
\end{array}$ & $\begin{array}{l}\text { Flux Trap to } \\
\text { Fuel Segaraţjion } \\
\text { (ca) }\end{array}$ \\
\hline 236 & $3.75 \pm 0.02$ & $0.95 \pm 0.61$ & 200 & $126.8^{(d)}$ & $3 \times 10^{-16}$ & $0.295 \pm 0.840$ \\
\hline 231 & $3.71 \pm 0.62$ & $0.45 \pm 0.01$ & 200 & $72.9^{(d)}$ & $10 \times 10^{-10}$ & $0.295 \pm 0.648$ \\
\hline
\end{tabular}

(a) Error linits are one standard deviation estinates

(b) Perpendicular distance between plates

(c) Water gap between fuel rods and flux trap plate

(d) Tine on period was 237 sec and 110 sec respectivaly for assemblies 230 and 231 
TABLE 3.5 Fission Rates in $0.05 \mathrm{~g} \mathrm{~B} / \mathrm{cm}^{2}$ and $0.45 \mathrm{~g} \mathrm{~B} / \mathrm{cm}^{2}$ Flux Trap Assemblies

\begin{tabular}{|c|c|c|c|c|}
\hline Isotope & $\begin{array}{l}\text { Deposit } \\
\text { Density } \\
\left(\mu \mathrm{g} / \mathrm{cm}^{2}\right) \\
\end{array}$ & $\begin{array}{c}\text { Track } \\
\text { Density } \\
\left(\text { Tracks } / \mathrm{cm}^{2}\right) \\
\end{array}$ & $\begin{array}{c}\text { Fission } \\
\text { Density } \\
\text { (Fission/Atom) } \\
\end{array}$ & $\begin{array}{c}\text { Fission } \\
\text { Rate } \\
\text { (Fissions/Atom sec) } \\
\end{array}$ \\
\hline & \multicolumn{4}{|c|}{$0.05 \mathrm{~g} \mathrm{~B} / \mathrm{cm}^{2}$ Flux Trap Assembly 230 (b) } \\
\hline $235 u$ & $46.22 \pm 1.0 \%$ & $5.963(10)^{3} \pm 1.1 \%$ & $5.096(10)^{-14} \pm 1.7 \%$ & $5.295(10)^{-7} \pm 1.7 \%$ \\
\hline${ }^{238} \mathrm{U}$ & $4522 \pm 1.6 \%$ & $3.42(10)^{2} \pm 5.5 \%$ & $2.99(10)^{-17} \pm 5.7 \%$ & $3.11(10)^{-10} \pm 5.7 \%$ \\
\hline & \multicolumn{4}{|c|}{$0.45 \mathrm{~g} \mathrm{~B} / \mathrm{cm}^{2}$ Flux Trap Assembly 231 (b) } \\
\hline $235 \mathrm{U}$ & $57.67 \pm 1.0 \%$ & $3.583(10)^{3} \pm 1.7 \%$ & $2.454(10)^{-14} \pm 2.2 \%$ & $8.992(10)^{-8} \pm 2.2 \%$ \\
\hline $23 \theta_{\mathrm{U}}$ & $4522 \pm 1.6 \%$ & $1.52(10)^{2} \pm 8.3 \%$ & $1.31(10)^{-17} \pm 8.5 \%$ & $4.80(10)^{-11} \pm 8.5 \%$ \\
\hline
\end{tabular}

(a) For comparison the fission rates measured in each assembly have also been divided by the relative power level in each assembly

(b) Error limits are one standard deviation estimates 


\subsection{CONCLUSIONS}

The nuclear criticality data obtained in this series of experiments involving LWR type fuel rod arrays separated by neutron flux traps indicate that the effectiveness of such flux traps for criticality control is relatively insensitive to boron loadings above about $0.1 \mathrm{~g} \mathrm{~B} / \mathrm{cm}^{2}$. A decrease from $0.5 \mathrm{~g}$ $\mathrm{B} / \mathrm{cm}^{2}$ to $0.1 \mathrm{~g} \mathrm{~B} / \mathrm{cm}^{2}$ in the boron content of the Boral plates creating the neutron flux traps resulted in a decrease of only about $7 \%$ in the number of fuel rods required for criticality. Below about $0.1 \mathrm{~g} \mathrm{~B} / \mathrm{cm}^{2}$, the effectiveness of the flux trap is very sensitive to the boron loading. Decreasing the boron loading in the experimental assemblies from about $0.1 \mathrm{~g} \mathrm{~B} / \mathrm{cm}^{2}$ to zero resulted in a factor of about 3 decrease in the number of fuel rods required for criticality. Similar variations in $k_{e f f}$ with boron loading were observed. The experimental criticality data also indicate that for maximum effectiveness the separation between fuel and flux trap should be less than $6 \mathrm{~cm}$ at separations greater than $6 \mathrm{~cm}$ the flux trap is essentially ineffective and isolation between units is due to absorption in the water alone.

Although a single spectral index is only indicative of spectral change, the measured fission rates indicate that a change in boron loading primarily affects the neutron density but not the neutron spectrum in a flux trap region. The ratio of ${ }^{235} U$ and ${ }^{238} U$ fissions (i.e., essentially thermal to epithermal fissions) differed by only about $10 \%$, which is within experimental error, between boron loadings of $0.05 \mathrm{~g} \mathrm{~B} / \mathrm{cm}^{2}$ and $0.45 \mathrm{~g} \mathrm{~B} / \mathrm{cm}^{2}$. However, the absolute fission rates differed by a factor of about 6 between the two assemblies. 



\subsection{REFERENCES}

Bierman, S. R. and E. D. Clayton. 1981. "Criticality Experiments with Subcritical Clusters of Light Water Reactor Type Fuel Separated by a Flux Trap." Nucl. Tech. 52:342.

Bierman, S. R. 1983. Existing Experimental Criticality Data Applicable to Nuclear Fuel Transportation Systems. PNL-4118. Pacific Northwest Laboratory, Richland, Washington, 99352.

Committee on the Safety of Nuclear Installations Working Group. 1982. Standard Problem Exercised on Criticality Codes for Spent LWR Fuel Transport Containers. CSNI Report No. 71. Oak Ridge National Laboratory, Oak Ridge, Tennessee, 37830 .

Garelis, E., and J. L. Russe11. 1963. "Theory of Pulsed Neutron Source Measurements." Nuclear Science and Engineering. 16: 263.

Gold, Raymond and Ronald J. Armani. 1968. "Absolute Fission Rate Measurements with Solid-State Track Recorders". Nuclear Science and Engineering. 34:13-32

Gozani, T., P1. DeMarmels, T. Hurliman and H. Winkler. 1965. "On the Modified Pulse Source Techniques." In Proceedings of Symposium on Pulsed Neutron Research. Vol. II, pp. 49-62. Held by the International Atomic Energy Agency at Karlsruhe. International Atomic Energy Agency, Vienna, Austria.

Gonzani, T. 1972. "Consistent Subcritical Fast-Reactor Kinetics". Dynamics Of Nuclear Systems. University of Arizona Press, Tucson, AZ.

Katz, G. H. 1969. N. S. Savannah Core II Nuclear Characteristics. NUS-597, prepared for Todd Shipyards, Corp. by NUS Corporation, Rockville, Maryland.

Lippincott, E. P., et al. 1979. "SSTR Dosimetry in Critical Mass Measurements". ANS Transactions. 32:325-326. 
McElroy, W. N., S. Berg and T. Crocket. 1967. AFWL-TR-67-41, Vol. I-IV $\underline{A}$ Computer-Automated Iterative Method of Neutron Flux Spectra Determined by Foil Activation.

Pfeiffer, W., J. R. Brown and A. C. Marshall. 1974. "Fort St. Vrain Startup Test A-3: Pulse Neutron Experiments." GA-A13079. Prepared for the United States Atomic Energy Commission, San Francisco Operations office by General Atomic Company, San Diego, CaTifornia, 92138.

Roberts, J. H. and Song-Teh Huang. 1968. "Fission Rate Measurements in LowPower Fast Critical Assemblies with Solid-State Track Recorders". Nuclear Applications. $5: 247-252$.

Sjostrand, N. G. 1956. "Measurements on a Subcritical Reactor Using a Pulsed Neutron Source". In Proceedings of United Nations International Conference on Peaceful Uses of Atomic Energy. 5: 52. Geneva, Switzerland.

Schmittroth, F. A. 1979. HEDL-TME 79-40. FERRET Data Analys is Code. 
APPENOIX A

Density and Chemical Composition of Type 6061 and Type 1100 Aluminum 


\section{APPENDIX A}

Density and Chemical Composition of Type 6061 and Type 1100 Aluminum

Density and American Society for Testing Materials (ASTM) chemical specifications for the aluminum present in the experimental assemblies are presented in this Appendix. 


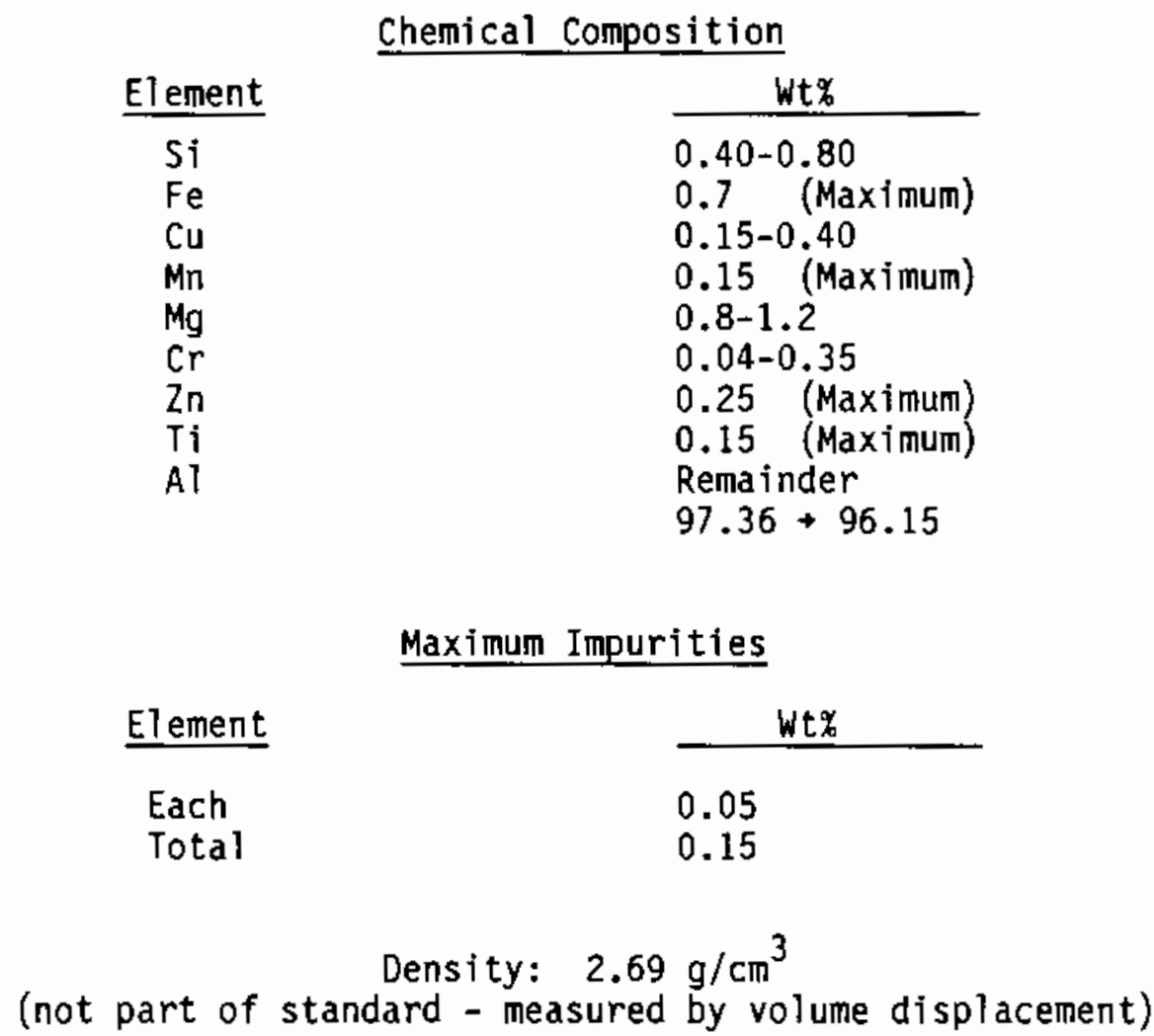


ASTM STANDARD B210-78 SPECIFICATIONS FOR TYPE 1100 ALUMINUM

\section{Chemical Composition}

\section{Element}

Si

$\mathrm{Fe}$

$\mathrm{Cr}$

$\mathrm{Mn}$

$\mathrm{Zn}$

A1

\begin{tabular}{|c|}
\hline Wt\% \\
\hline 1.0 (Combined Maxium) \\
\hline $\begin{array}{r}0.05-0.20 \\
0.05 \text { (Maximum) } \\
0.10 \text { (Maximum) } \\
99.00 \text { (Minimum) }\end{array}$ \\
\hline
\end{tabular}

Maximum Impurities

Element

Each

Tota 1

Density: $2.70 \mathrm{~g} / \mathrm{cm}^{3}$

(not part of standard - measured by volume displacement) 
.

-

. 


\section{APPENDIX B}

Trace Impurities Present in Water

Used as Moderator-Reflector in Experiments 


\section{APPENDIX B}

\section{Water Sample Analysis}

Samples were taken during the experiments of the water moderatorreflector. The results of the sample analyses are presented in this Appendix. All analyses were performed in accordance with Standard Methods for the Examination of Water and Waste Water, 15th ed., American Public Health Association, Washington, DC. 
TABLE B.1 Analysis of Water Sample

Sample Number

Analysis

$\underline{\text { TTC-1 }}$ ITC-2 $\quad$ TTC-3

$\mathrm{pH}$

7.7

7.7

7.7

Total alkalinity mg/liter as $\mathrm{CaCO}_{3}$

51.2

49.2

49.7

Bicarbonate alkalinity $\mathrm{mg} / \mathrm{liter}$ as $\mathrm{CaCO}_{3}$

49.5

42

42

Carbonate alkalinity $\mathrm{mg} / \mathrm{liter}$ as $\mathrm{CaCO}_{3}$

$<0.5$

$<0.5$

$<0.5$

Total dissolved solids $\mathrm{mg} / \mathrm{liter}$

109

98

100

Sulfate $\mathrm{mg} / \mathrm{liter}$

16

20

21

Nitrate (as N) mg/liter

$<0.38$

0.13

0.13

Fluoride $\mathrm{mg} / \mathrm{liter}$

$<0.1$

0.12

0.11

Chloride mg/liter

Cadmium mg/liter

11

3.7

3.7

Copper mg/liter

0.0018

0.002

0.002

$<0.01$

$<0.05$

$<0.05$

Chromium mg/liter

$<0.01$

$<0.01$

$<0.01$

Iron $\mathrm{mg} / \mathrm{liter}$

0.12

$<0.05$

$<0.08$

Lead mf/liter

$<0.002$

$<0.002$

$<0.002$

Manganese $\mathrm{mg} / \mathrm{liter}$

$<0.01$

$<0.01$

$<0.01$

Zinc $\mathrm{mg} / \mathrm{liter}$

$<0.05$

$<0.05$

$<0.05$ 
APPENDIX $C$

Impurities Measured in Lattice Plate Material 


\section{APPENDIX C}

\section{Trace Impurities Measured in Lattice Plate Material}

Trace impurity levels are presented in this Appendix for the polypropylene material used in fabricating the lattice plates for these experiments. The analytical results are from a spark source mass spectrographic analysis of samples taken from, and considered representative of, the polypropylene lattice plates. The spectrographic analysis were performed by the Hanford Engineering Development Laboratory, Richland, Washington, on October 17, 1985. 
TABLE C.1 Trace Impurities Present in Lattice

Plates Parts per Million by Weight

Sample Number

Element

Li

$\mathrm{Be}$

8

$\mathrm{F}$

$\mathrm{Na}$

$\mathrm{Mg}$

Al

Si

$P$

Cl

K

$\mathrm{Ca}$

$\mathrm{Ti}$

$\checkmark$

$\mathrm{Cr}$

Mn

$\mathrm{Fe}$

$\mathrm{Cu}$

Zn

$\mathrm{Ge}$

As

$\mathrm{Rb}$

$Y$

$\mathrm{Zr}$

Mo

Sn

$\mathrm{Br}$

\begin{tabular}{|c|c|}
\hline ITC-4 & $T T C-5$ \\
\hline 0.2 & 7 \\
\hline 1 & 1 \\
\hline 0.04 & 0.04 \\
\hline ------ & $\cdots-\cdots$ \\
\hline$<10$ & 20 \\
\hline$<6$ & 10 \\
\hline 30 & 30 \\
\hline 8 & 8 \\
\hline 5 & 5 \\
\hline 1 & 1 \\
\hline 40 & 60 \\
\hline----- & $-\cdots$ \\
\hline$<100$ & 100 \\
\hline 3 & 10 \\
\hline$<10$ & 50 \\
\hline$<2$ & 2 \\
\hline - --- & $-\cdots-$ \\
\hline 100 & 100 \\
\hline$<10$ & 10 \\
\hline---- & $-\cdots$ \\
\hline$<5$ & 20 \\
\hline$\cdots$ & $---\cdots$ \\
\hline ----- & $--\cdots--$ \\
\hline - & $\cdots-\cdots$ \\
\hline -...- & $\cdots-\cdots$ \\
\hline --...-- & $\cdots$ \\
\hline ----- & \\
\hline
\end{tabular}


APPENDIX D

Loading Diagrams for Critical and Subcritical Assemblies 


\section{Loading Diagrams for Critical and Subcritical Assemblies}

A loading diagram for each critical and subcritical assembly is presented in numerical order in this Appendix except for assemblies 222 and 225. Measurements on assembly 222 were performed in compliance with operating procedures and not reported herein since experimental data was not obtained. Assembly 225 is an identification number assigned to a set of conditions based on extrapolation (as indicated in the text). Experimental assembly identification numbers are provided in each diagram for cross reference with tables presented in the text. The neutron flux trap involved is identified in each diagram, and the fuel arrangement is shown for each critical and subcritical measurement. For the criticality experiments, the last neutronically symmetrical fuel rod loading is shown for which the delayed critical condition was predicted by extrapolation. In essentially all cases the indicated predicted delayed critical condition was verified by adding a partially symmetrical loading and partially withdrawing the control rods to obtain a positive period. For the subcritical assemblies the actual fuel loadings, with the neutron detector and the pulse neutron source in place, are shown. Based on replacement type measurements, the neutron detector has a positive reactivity worth equivalent to two fuel rods on the periphery of an assembly.

The location of controls and safety rod guided sleeves are shown in each diagram. In those assemblies in which the guide sleeves occupied fuel positions, replacement type measurements were made to evaluate their reactivity worth in terms of fuel rods. 


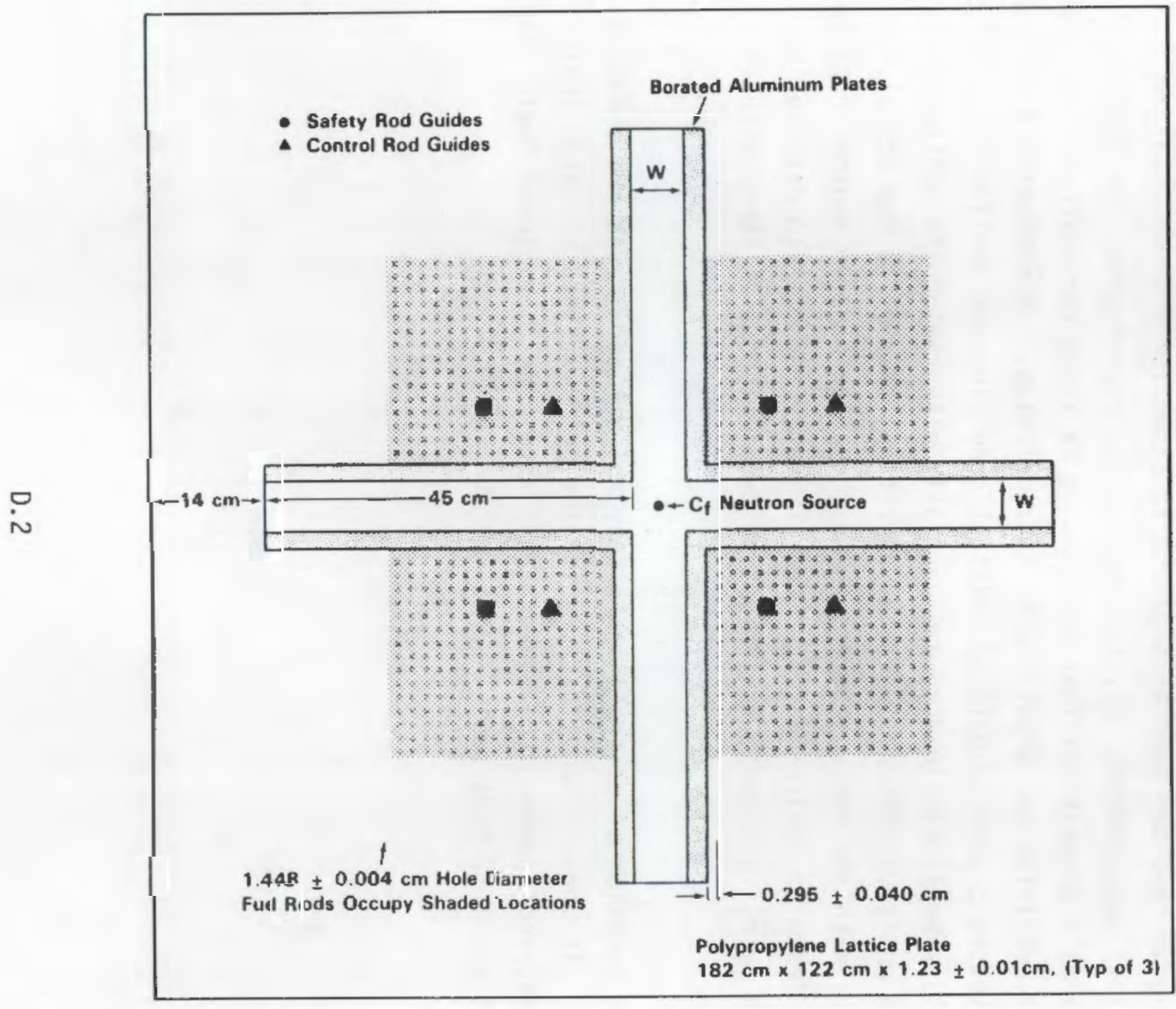

Polypropylene Lattice Plate

$1.448 \pm 0.004 \mathrm{~cm}$ Hole Diameter 


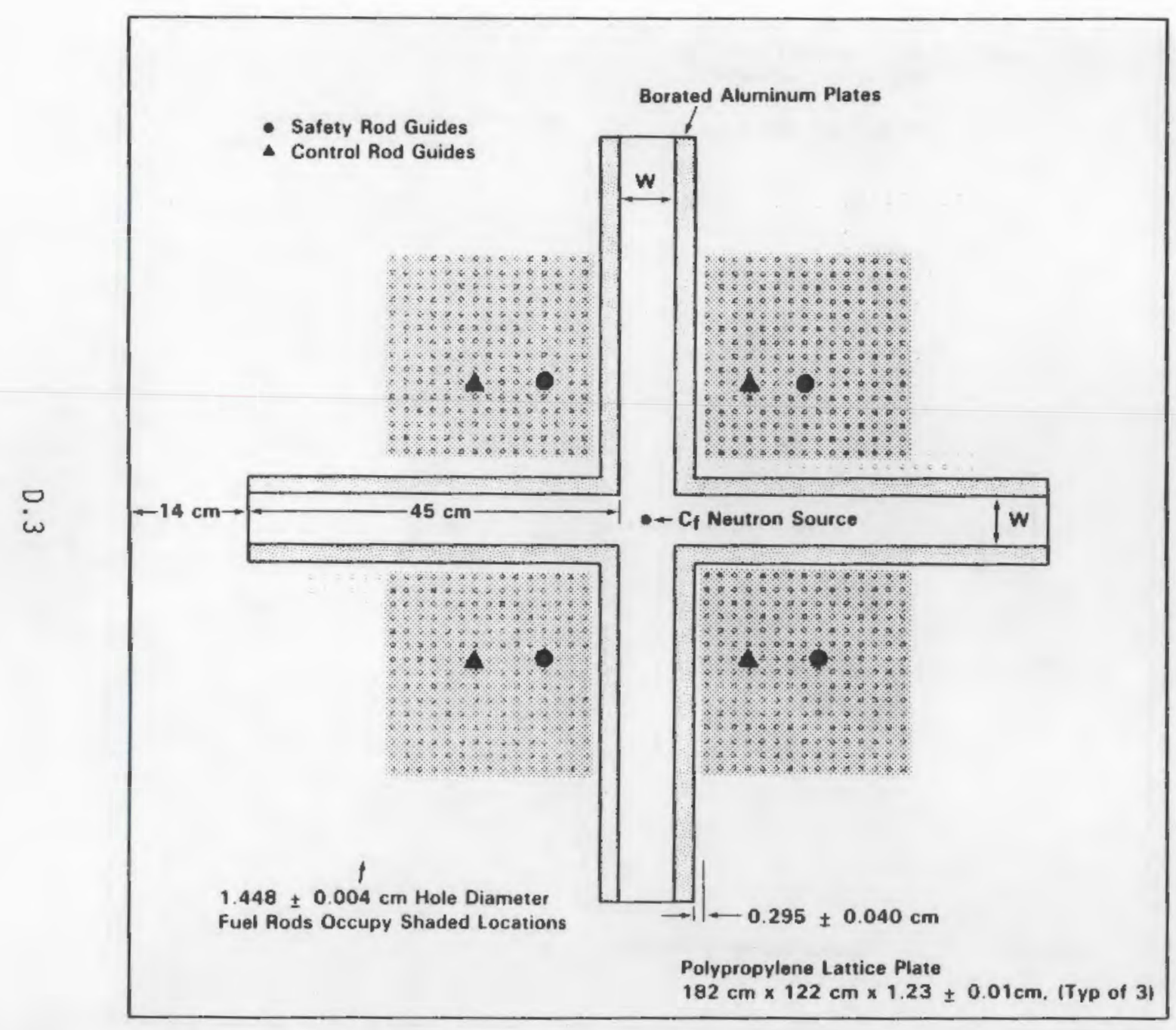

Assembly Number : 215

Lattice Pitch : $1.891 \pm 0.001 \mathrm{~cm}$

Out of System

Control Rods

Out of System

Fuel Rods : 892

Fuel : 4.31 wt $\%{ }^{235} \mathrm{U}$ Enriched $\mathrm{UO}_{2}$

Flux Trap Width, $w: 3.73 \pm 0.02 \mathrm{~cm}$

Plates : Boral

Boron $\quad 0.36 \pm 0.02 \mathrm{~g} / \mathrm{cm}^{2}$

koff : See Comments

Comments : 909 Aods Predicted for Delayed

Criticality with \& Water Cells

Created by Saftey and Control Rod Guide

923 Rods Predicted for Delayed

Criticality with Safety and Controll

Rod Guides Replaced with Fuel Rods

Polypropylene Lattice Plate

$182 \mathrm{~cm} \times 122 \mathrm{~cm} \times 1.23 \pm 0.01 \mathrm{~cm}$. (Typ of 3 ) 


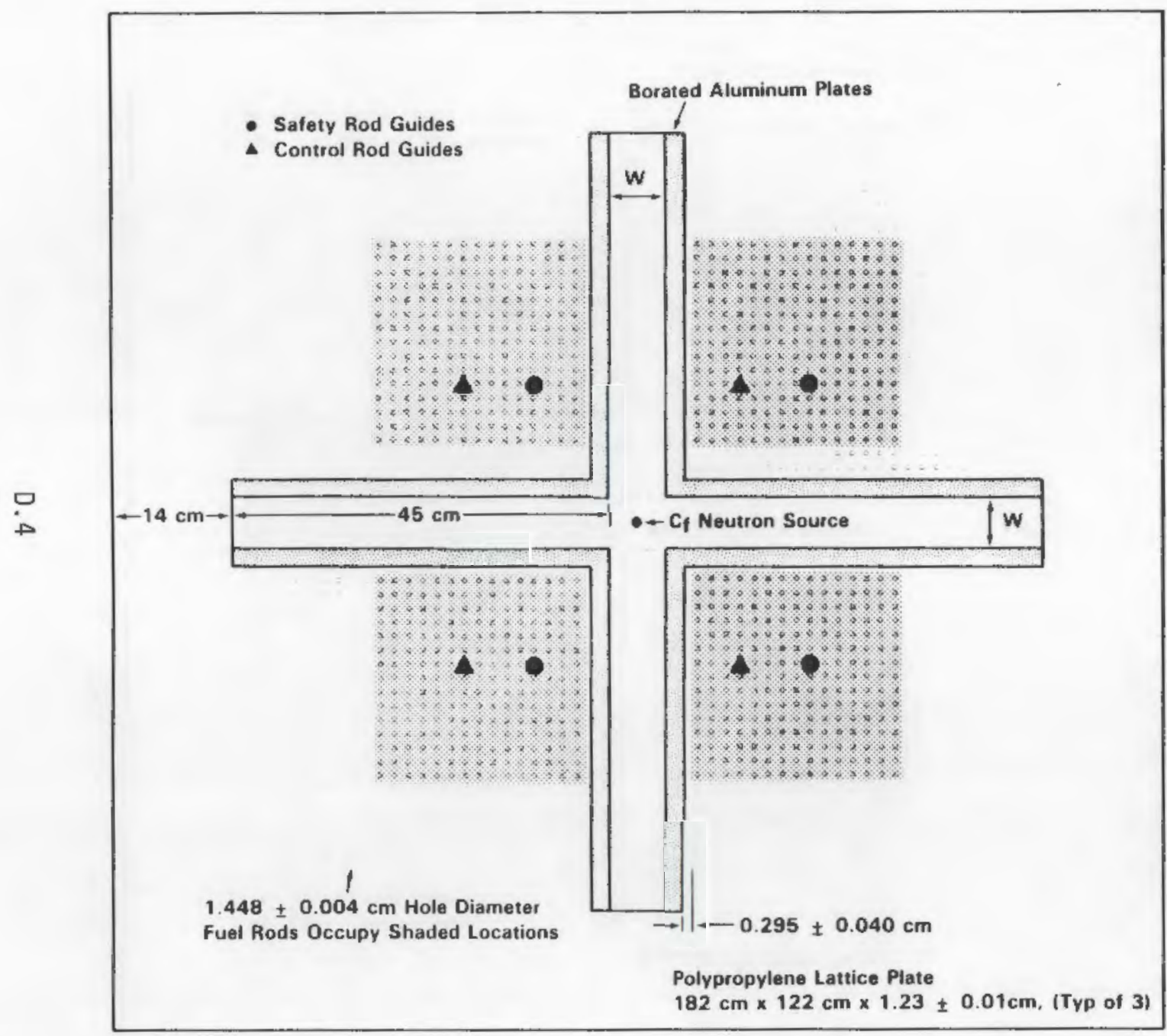

$\begin{array}{lll}\begin{array}{l}\text { Assembly Number } \\ \text { Lattice Pitch }\end{array} & : 216 \\ \text { Safety Rods } & : 891 \pm 0.001 \mathrm{~cm} \\ \text { Control Rods } & : \text { Out of System } \\ & : \text { Out of System } \\ \text { Fuel Rods } & : 892 \\ \text { Fuel } & : 4.31 \mathrm{wt} \%{ }^{235} \mathrm{U} \text { Enriched } \mathrm{UO}_{2} \\ \text { Flux Trap Width, } \mathbf{:} & 3.73 \pm 0.02 \mathrm{~cm} \\ \text { Plates } & : \text { Boral } \\ \text { Boron } & : 0.36 \pm 0.02 \mathrm{~g} / \mathrm{cm}^{2} \\ \text { Koll } & : \text { See Comments } \\ \text { Comments } & : 897 \text { Rods Predicted for Delayed } \\ & \text { Criticality with } 8 \text { Water Cells } \\ & \text { Created by Saftey and Control Rod } \\ & \text { Guide }\end{array}$

910 Rods Predicted for Delayed Criticality with Safety and Controll Rod Guides Replaced with Fuel Rods 


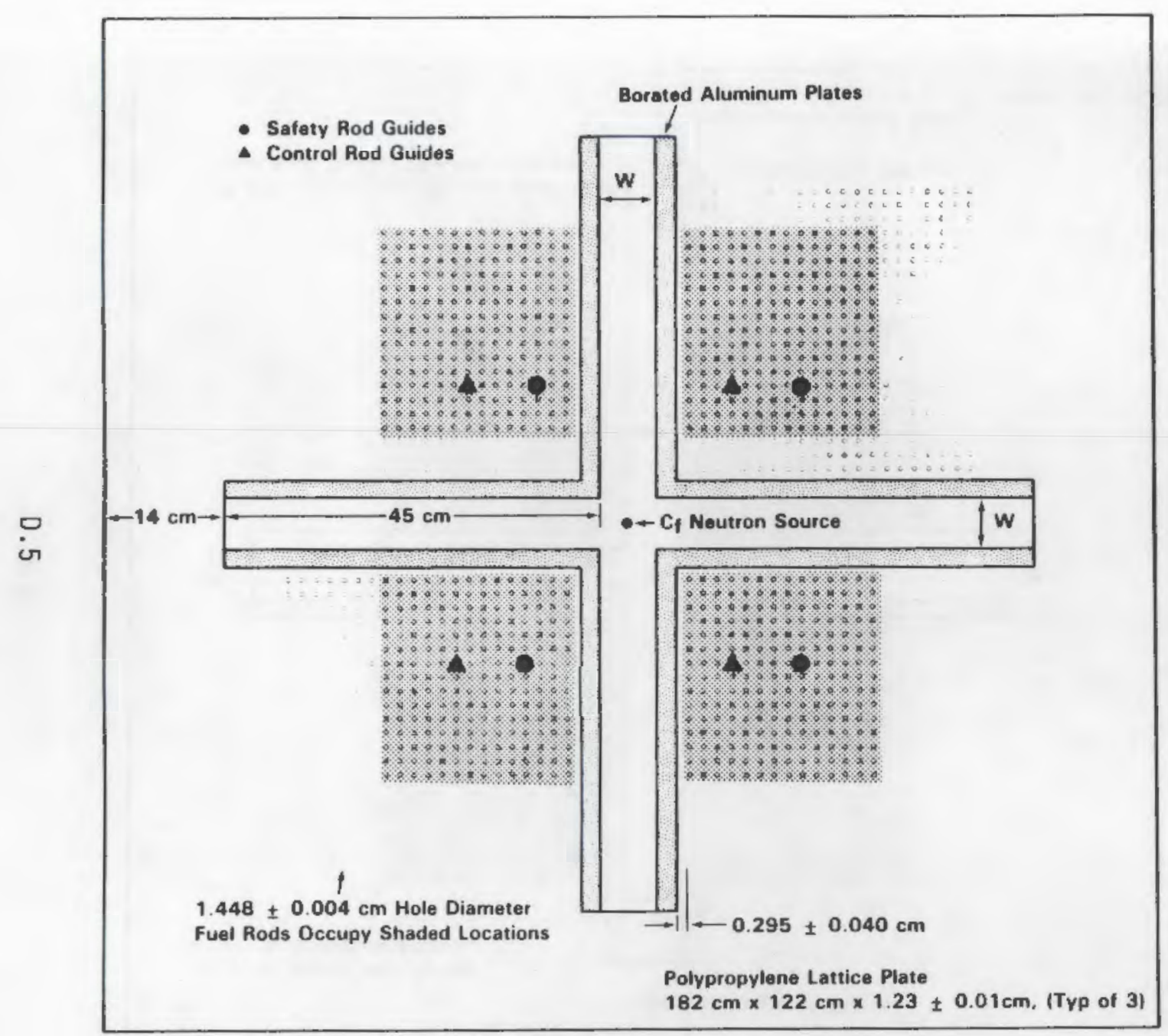




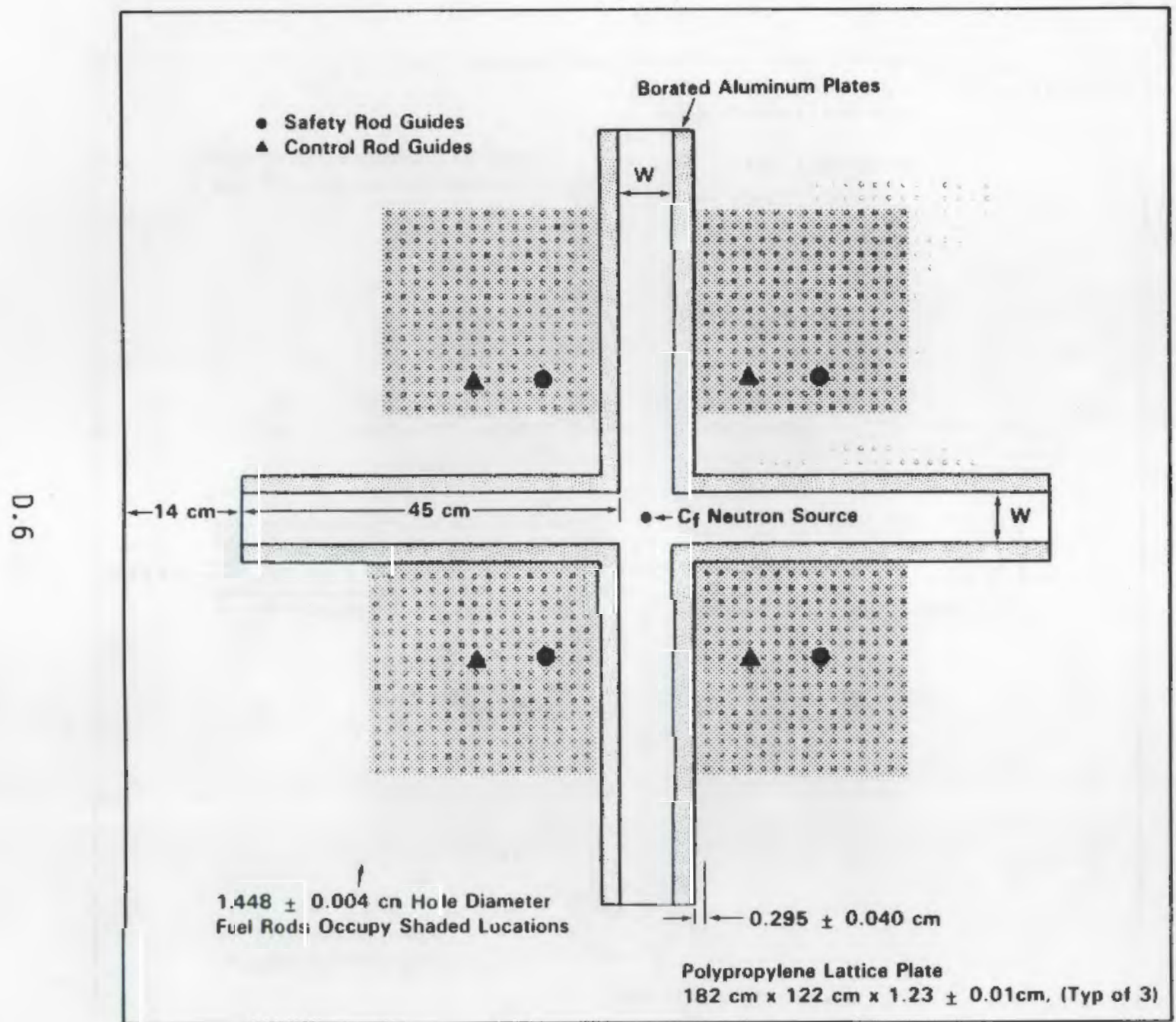

Assembly Number : 218

: $1.891 \pm 0.001 \mathrm{~cm}$

Safety Rods : Out of System

Control Rods : Out of System

Fuel Rods $\quad: 892$

Fuel $\quad 4.31$ wt $\%{ }^{235} \cup$ Enriched $\mathrm{uO}_{2}$

Flux Trap Width, $W: 3.73 \pm 0.02 \mathrm{~cm}$

Plates : Boral

Boron $\quad: 0.36 \pm 0.02 \mathrm{~g} / \mathrm{cm}^{2}$

koft

See Comments

Comments : 895 Rods Predicted for Delayed

Criticality with 8 Water Cells Created

by Safety and Control Rod Guide

907 Rods Predicted for Delayed

Criticality with Safety and Control Rod Guides Replaced with Fuel Rods

Polypropylene Lattice Plat 


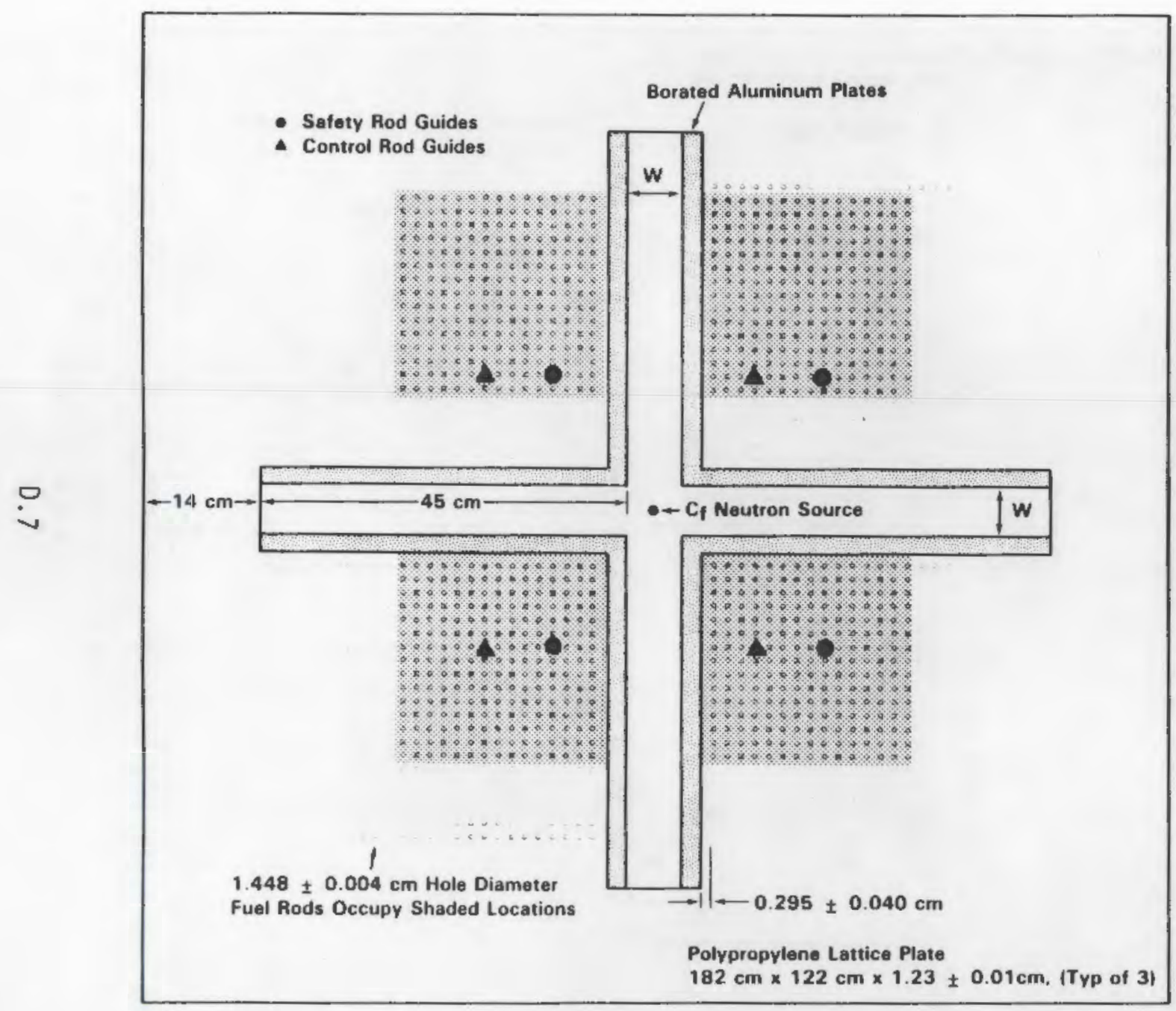

Assembly Number : 219

Lattice Pitch : $1.891 \pm 0.001 \mathrm{~cm}$

Safety Rods : Out of System

Control Rods : Out of System

Fuel Rods : : 892

Fuel : 4.31 wt $\%{ }^{235} \mathrm{U}$ Enriched $\mathrm{UO}_{2}$

Flux Trap Width, $W: 3.75 \pm 0.02 \mathrm{~cm}$

Plates : Boral

Boron : $0.36 \pm 0.02 \mathrm{~g} / \mathrm{cm}^{2}$

kefi : See Comments

Comments : 897 Rods Predicted for Delayed

Criticality with 8 Water Cells

Created by Saftey and Control Rod

Guide

909 Rods Predicted for Delayed

Criticality with Safety and Control

Rod Guides Replaced with Fuel Rods

$1.448 \pm 0.004 \mathrm{~cm}$ Hole Diameter

Fuel Rods Occupy Shaded Locations

Polypropylene Lattice Plate

$182 \mathrm{~cm} \times 122 \mathrm{~cm} \times 1.23 \pm 0.01 \mathrm{~cm}$. (Typ of 3 ) 


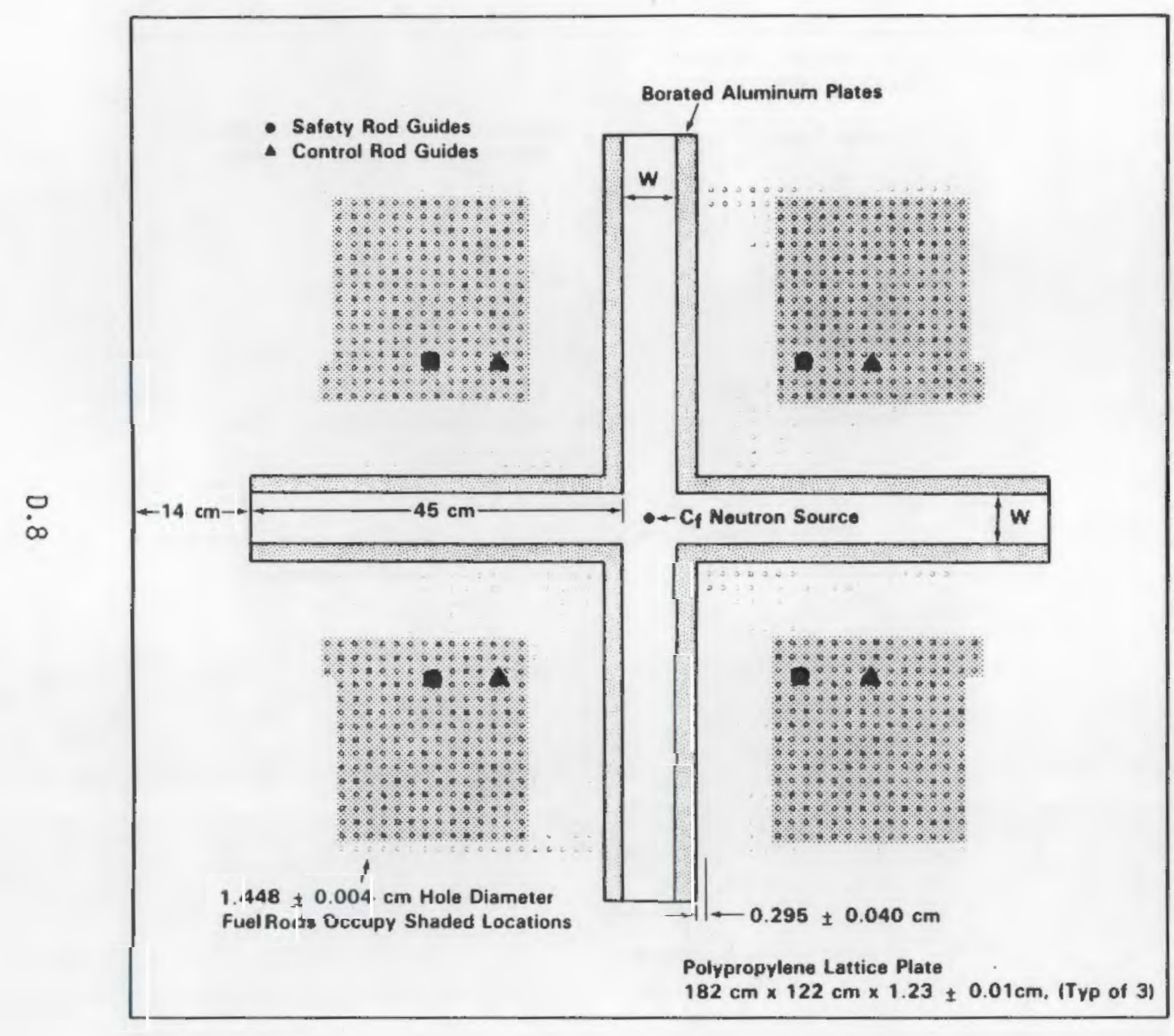

Assembly Number : $220 \mathrm{R}$

Lattice Pitch $\quad: 1.891 \pm 0.001 \mathrm{~cm}$

Safety Rods : Out of System

Control Rods : : Out of System

Fuel Rods

852

Fuel $\quad: 4.31 \mathrm{wt} \%{ }^{235} \mathrm{U}$ Enriched $\mathrm{UO}_{2}$

Flux Trap Width, $w: 3.73 \pm 0.02 \mathrm{~cm}$

Plates : Boral

Boron : $0.36 \pm 0.02 \mathrm{~g} / \mathrm{cm}^{2}$

kefl :See Comments

Comments : 860 Rods Predicted for Delayed

Criticality 


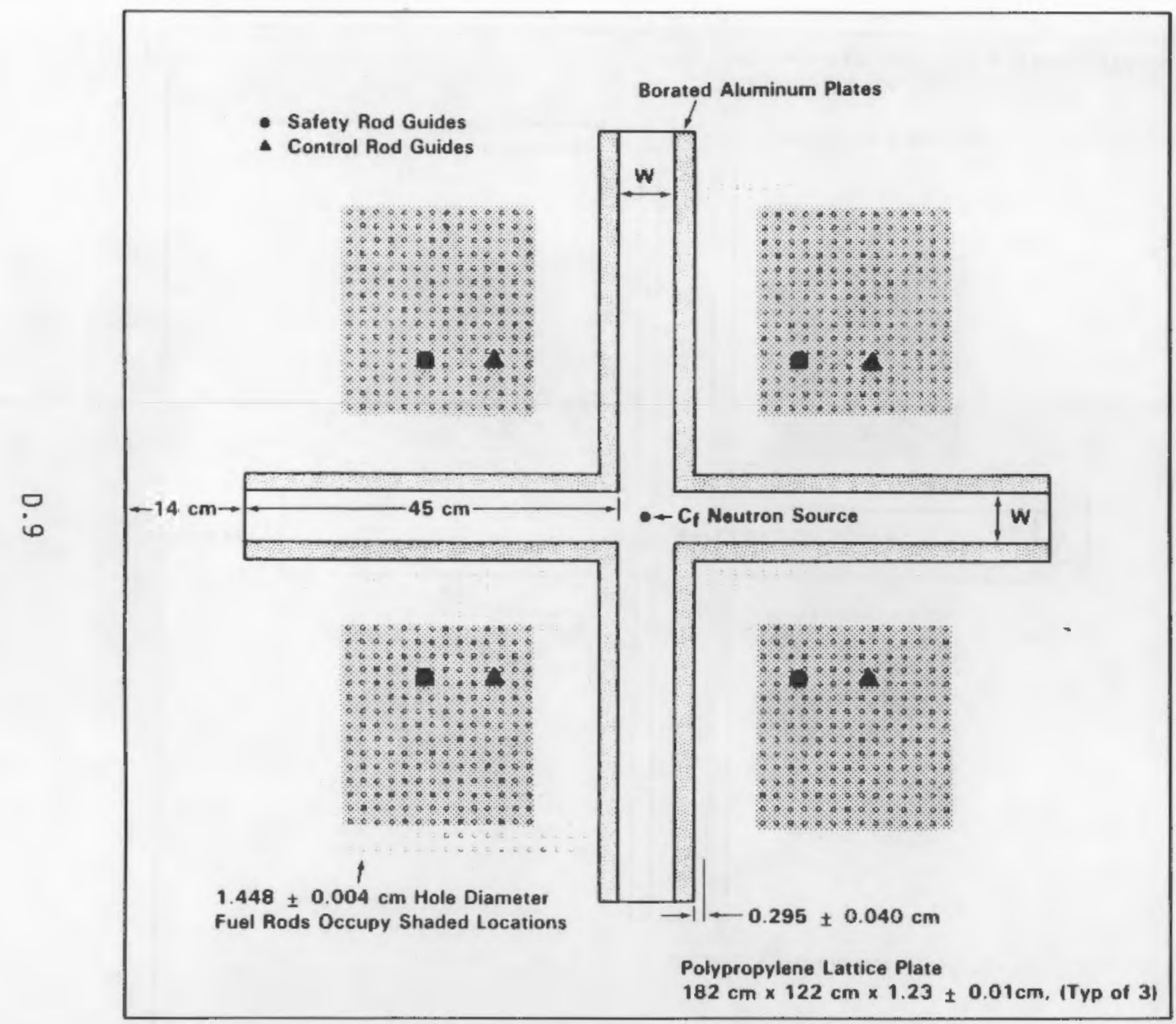
Assembly Number : $221 \mathrm{R}$
Lattice Pitch : $1.891 \pm 0.001 \mathrm{~cm}$
Safety Rods : Out of System
Control Rods : Out of System
Fuel Rods : : 840
Fuel $\quad: 4.31$ wt $\%{ }^{236} \mathrm{U}$ Enriched UO
Flux Trap Width, $w: 3.73 \pm 0.02 \mathrm{~cm}$
Plates : Boral
Boron $\quad 0.36 \pm 0.02 \mathrm{gB} / \mathrm{cm}^{2}$
kefl :See Comments
Comments : 858 Rods Predicted for Delayed
Criticality




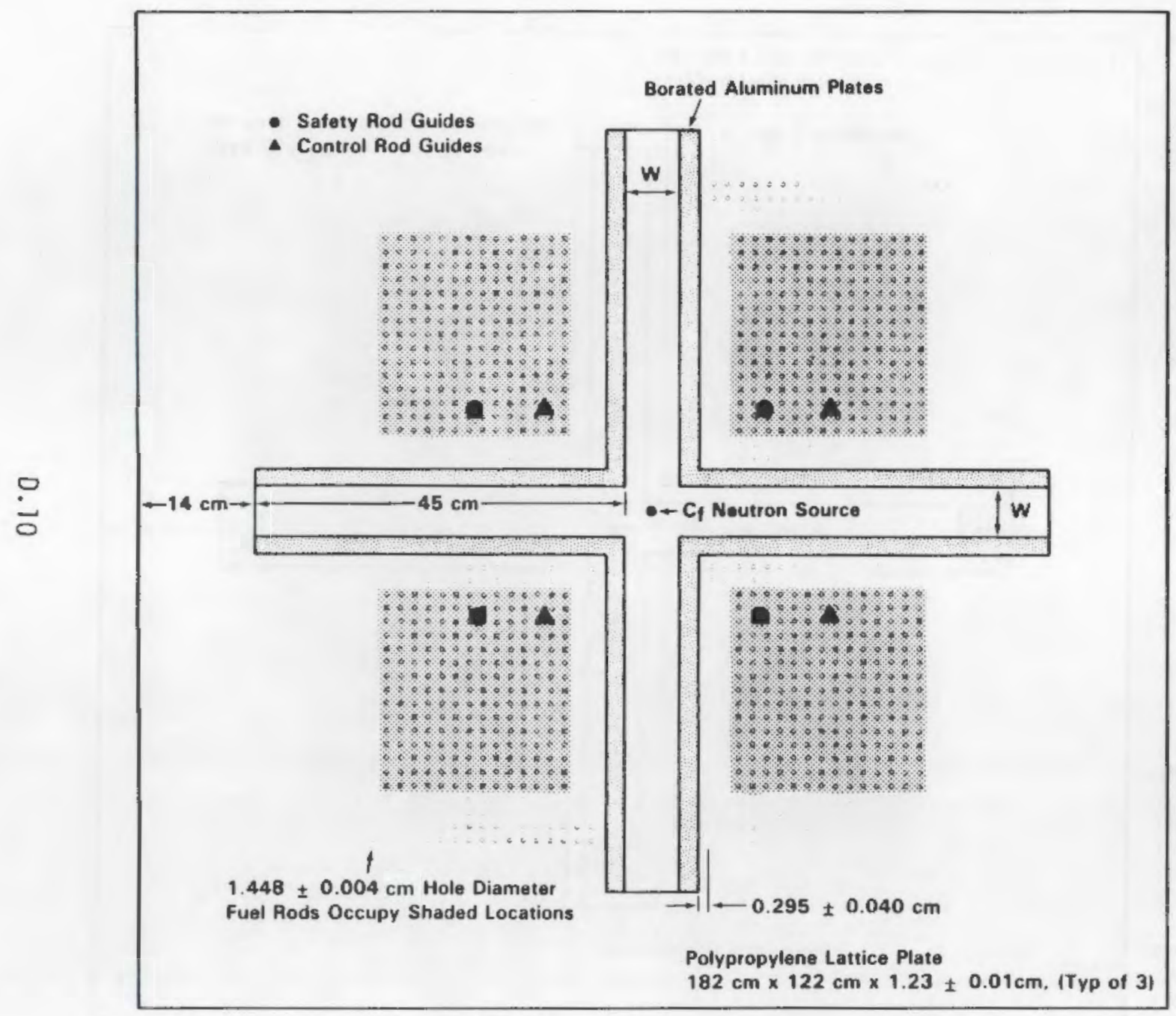




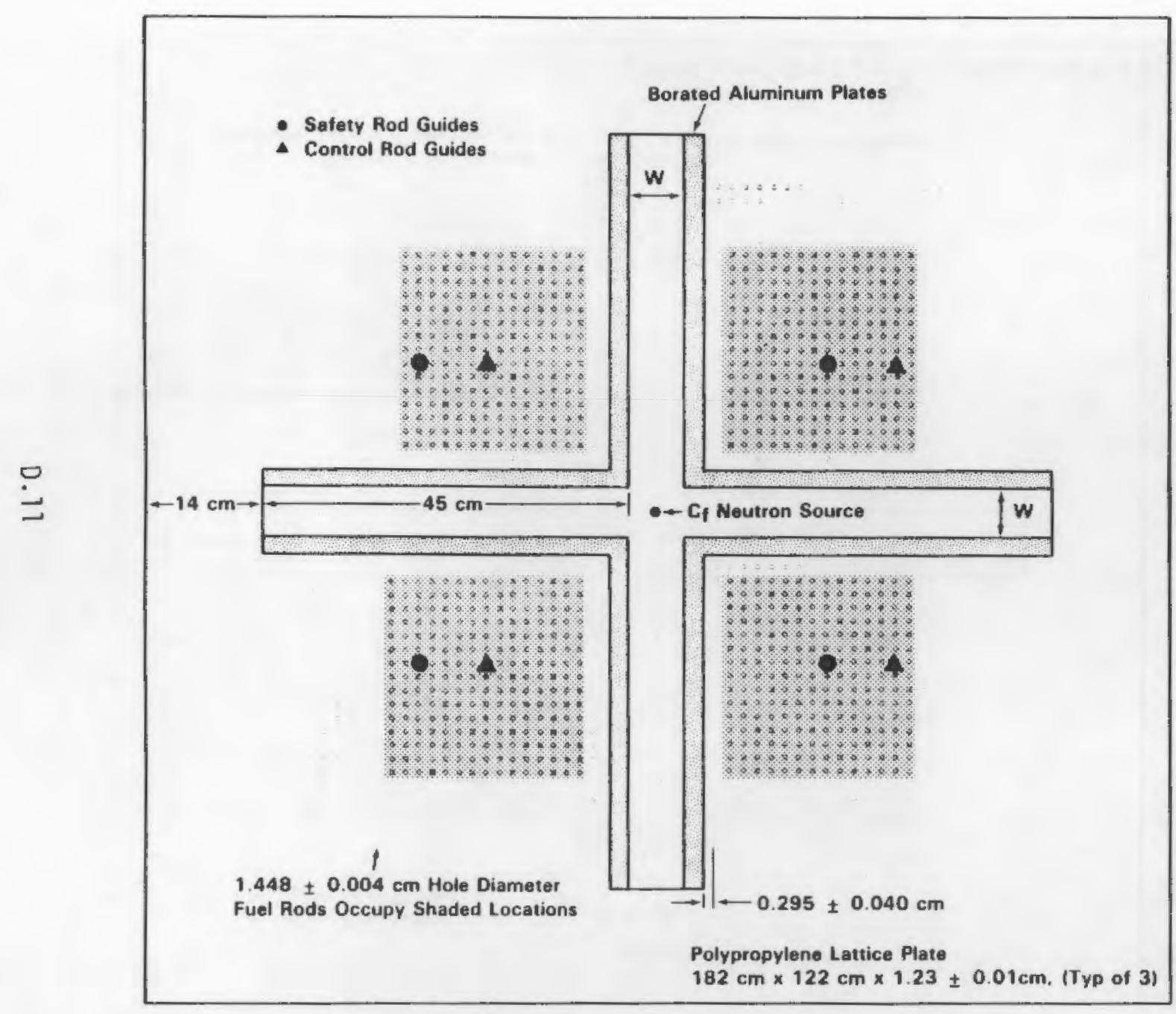
Assembly Number : 224
Lattice Pitch : $1.891 \pm 0.001 \mathrm{~cm}$
Safety Rods : Out of System
Control Rods : Out of System
Fual Rods : 847
Fuel $\quad: 4.31$ wt $\%{ }^{235} \mathrm{U}$ Enriched $\mathrm{UO}_{2}$
Flux Trap Width, $W: 3.73 \pm 0.02 \mathrm{~cm}$
Plates : Boral
Boron $: 0.36 \pm 0.02 \mathrm{~g} / \mathrm{cm}^{2}$
kell : See Comments
Cornments : 858 Rods Predicted for Delayed
Criticelity with 8 Water Cells
Created by Saftey and Control Rod Guide

874 Rods Predicted for Delayed

Criticality with Safety and Control

Rod Guides Replaced with Fuel Rods 


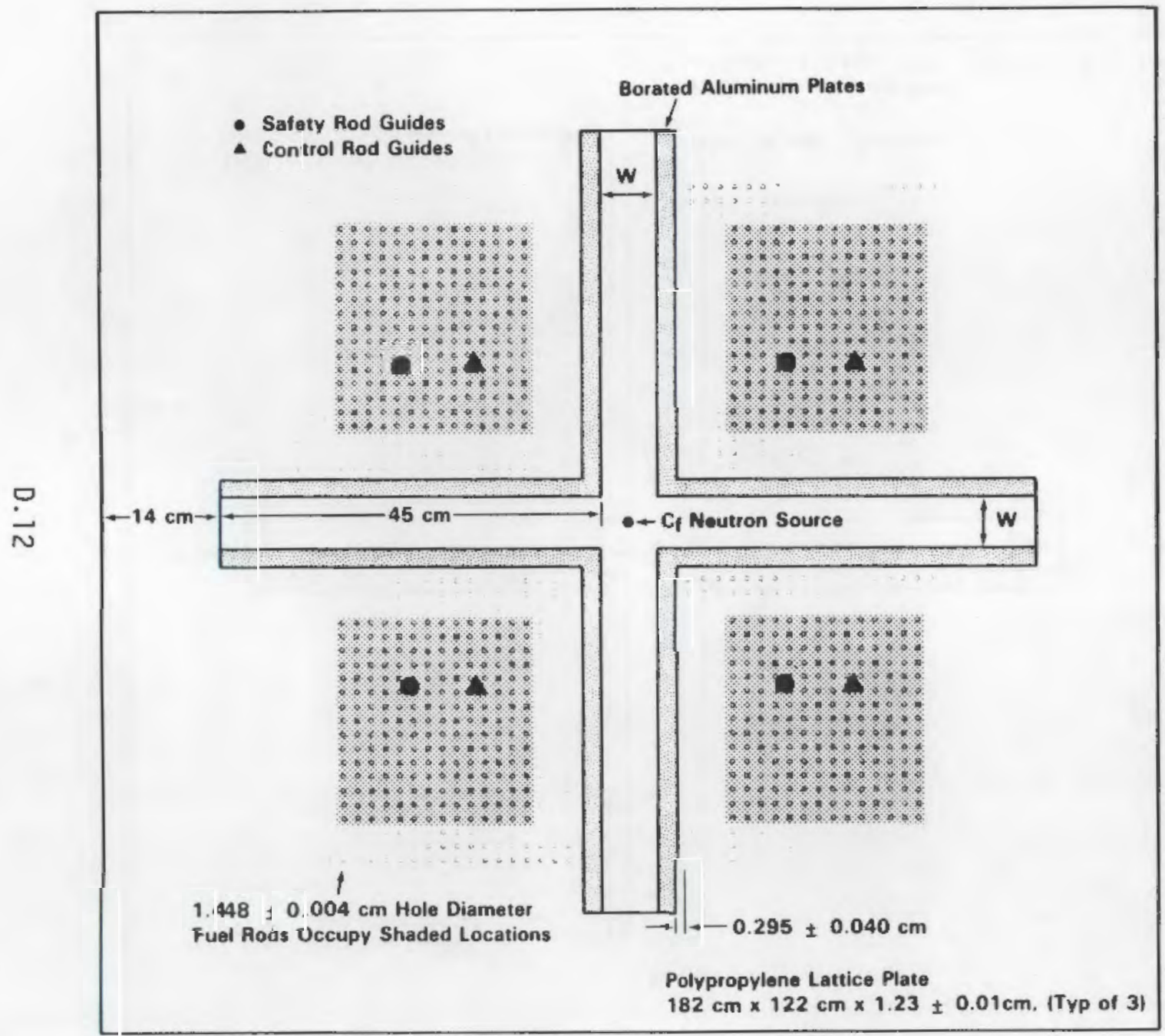

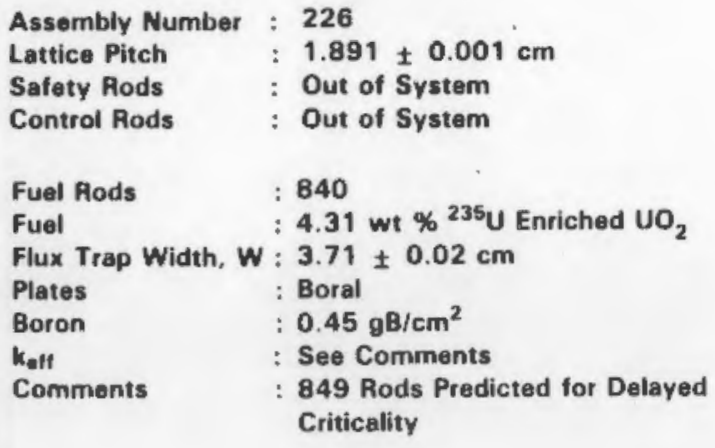

Assembly Number : 226

Out of System

- Safaty Rod Guides

Control Rod Guides

Criticality 


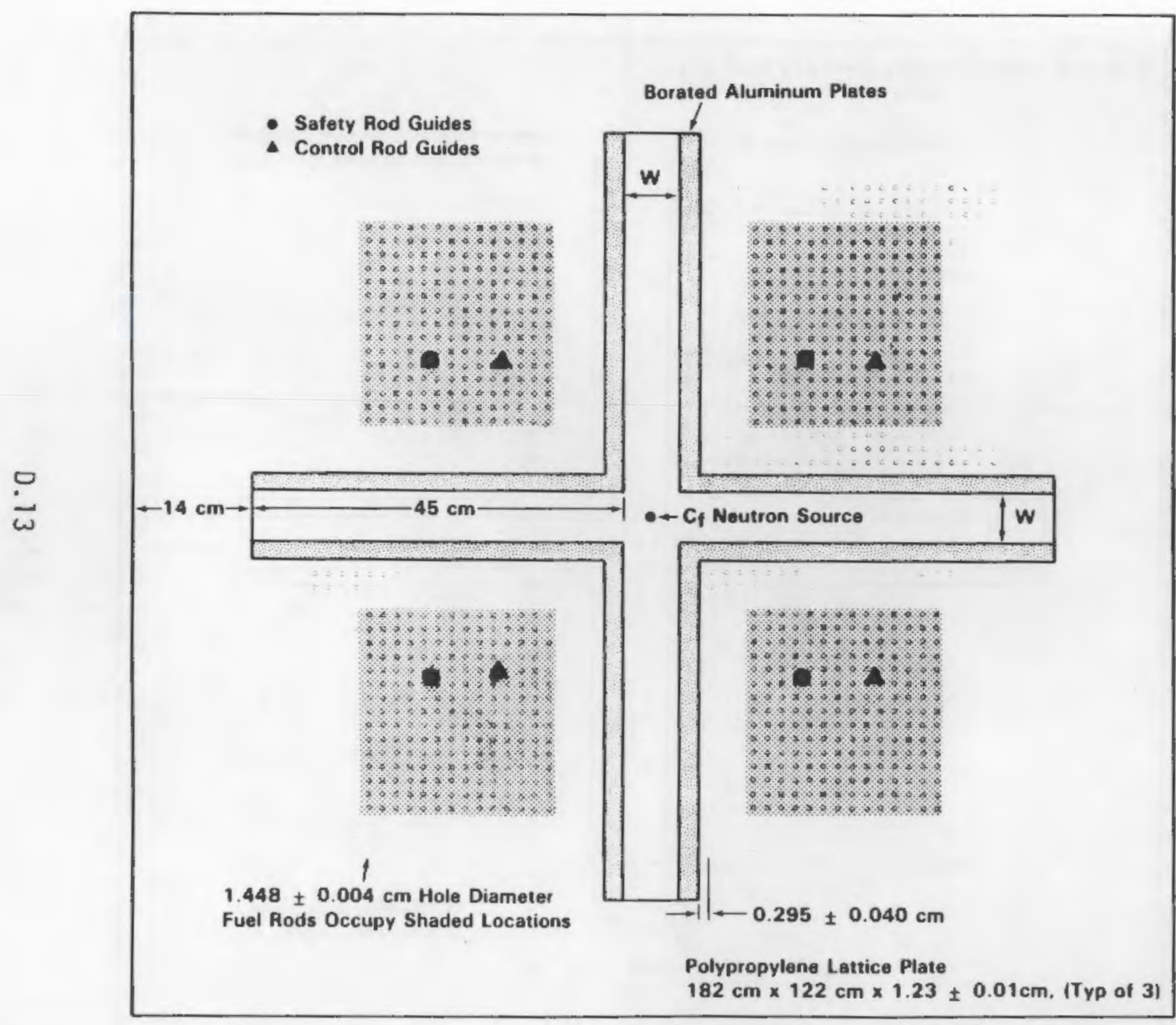




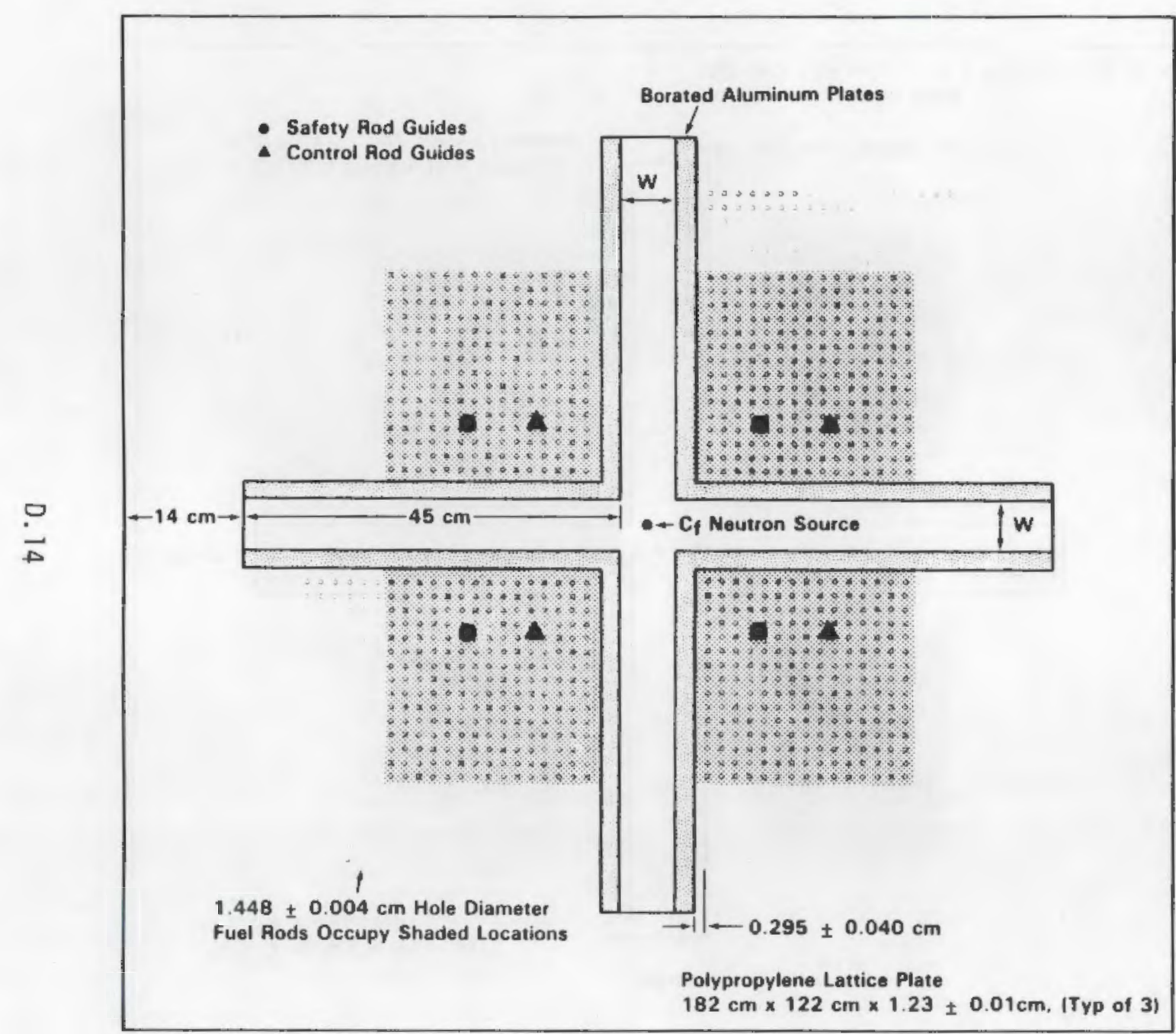




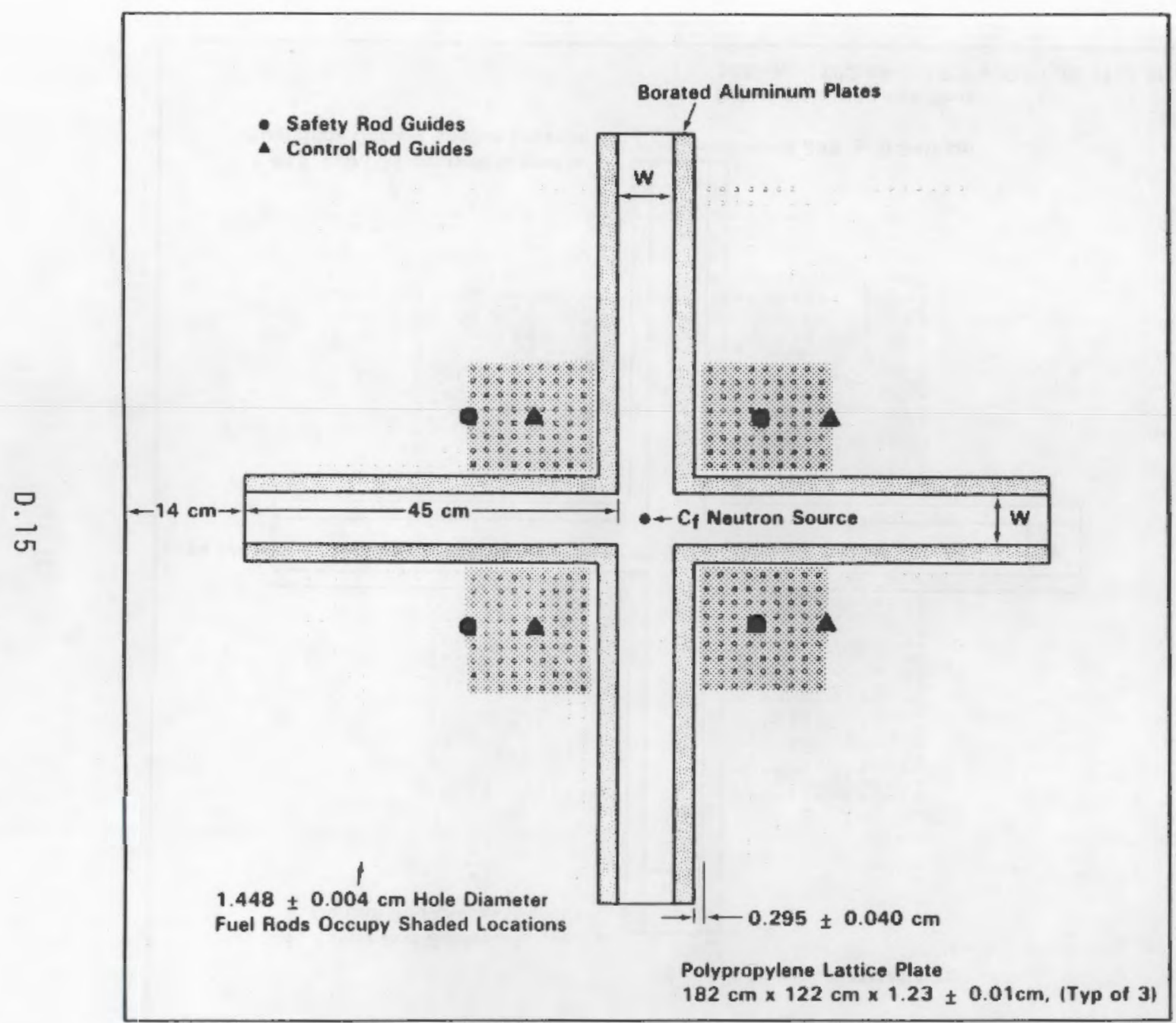

Assembly Number : 229

Lattice Pitch $\quad: 1.891 \pm 0.001 \mathrm{~cm}$

Safety Pods : Out of System

Control Rods : Out of System

Fuel Rods : 306

Fuel : 4.31 wt \% ${ }^{235} \mathrm{U}$ Enriched UO

Flux Trap Width, $W: 3.81 \pm 0.02 \mathrm{~cm}$

Plates : A6061 Aluminum

Boron :0

keff : See Comments

Comments : 308 Rods Predicted for Delayed

Criticality 


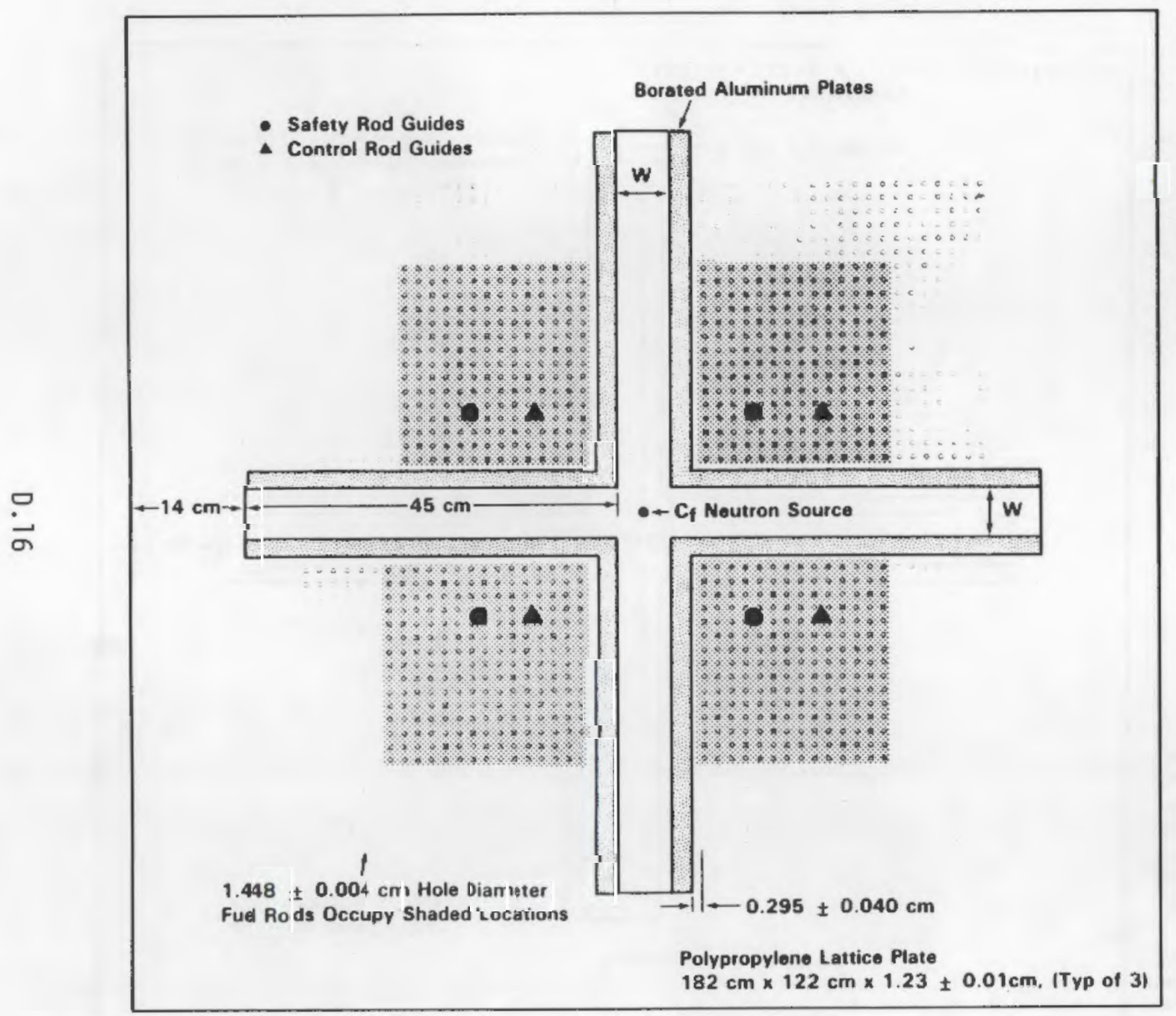
Assembly Number : 230
Lattice Pitch $: 1.891 \pm 0.001 \mathrm{~cm}$
Safety Rods : Out of System
Control Rods : Out of System
Fuel Rods $\quad: 855$
Fuel $\quad: 4.31$ wt $\%{ }^{235} \mathrm{U}$ Enriched $\mathrm{UO}_{2}$
Flux Trap Width, $W: 3.75 \pm 0.02 \mathrm{~cm}$
Plates : 8oral
Boron $0.05 \pm 0.01 \mathrm{~g}^{2} \mathrm{~cm}^{2}$
keff : See Comments
Comments : $\mathbf{8 5 6}$ Rods Predicted for Delayed Criticality




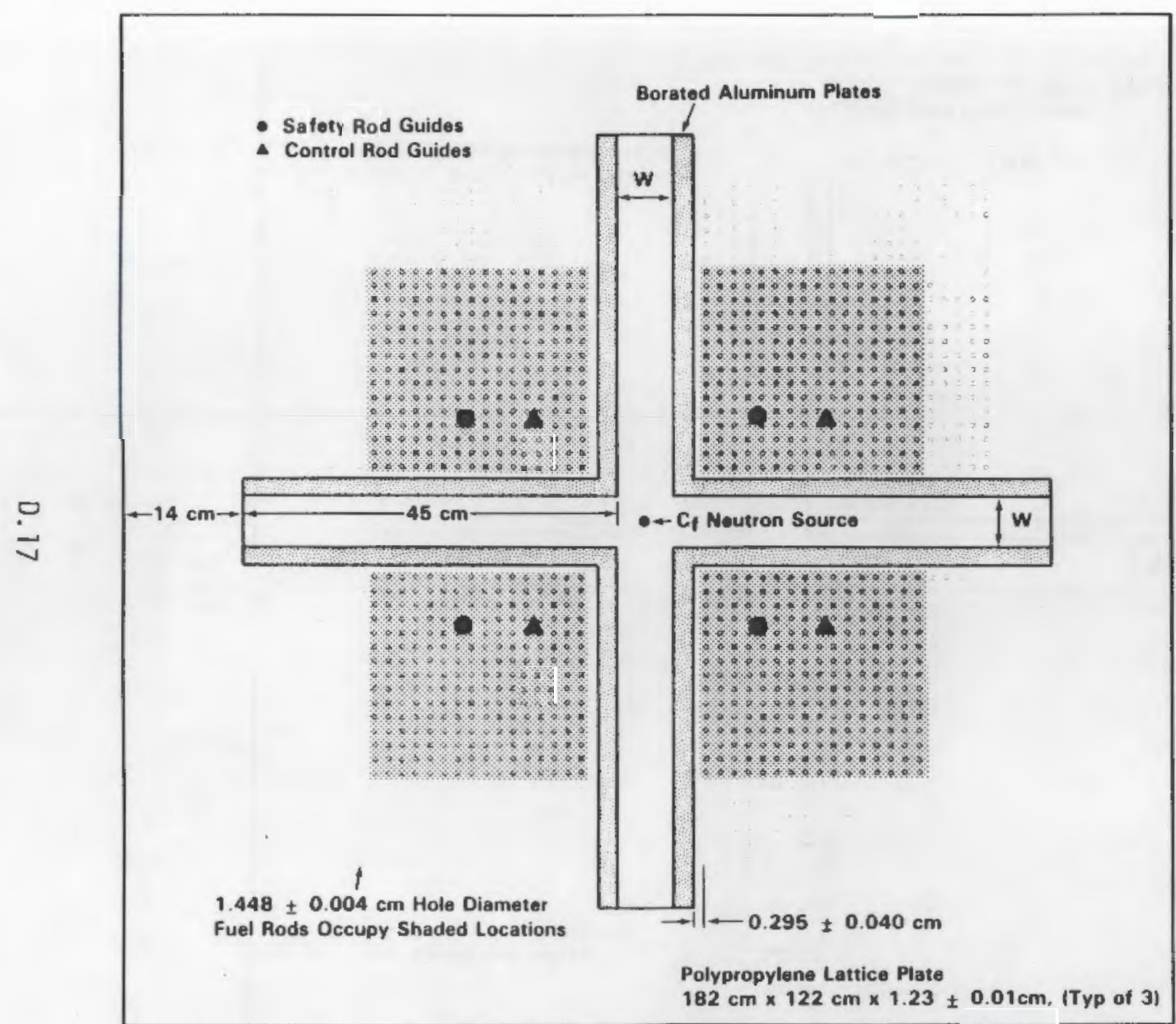
Assembly Number : 231
Lattice Pitch $: 1.891 \pm 0.001 \mathrm{~cm}$
Safoty Rods : Out of System
Control Rods : Out of System
Fuel Rods $\quad: 960$
Fuel $\quad 4.31$ wt $\%{ }^{235} \mathrm{U}$ Enriched $\mathrm{UO}_{2}$
Flux Trap Width, $\mathbf{W}: \mathbf{3 . 7 1} \pm 0.020$
Plates $\quad: 0.45 \pm 0.01 \mathrm{~g} / \mathrm{cm}^{2}$
Boron : Boral
k eff : See Comments
Comments : 963 Rods Predicted for Delayed Criticality




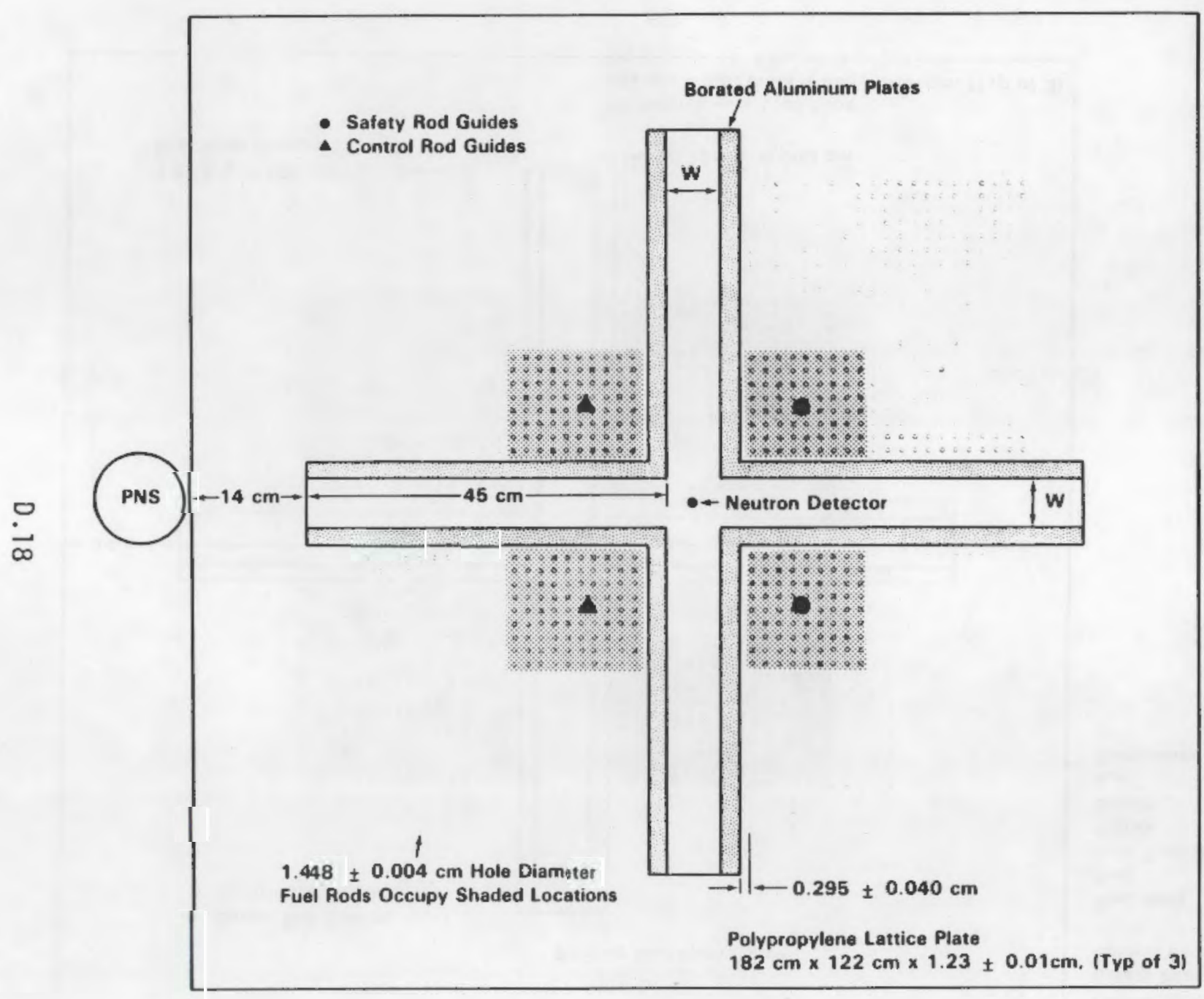

\begin{tabular}{|c|c|c|c|c|}
\hline \multicolumn{2}{|c|}{$\begin{array}{l}\text { Assembly Number } \\
\text { Lattice Pitch } \\
\text { Safety Rods } \\
\text { Control Rods }\end{array}$} & \multicolumn{3}{|c|}{$\begin{array}{l}\text { : See Comments } \\
: 1.891 \pm 0.001 \mathrm{~cm} \\
: \text { Out of System } \\
: \text { Out of System }\end{array}$} \\
\hline \multicolumn{2}{|l|}{$\begin{array}{l}\text { Fuel Rods } \\
\text { Fuel } \\
\text { Flux Trap w } \\
\text { Plates } \\
\text { Boron } \\
k_{\text {off }} \\
\text { Comments }\end{array}$} & \multicolumn{3}{|c|}{$\begin{array}{l}: 306 \\
4.31 \text { wt } \%{ }^{235} u \\
\text { See Comments } \\
: \text { See Comments } \\
: \text { See Comments } \\
\text { : See Comments } \\
: \text { See Table Below }\end{array}$} \\
\hline \multirow{2}{*}{$\begin{array}{l}\text { Assembly } \\
\text { Number } \\
\end{array}$} & \multirow[b]{2}{*}{$\begin{array}{c}w \\
\{(\mathrm{~cm})\end{array}$} & \multirow{2}{*}{$\begin{array}{c}\mathrm{B} \\
\left(\mathrm{gB} / \mathrm{cm}^{2}\right) \\
\end{array}$} & \multicolumn{2}{|c|}{$K_{\text {oft }}$} \\
\hline & & & (GO) & (GA) \\
\hline 229 & 3.81 & 0 & $1.0^{*}$ & $1.0^{*}$ \\
\hline 230 & 3.75 & 0.05 & 0.87 & 0.84 \\
\hline 228 & 3.76 & 0.13 & 0.87 & 0.83 \\
\hline 214 & 3.73 & 0.36 & 0.86 & 0.81 \\
\hline 231 & 3.71 & 0.45 & 0.85 & 0.80 \\
\hline
\end{tabular}

* Determined by Critical Apprroach Experiment 


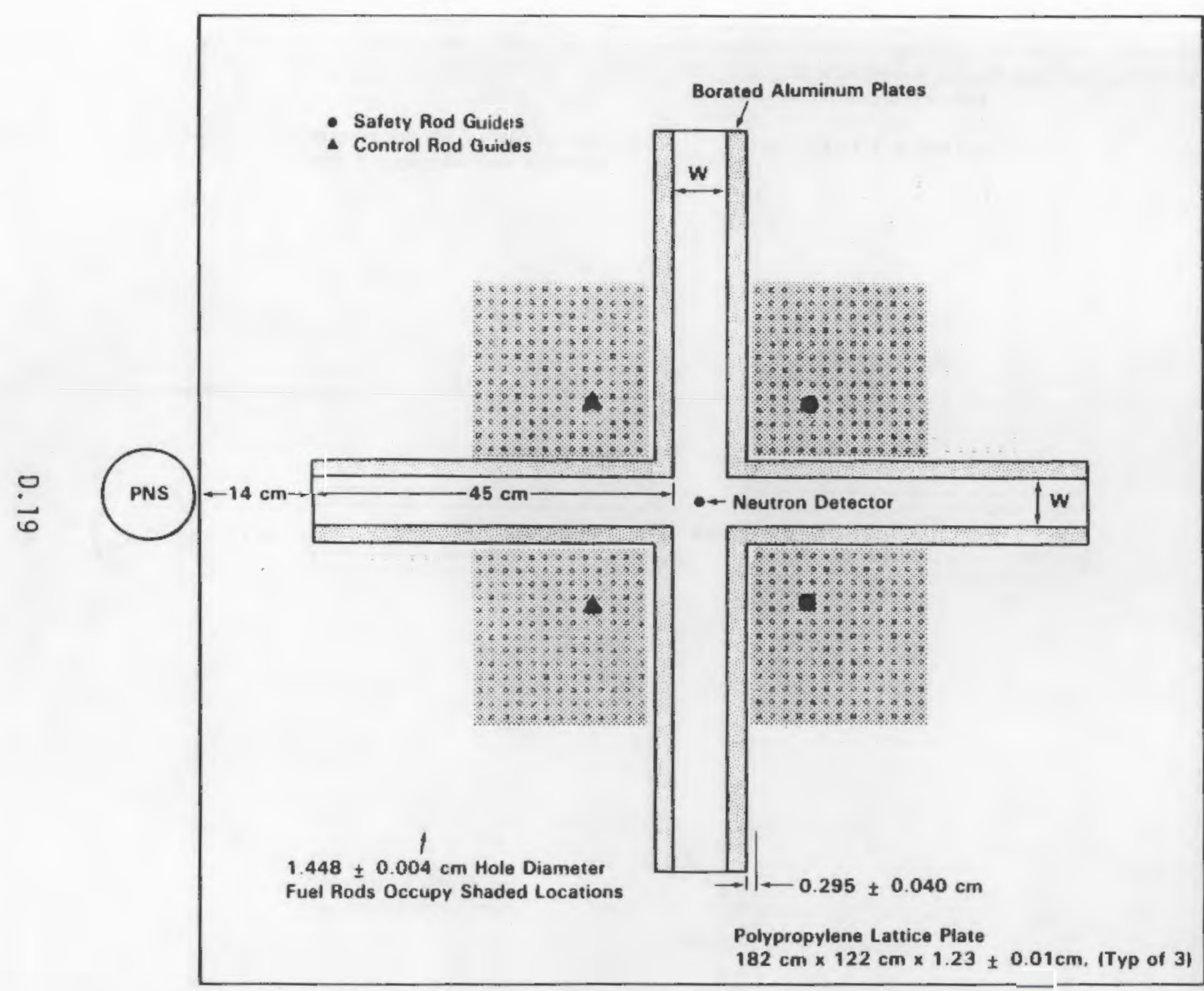

Assembly Number : See Comments Lattice Pitch : $1.891 \pm 0.001 \mathrm{~cm}$ Safety Rods : Out of System

Control Rods : : Out of System

Fuel Rods

Fuel

: 676

$\therefore 4.31 \mathrm{wt} \%{ }^{235} \mathrm{U}$ Enriched UO

Trap Width, W: See Comments

Plates : See Comments

Boron : See Comments

kelt : See Comments

Comments : See Table Below

\begin{tabular}{|c|c|c|c|c|}
\hline \multirow{2}{*}{$\begin{array}{c}\text { Assembly } \\
\text { Number }\end{array}$} & \multirow{2}{*}{$\begin{array}{c}w \\
(\mathrm{~cm})\end{array}$} & \multirow{2}{*}{ 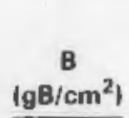 } & \multicolumn{2}{|c|}{$K_{\text {oft }}$} \\
\hline & & & (GO) & [GR] \\
\hline 229 & 3.81 & 0 & $\ldots$ & $\ldots$ \\
\hline 230 & 3.75 & 0.05 & -.. & -.. \\
\hline 228 & 3.76 & 0.13 & 0.94 & 0.94 \\
\hline 214 & 3.73 & 0.36 & 0.93 & 0.93 \\
\hline 231 & 3.71 & 0.45 & 0.94 & 0.93 \\
\hline
\end{tabular}




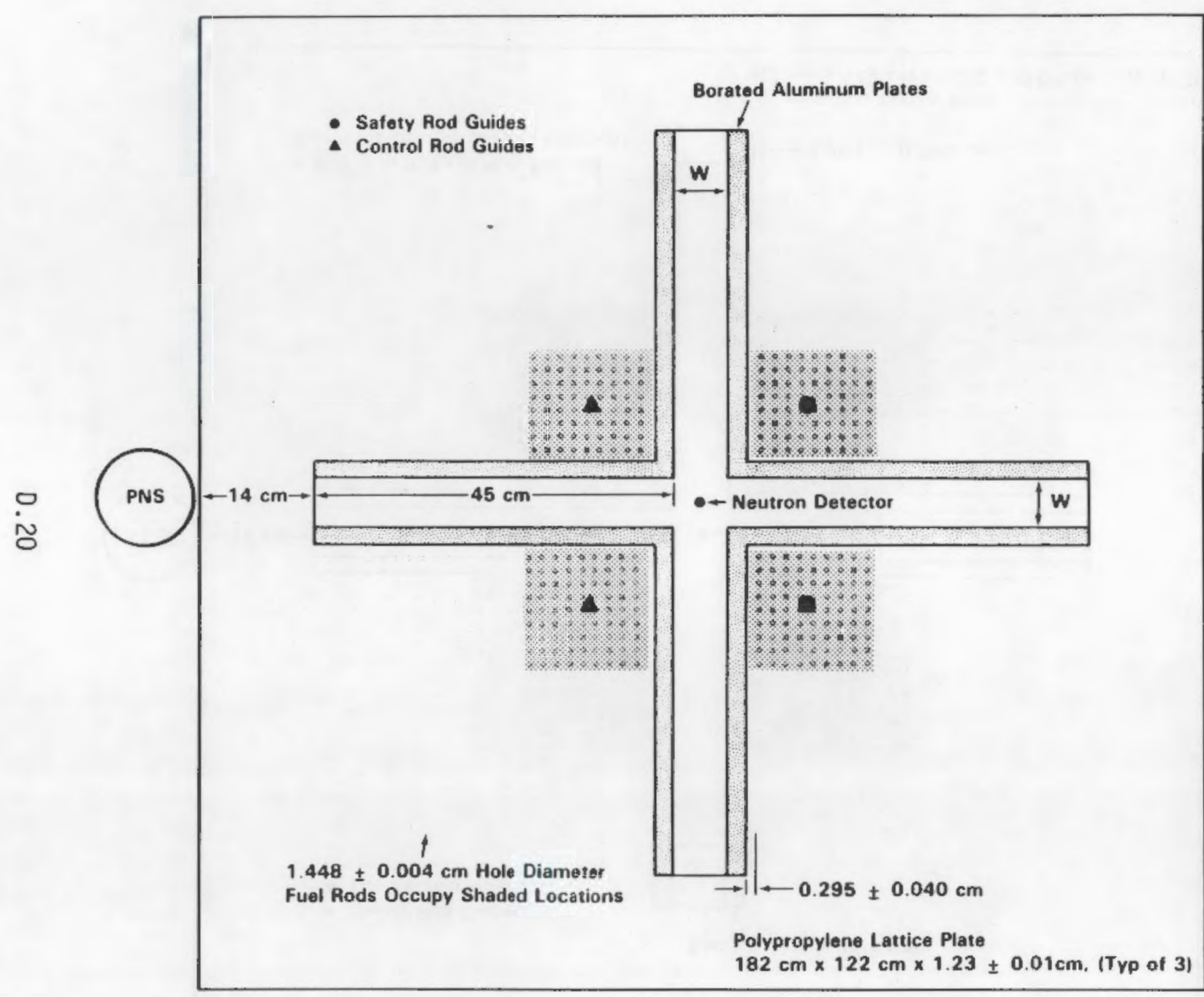

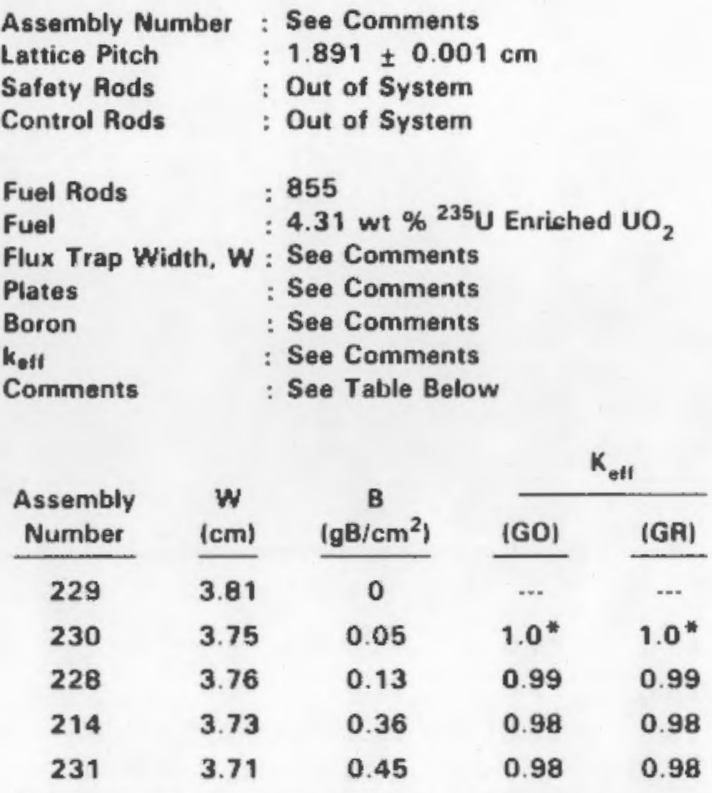

* Oetermined by Critical Approch Experiment 


\section{APPENDIX E}

Computerized Plots of Pulse Neutron Source Measurement Data 


\section{Computerized Plots of Pulse Neutron Source Measurement Data}

The observed time behavior of the neutron flux in each of the pulsed neutron source measurements is presented in this Appendix as photoreproductions of computer plots obtained following data reduction and analysis. In each of the measurements, 511 data channels were used in accumulating and analyzing the time dependent data. All of the data have been corrected for coincidence losses. The least-square calculated fit of the data is also shown in each of the plots. The data indicated by an " $X$ " were not considered in the least-squares fitting process; however, these data were included in the (Garelis and Russell 1963) reactivity determinations. The first data channel used in the least-squares fitting is identified as start channel in the legend.

The fundamental mode and the delayed neutron plus background level, as determined by the least-squares fitting of the data, are shown as solid lines in each figure. The slope of the fundamental mode curve is tabulated in the legend of each figure as alpha in sec. ${ }^{-1}$ Also included in the legend of each figure are the Garelis-Russell (GRRHO) and the Gozani (GOZRHO) determined reactivities in dollars, the neutron background level during each measurement, the delayed neutron level as determined by the least-squares fit, and the data accumulating channel widths in microseconds. 
TTC. 4 ASSEMH3LY 230 WITH .0515 GB/CMZ AND 306 FUEI. RODS. IAFRIL86.

DETECTOR FOUR IN CENTER AT MIDPLAINE DF FLUX TRAP. WATER TEMPERATURE $15 C$.

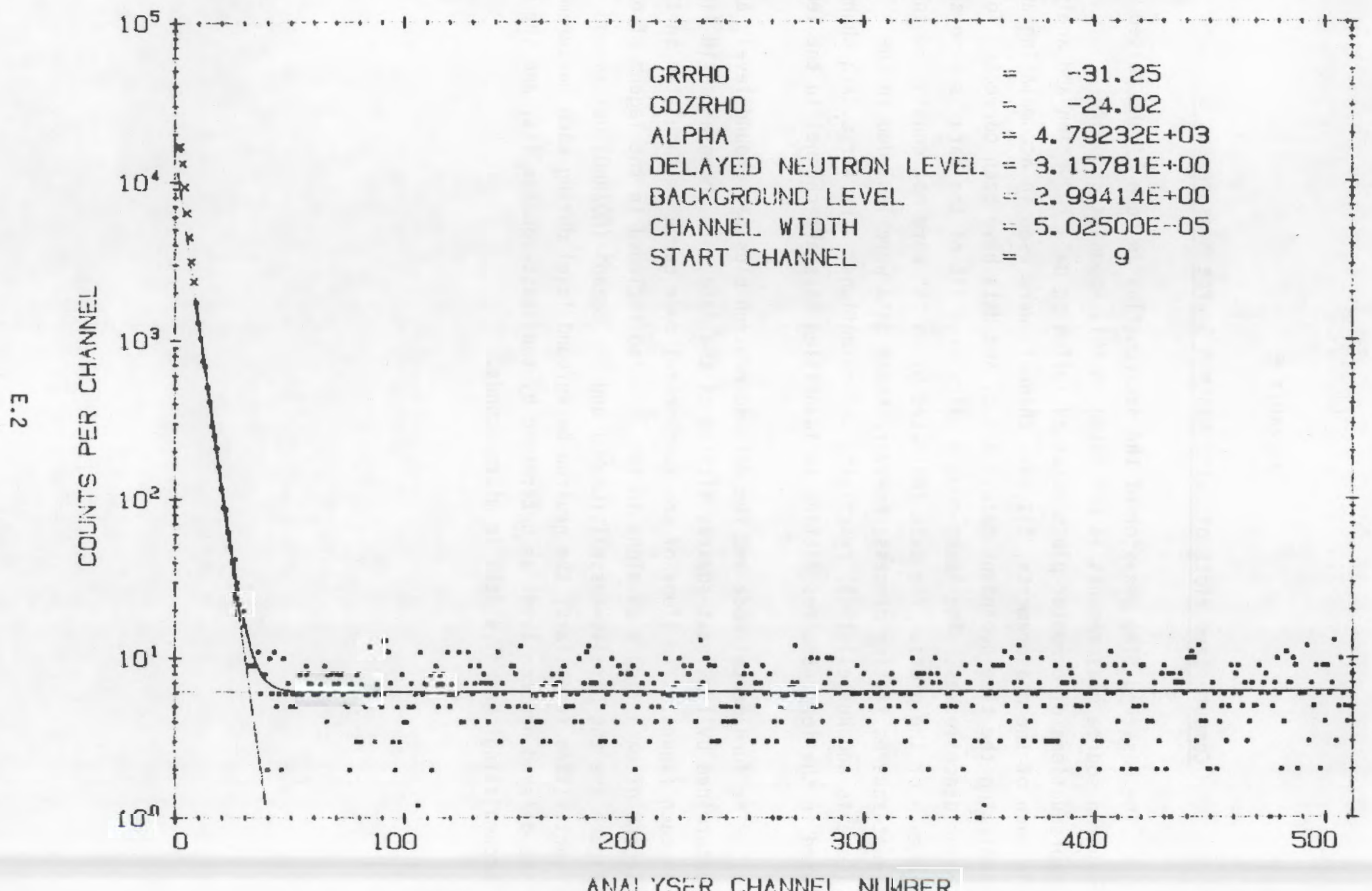


TTC-4 ASSEMBLY 230 WITH 0.0515 GB/CMZ AND 306 FUEL RODS. 2APRIL86.

DETECTOR FOUR IN CENTER AT MIDPLANE OF FLUX TRAP. WATER TEMPERATURE 15C.

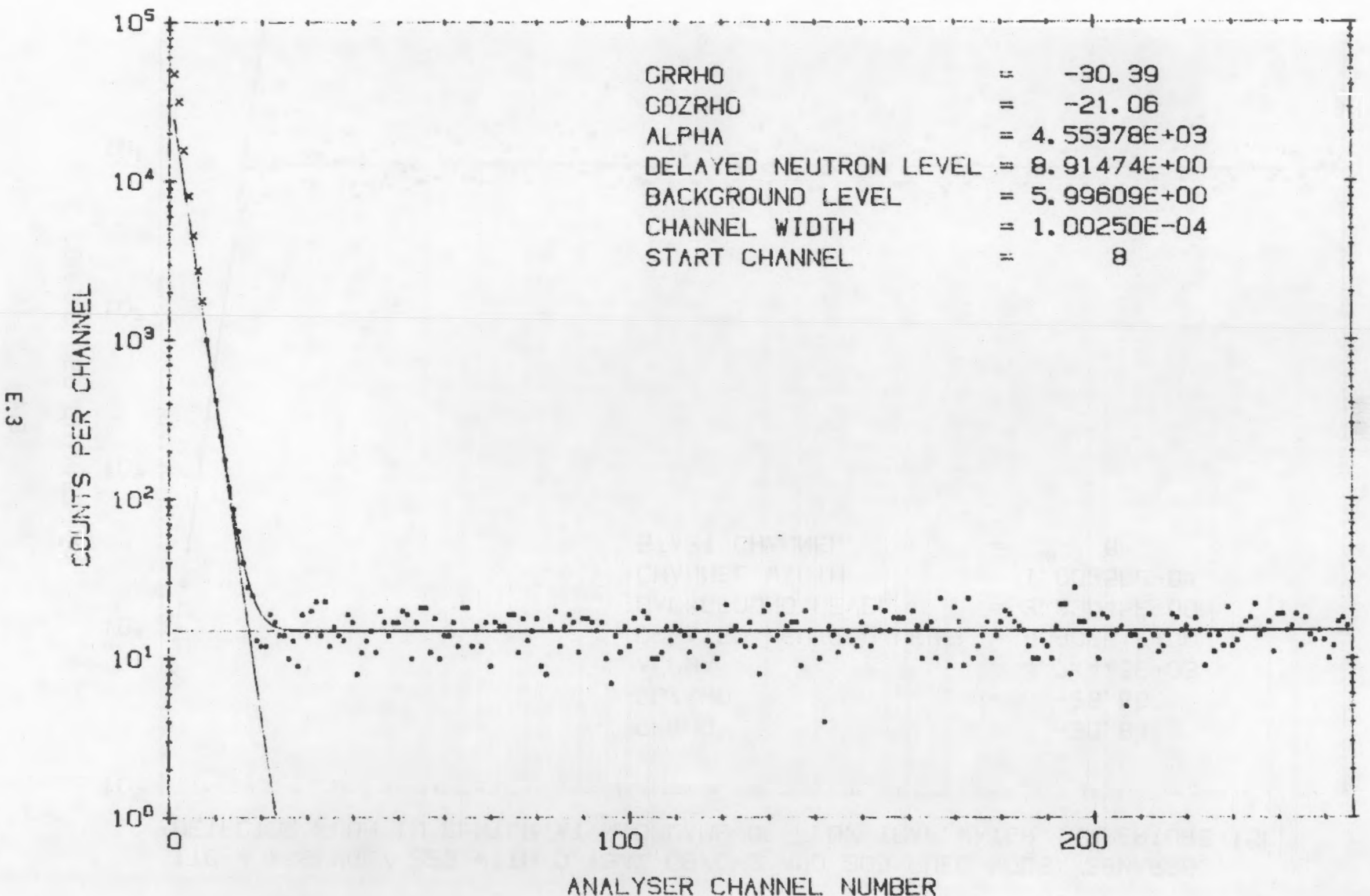


TTC-4 ASSEMBLY 228 WITH 0. 1345 GB/CM2 ANO 306 FUEL ROOS. 28MAR86. DETECTOR FOUR IN CENTER AT MIDPLANE OF FLUX TRAP. WATER TEMPERTURE $15 C$.

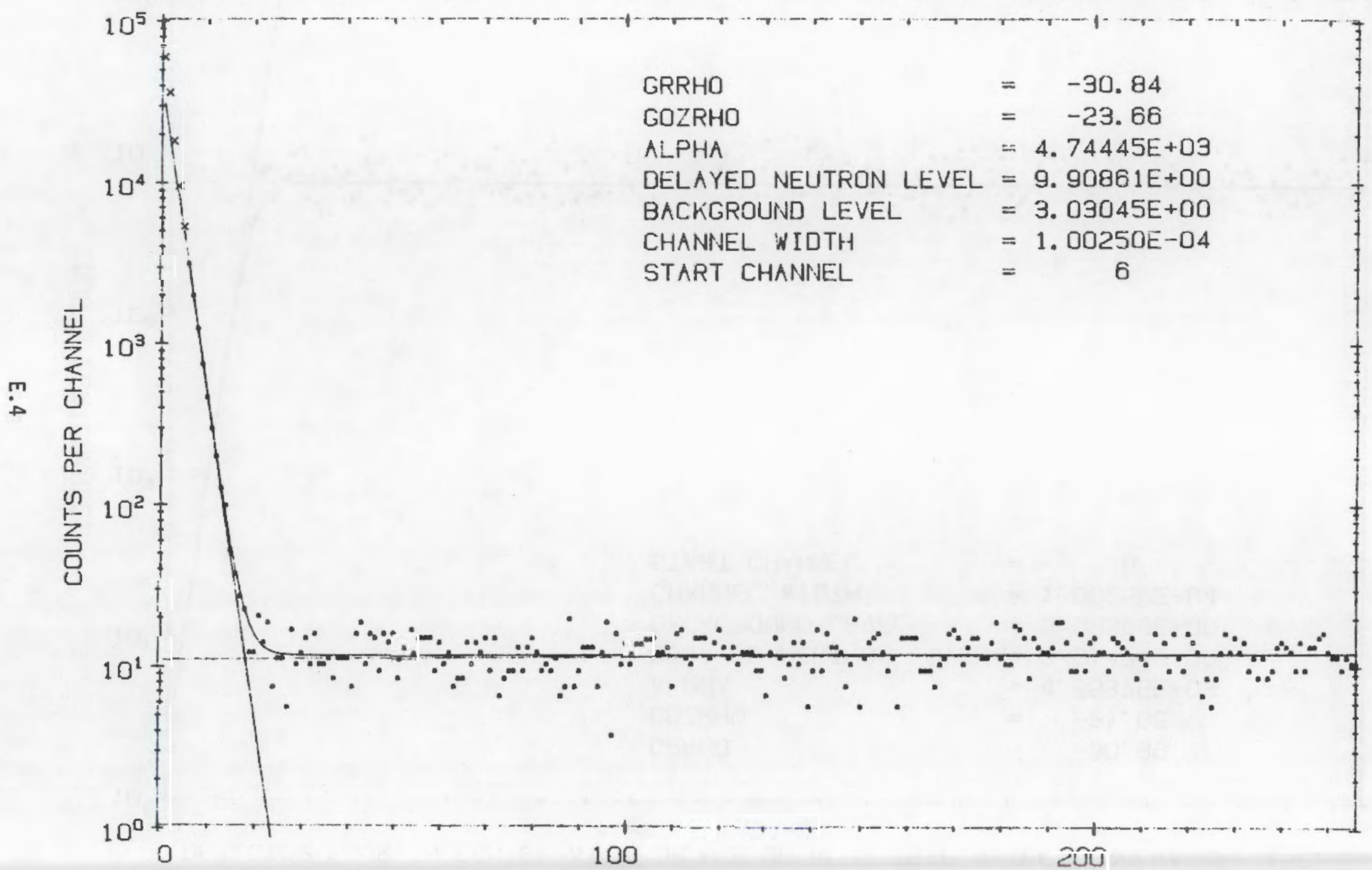

ANALYSER CHANNEL NUMBER 
TTC-4 ASSEMBLY 228 WITH 0. 1345 GB/CM2 AND 306 FUEL RODS. 31MAR86.

DETECTOR FOUR IN CENTER AT MIDPLANE OF FLUX TRAP. WATER TEMPERATURE $15 C$.

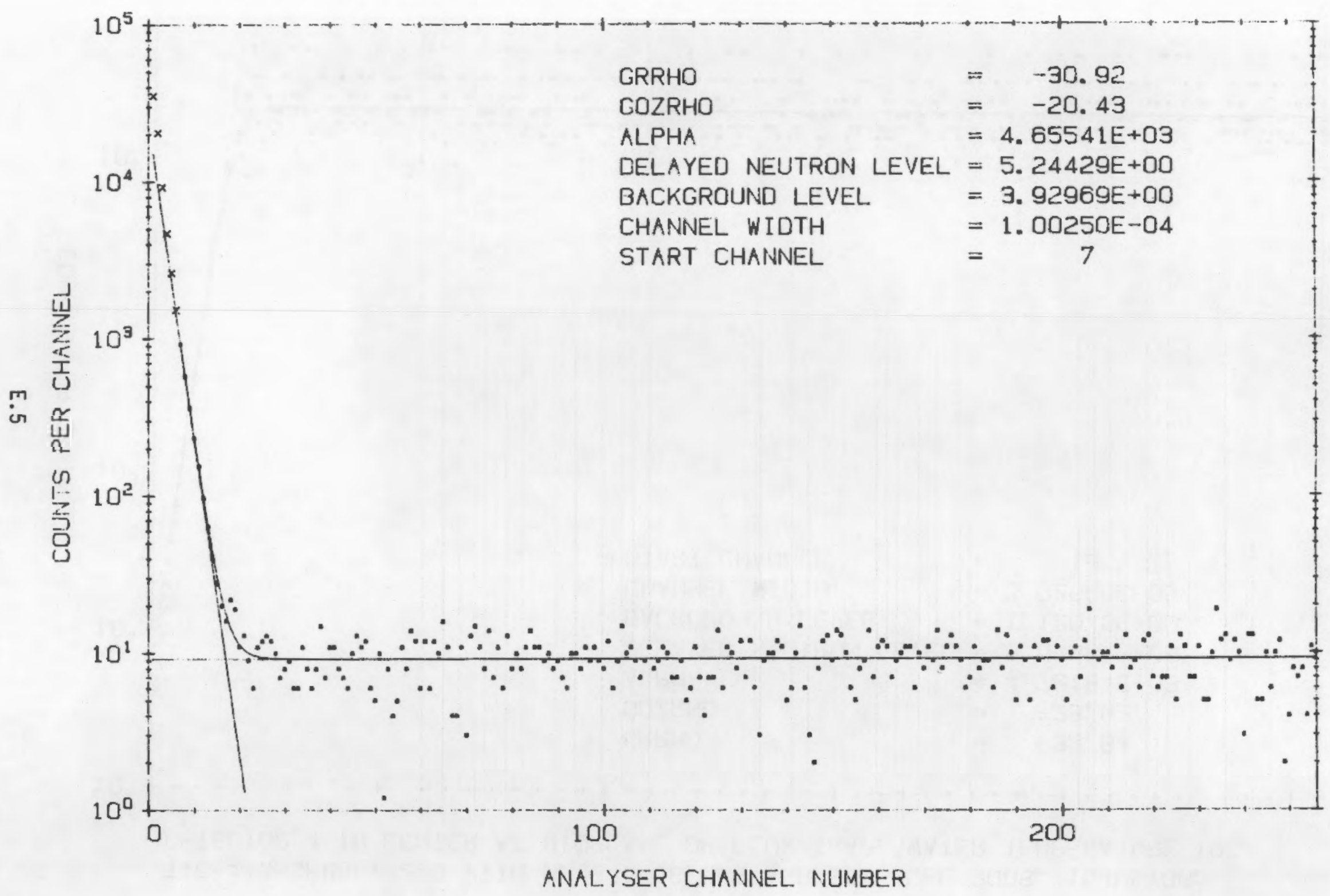


TTC -4 ASSEMBLY 228 WITH D. 1345 GB/CM2 AND 306 FUEL. RODS. 15JULY86.

DETECTOR 4 IN CENTER AT MIDPL.ANE OF FLUX TRAP. WATER TEMPERATURE 19C.

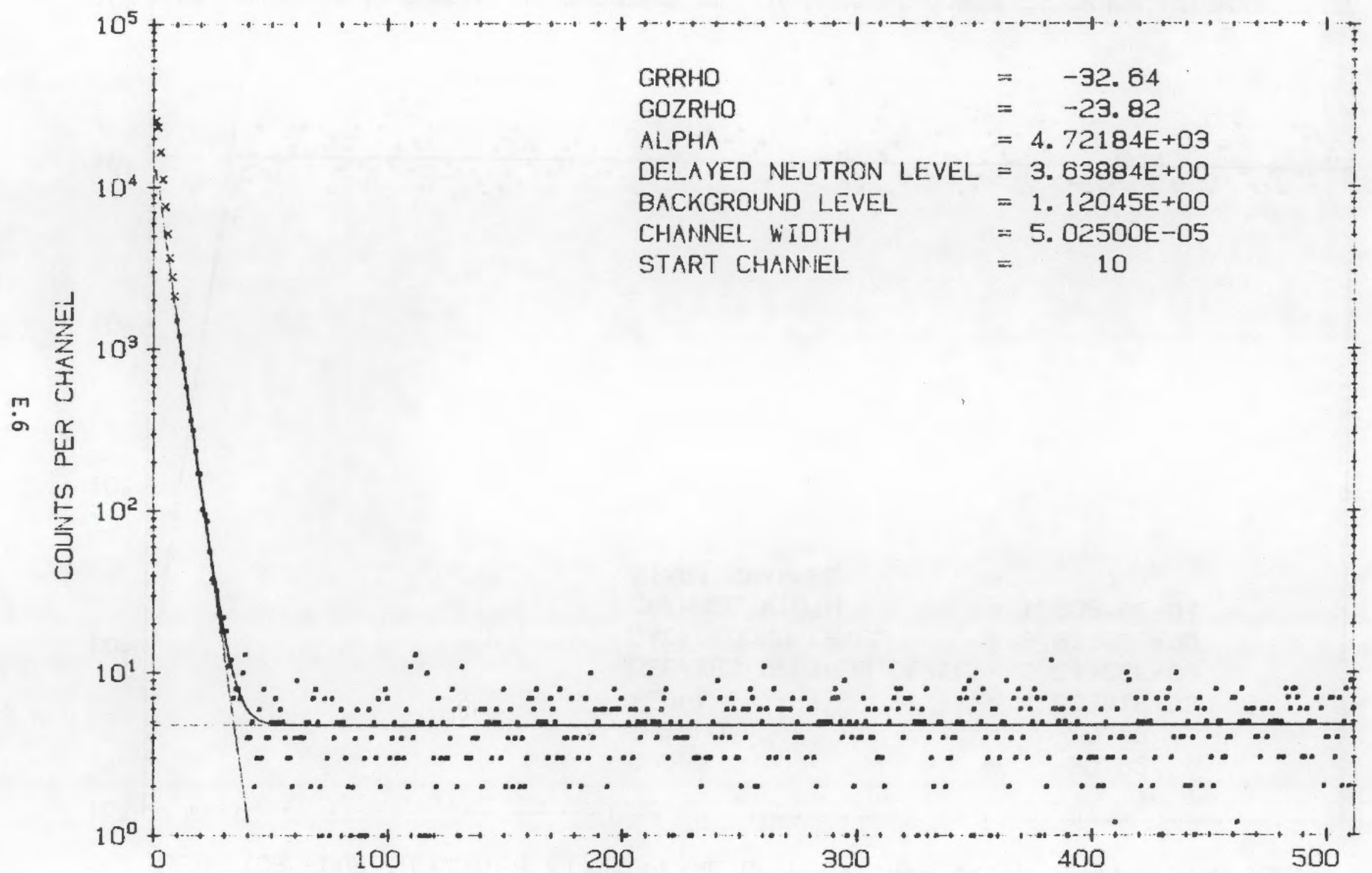

ANAL.YSER CHANNEL NUMBER 
TTC-4 ASSEMBLY 228 WITH 0.1345 GB/CM2 AND 306 FUEL RODS. 15JULY86.

DETECTDR 4 IN CENTER AT MIDPLANE DF FLUX TRAP. WATER TEMPERATURE 19C

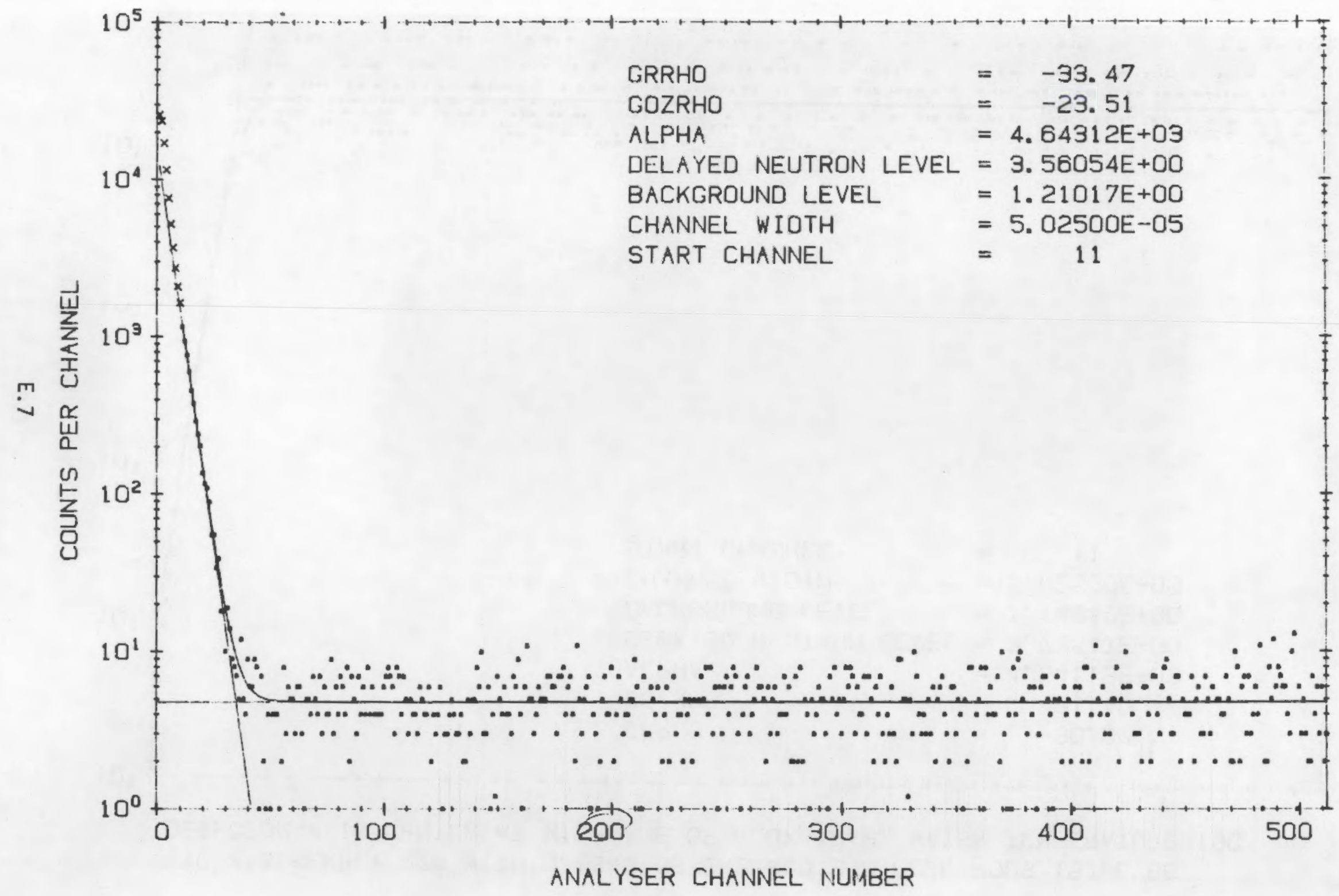


TTC-4 ASSEMBLY 228 WITH 0. 1345 GB/CMZ AND 306 FUEL RODS. $15 J U L Y 86$.

DETECTOR 4 IN CENTER AT MIDPLANE OF FLUX. TRAP. WATER TEMPERATURE 19C

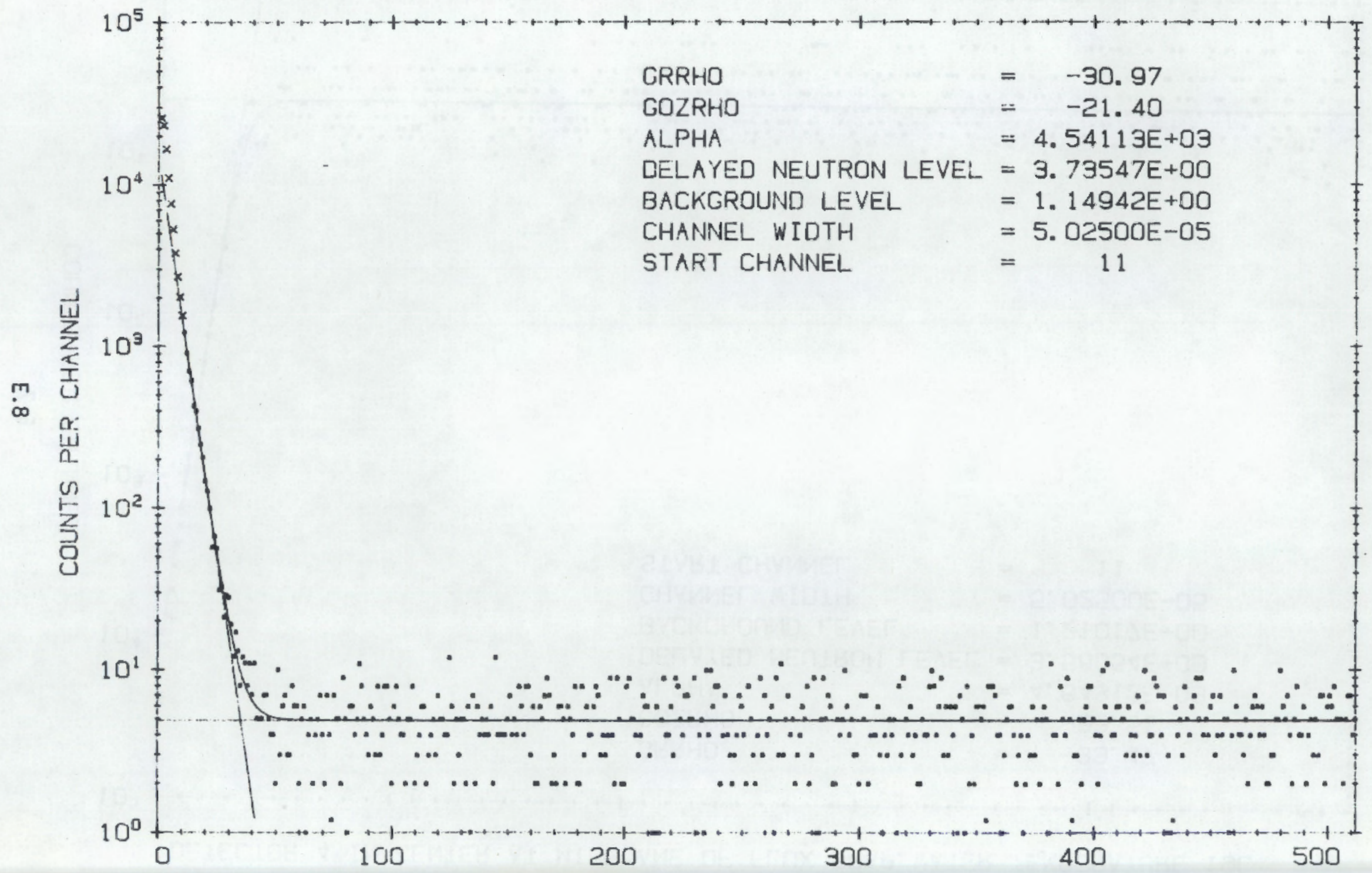

ANALYSER CHANNEL NUMBER 
TTC-4 ASSEMBLY 228 WITH 0. 1345 GB/CM2 AND 676 FUEL RODS. 14 JUL Y86.

DETECTOR 4 IN CENTER AT MIDPLANE OF FLUX TRAP. WATER TEMPERATURE $19 C$.

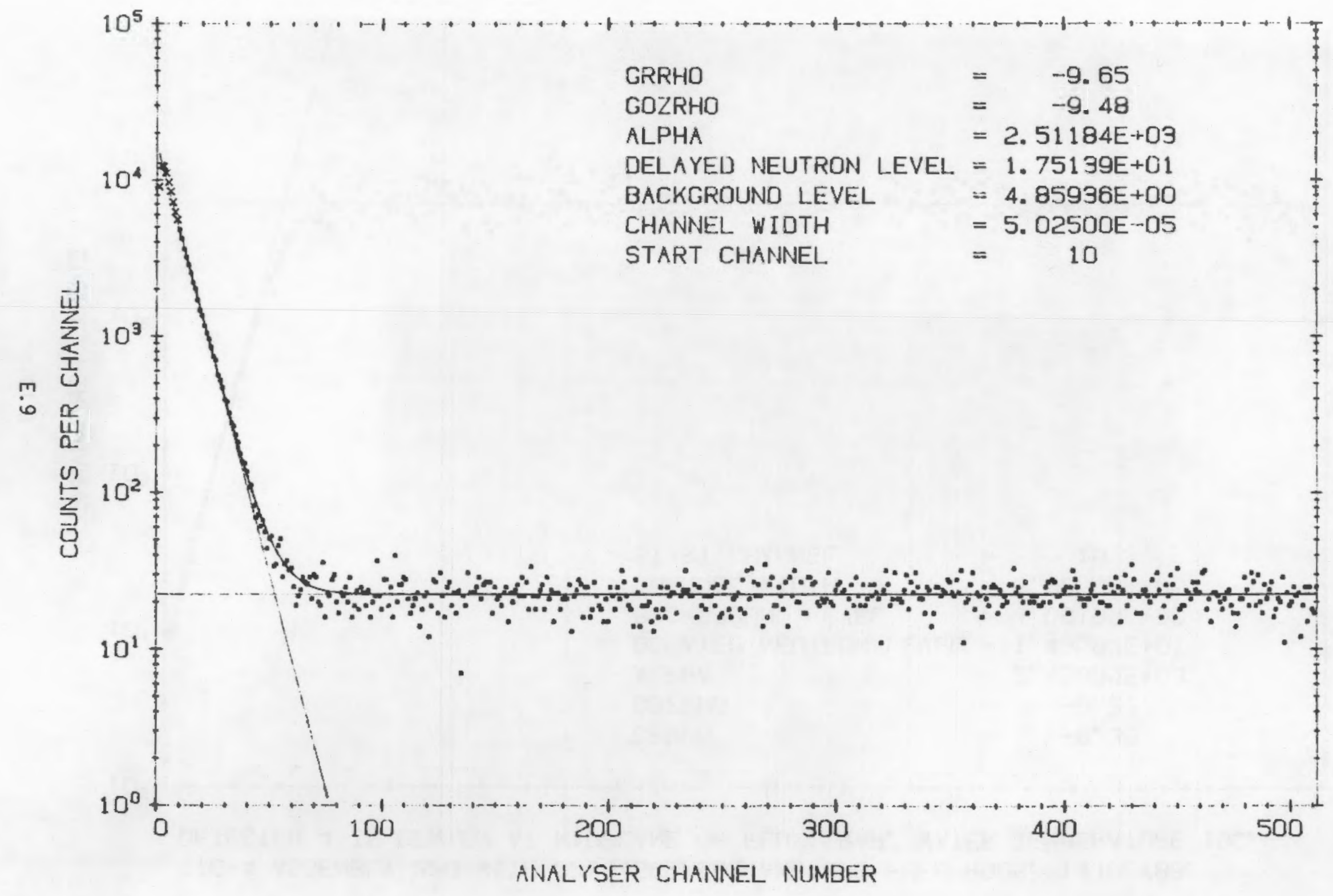


TTC-4 ASSEMBLY 22B WITH D. 1345GB/CM2 AND 676 FUEL RODS. 14 JULY86.

DETECTOR 4 IN CENTER AT MIDPLANE OF FLUX TRAP. WATER TEMPERATURE $19 \mathrm{C}$.

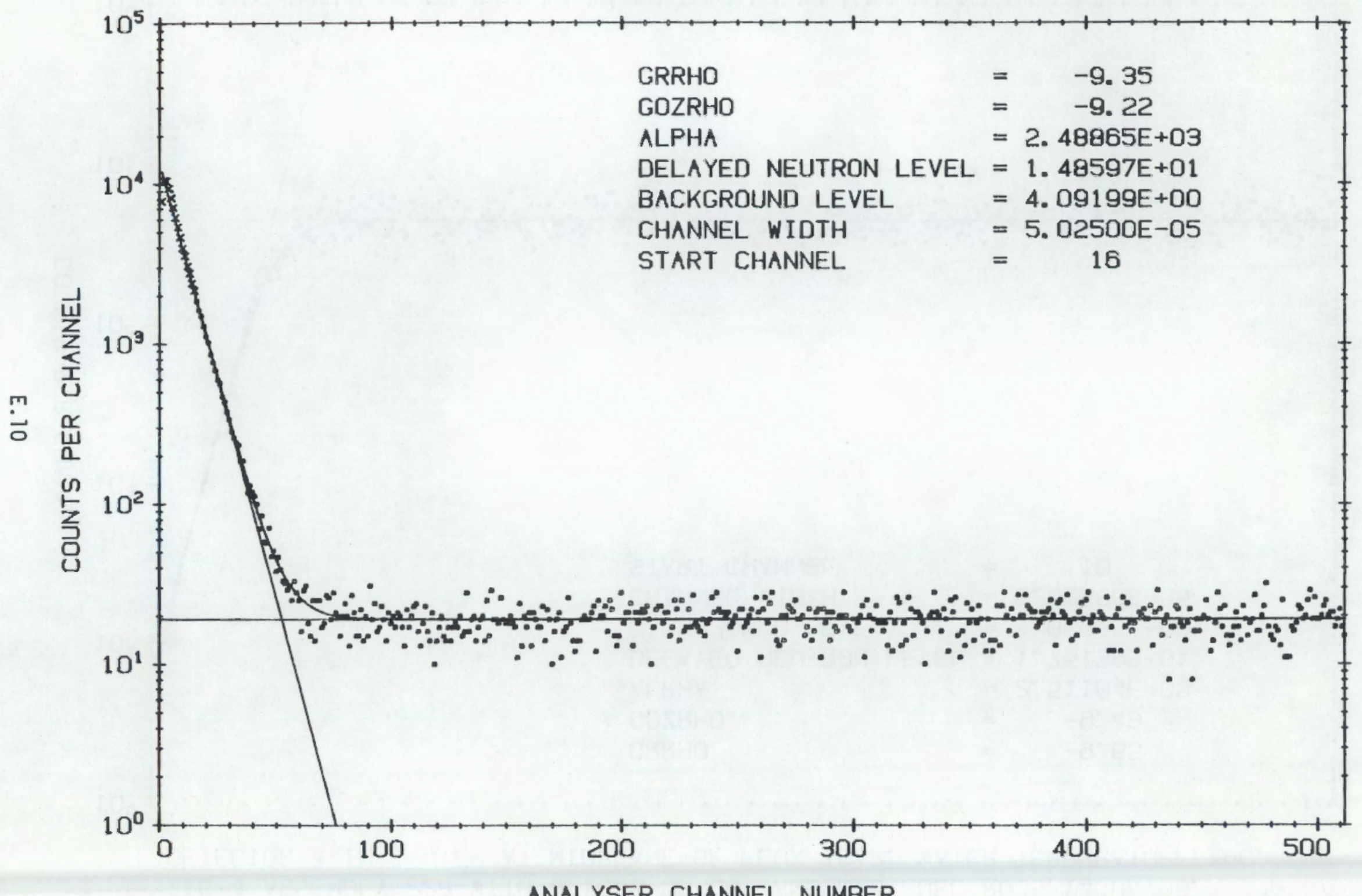


TTC-4 ASSEMBLY 228 WITH 0. 1345GB/CM2 AND 855FUUEL. RODS. 14JUI_Y86

DETECTOR 4 IN CENTER AT MIDPLANE OF FL.UX TRAP. WATER TEMPERATURE $19 C$.

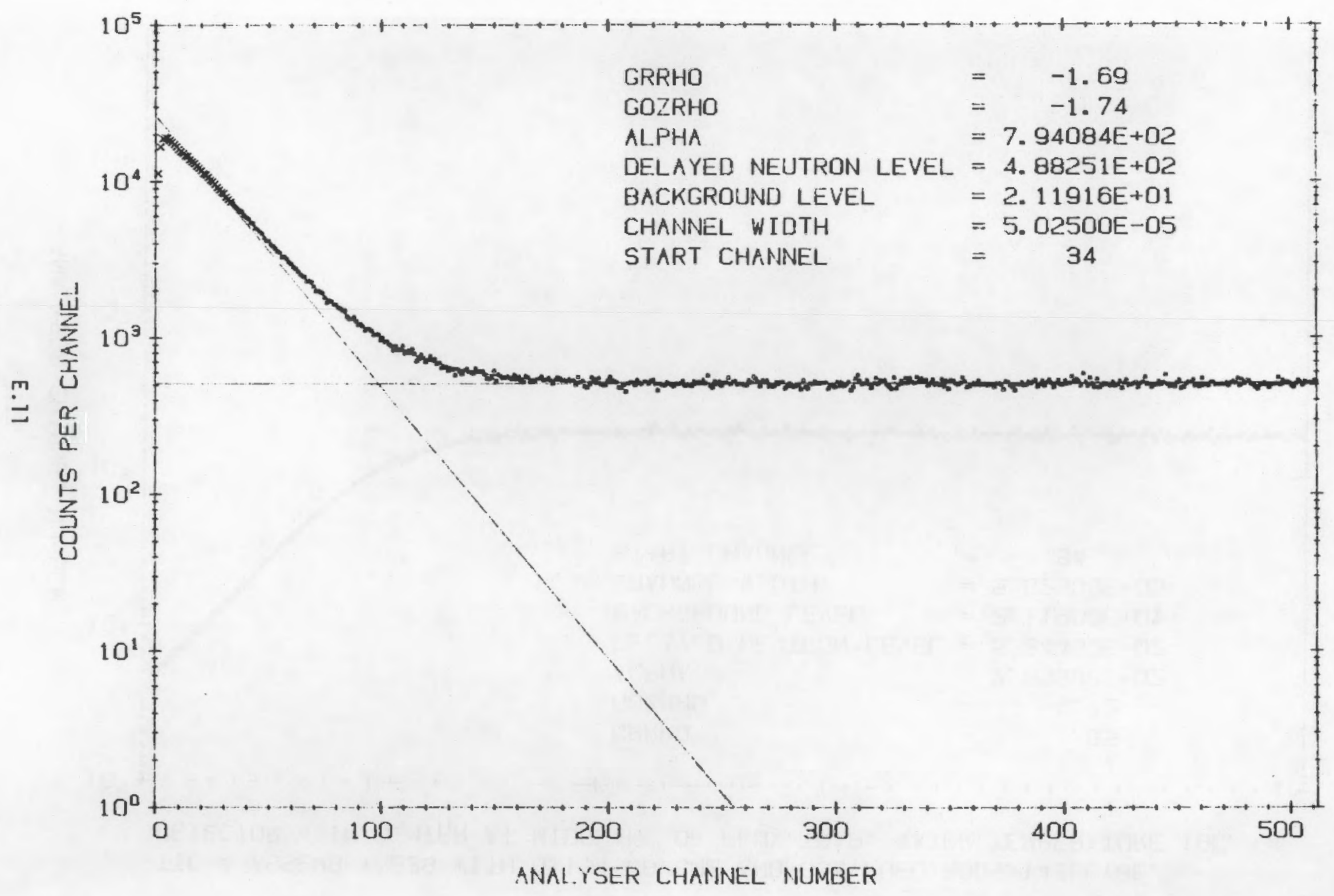


TTC-4 ASSEMBLY 228 WITH 0. 1345GB/CM2 AND 855 FUEL RODS. 14 JULY86.

DETECTOR 4 IN CENTER AT MIDPLANE OF FLUX. TRAP. WATER TEMPER,ATURE $19 C$.

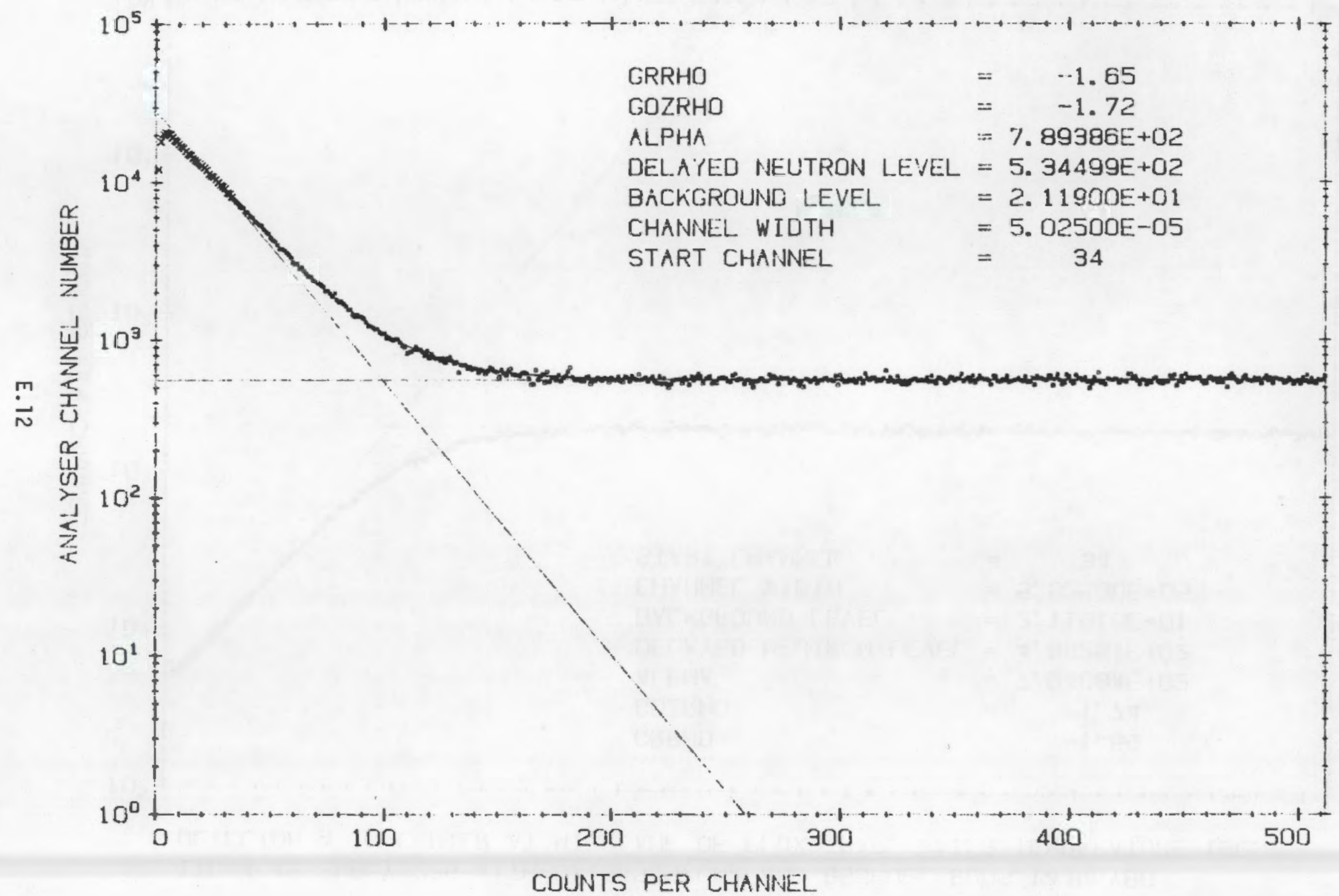


TTC-4 ASSEMBLY 214 WITH 0. $3626 \mathrm{~GB} / \mathrm{L}$ AND 306 FUEL RODS. 9APRIL86

DETECTOR FOUR IN CENTER AT MIDPLANE OF FLUX TRAP. WATER TEMPERATURE $15 C$.

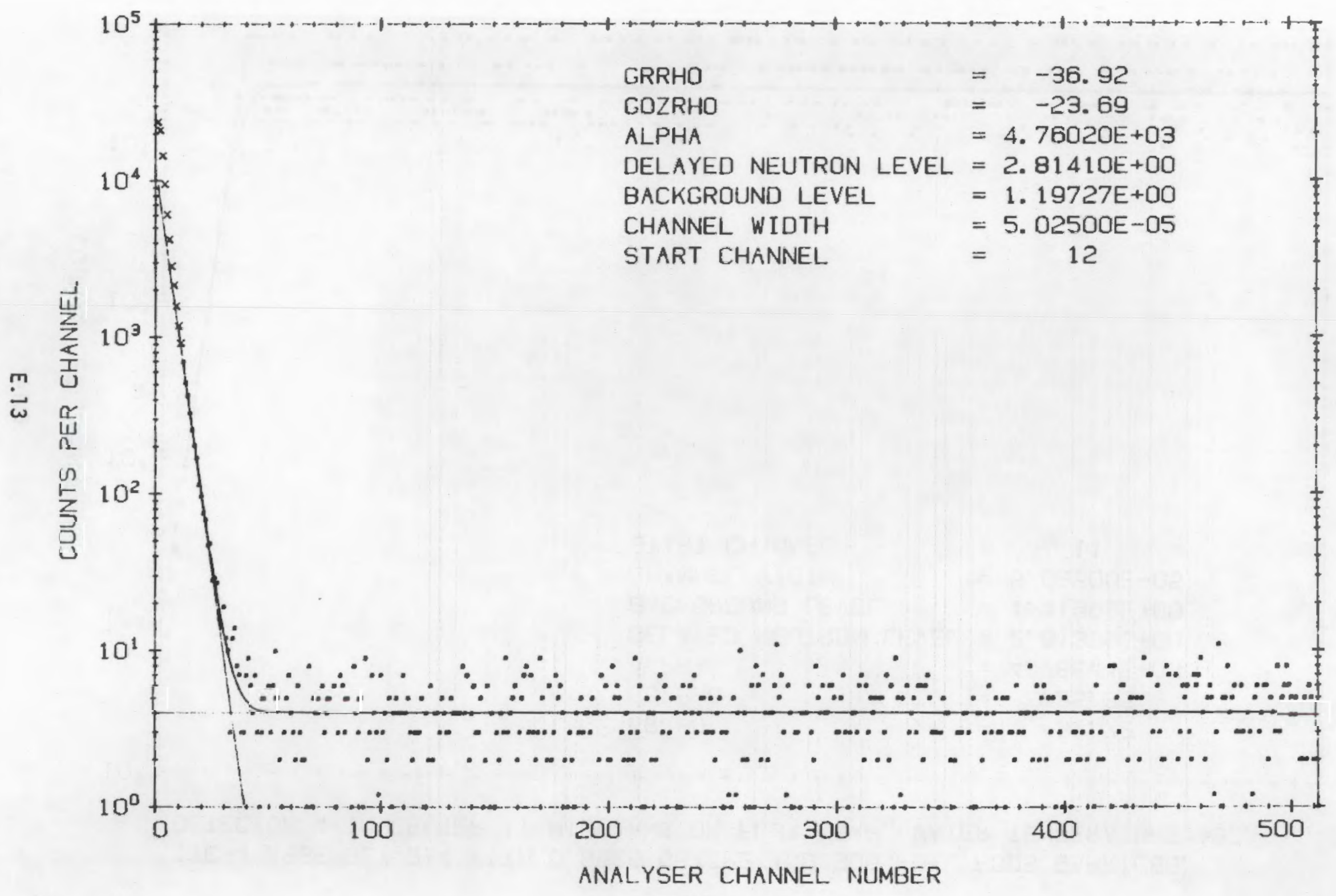


TTC-4 ASSEMBLY 214 WITH 0. 3626 G8/CM2 AND 306 FUEL RODS. 9APRIL86.

DETECTOR 4 IN CENTER AT MIDPLANE OF FLUX TRAP. WATER TEMPERATURE $15 C$.

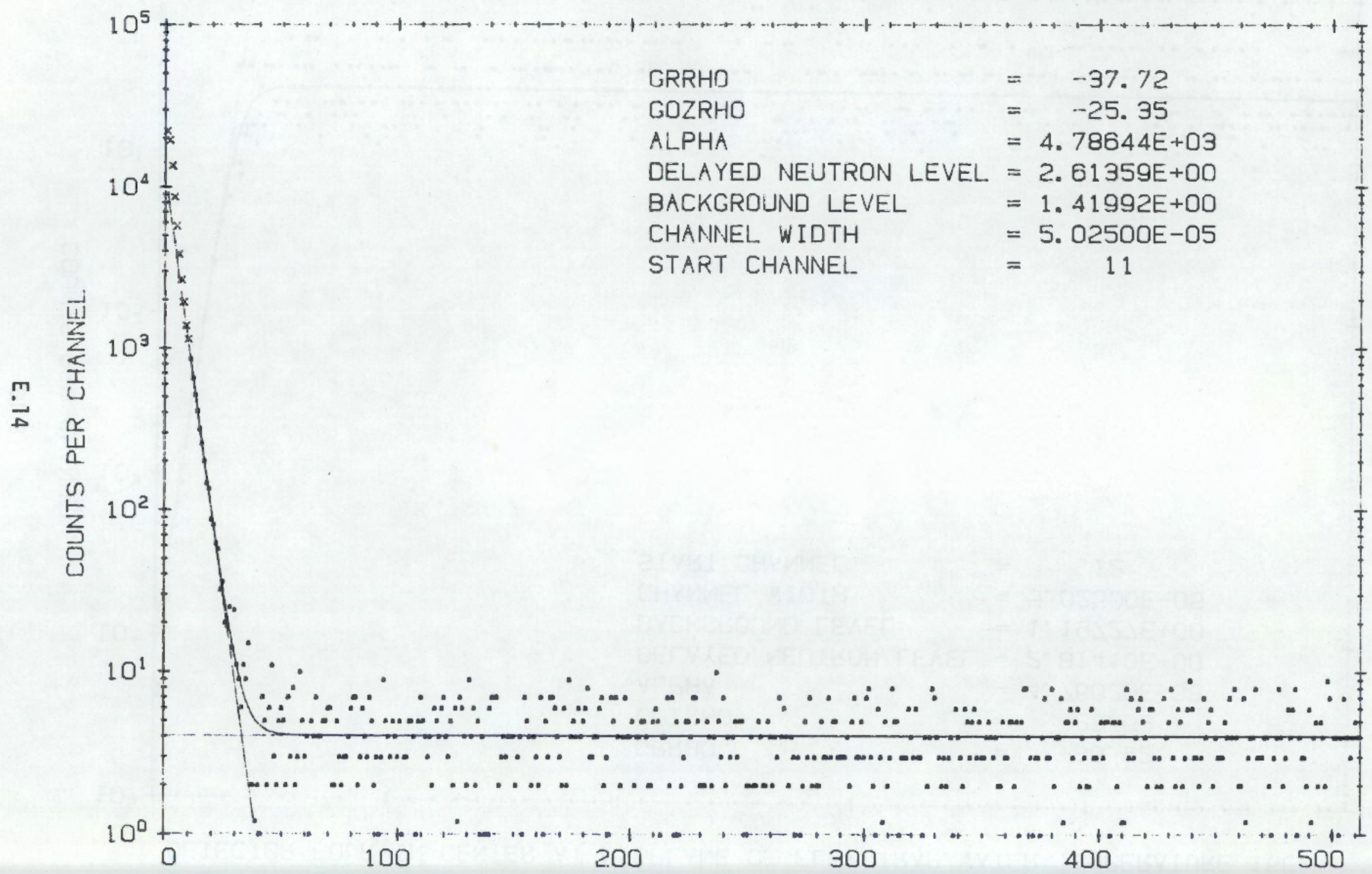

ANALYSER CHANNEEL. NUMBER 
TTE -4 ASSEMBL.Y 214 WITH 0. 3626 GB/CM2 AND 676 FUEL RODS. 9APRIL86.

DETECTOR FOUR IN CENTER AT MIDPLANE OF FLUX TRAP. WATER TEMPERATURE $15 C$.

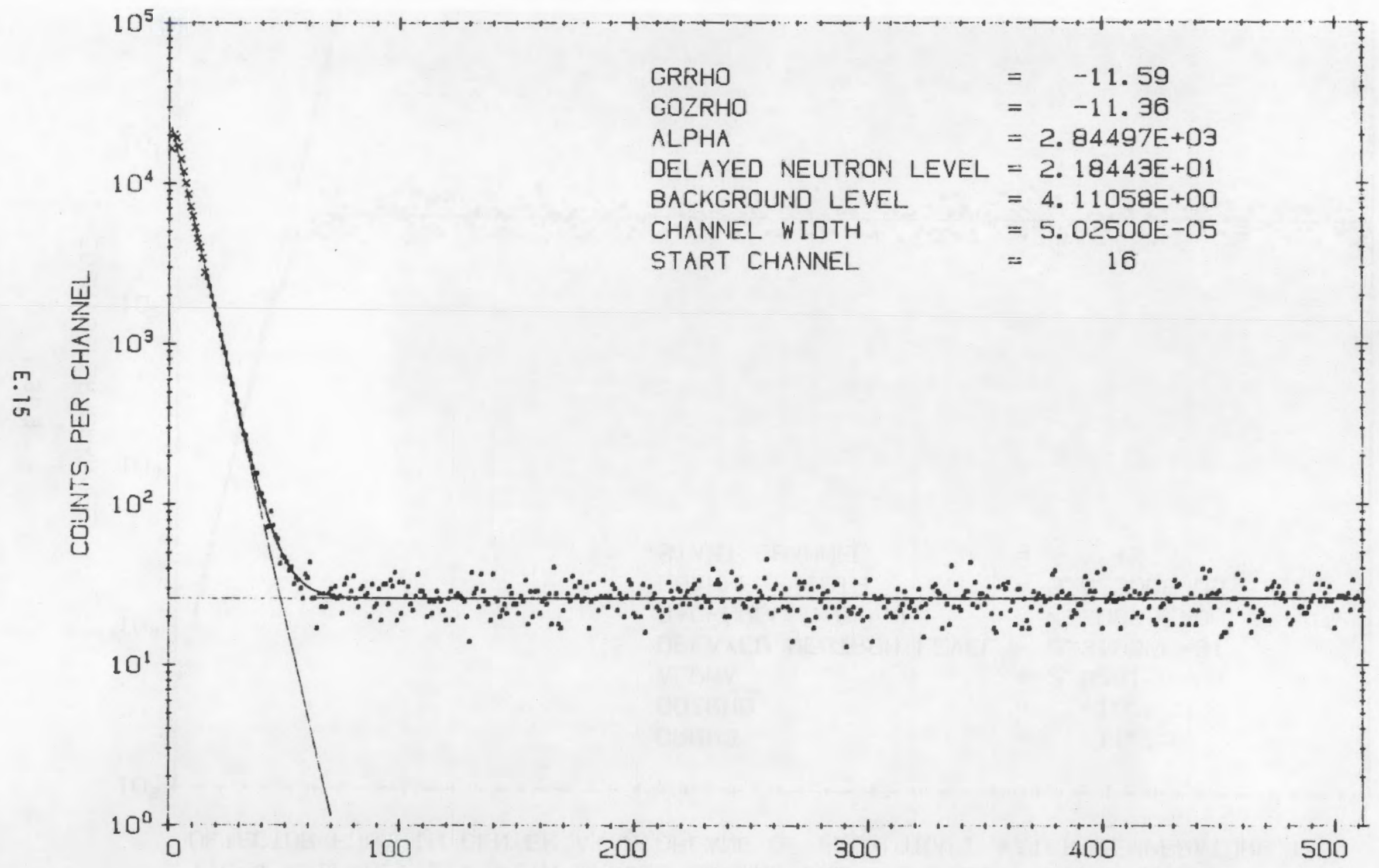

ANALYSER CHANNEL NUMBER 
TTC-4 ASSEMBLY 214 WITH 0. 3626 GB/CM2 AND 676 FUEL RODS. 9APRIL86.

DETECTOR FOUR IN CENTER AT MIDPLANE OF FLUX TRAP. WATER TEMPERATURE 15C.

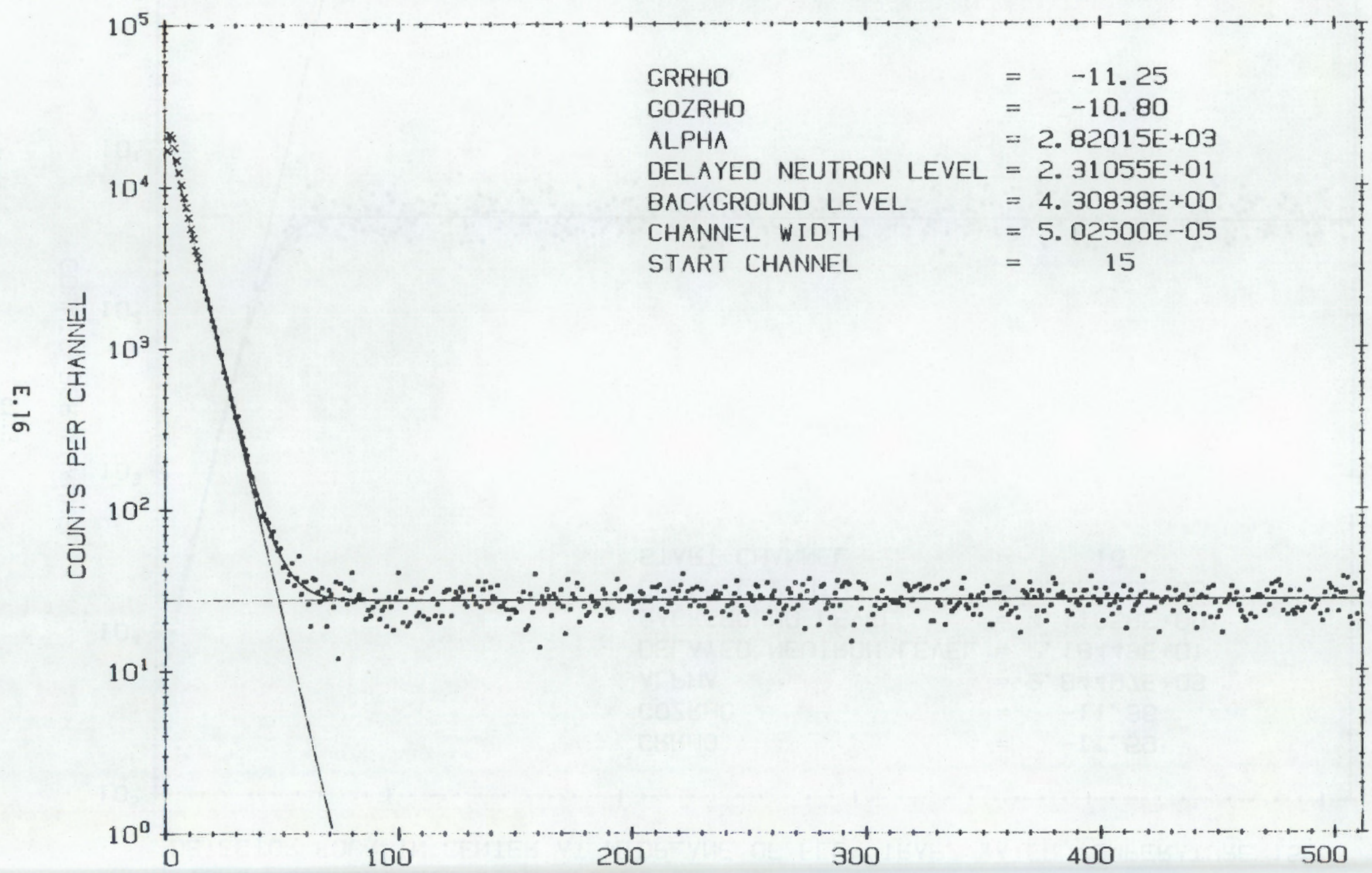

ANALYSER CHANNEL NUMBER 
TTC-4 ASSEMBL:i 214 WITH 0. 3626 GB/CM2 AND 855 FUEL RODS. 9APRIL86.

DETECTOR FOUR IN CENTER AT MIDPLANE OF FLUX TRAP. WATER TEMPERATURE $15 C$.

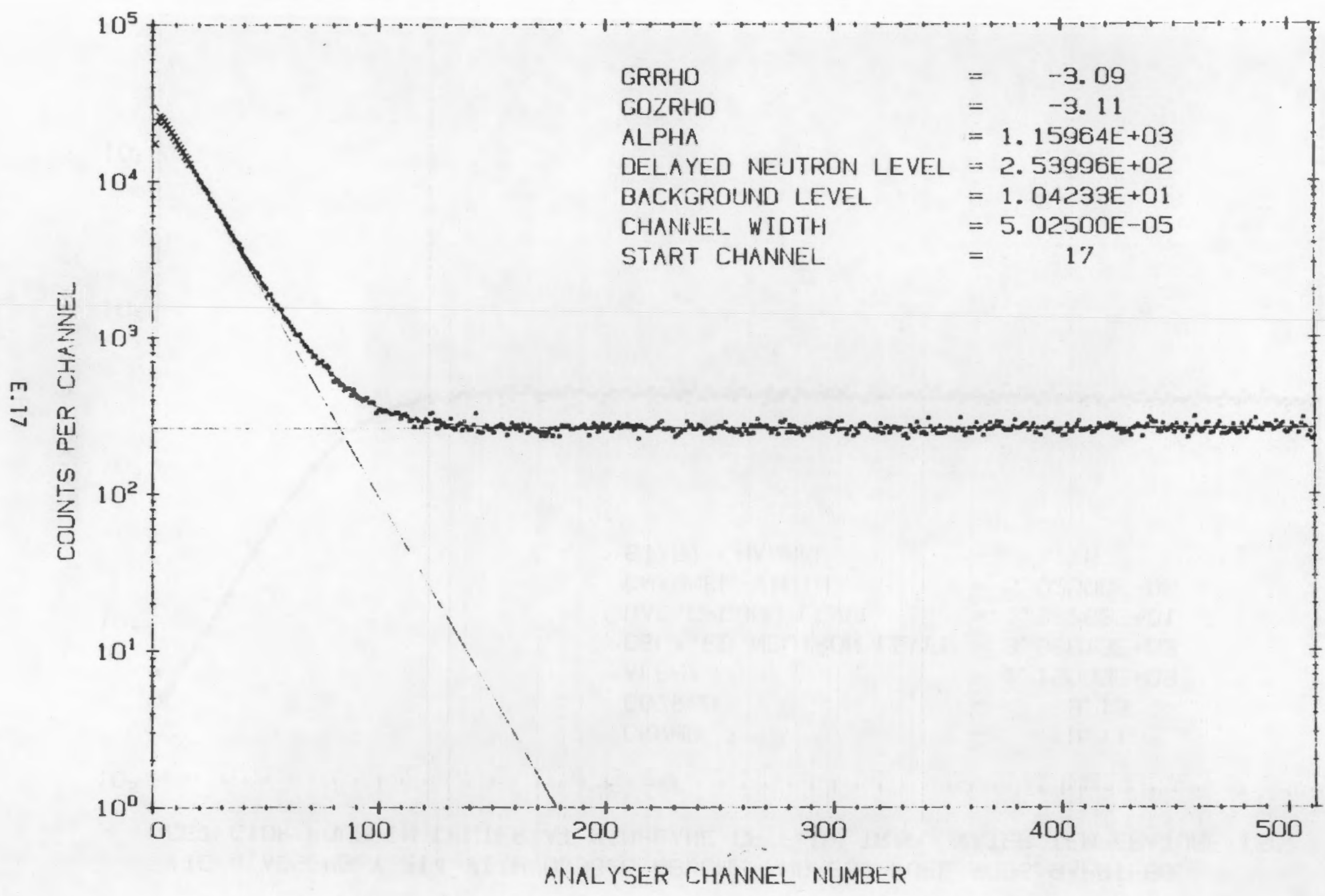


TTC-4 ASSEMBLY 214 WITH O. 3626 GB/CM2 AND 855 FUEL RODS. 9APRIL86.

DETECTOR FDUR IN CENTTER AT MIDPLANE OF FLUX TRAP. WATER TEMPERATURE. $15 C$.

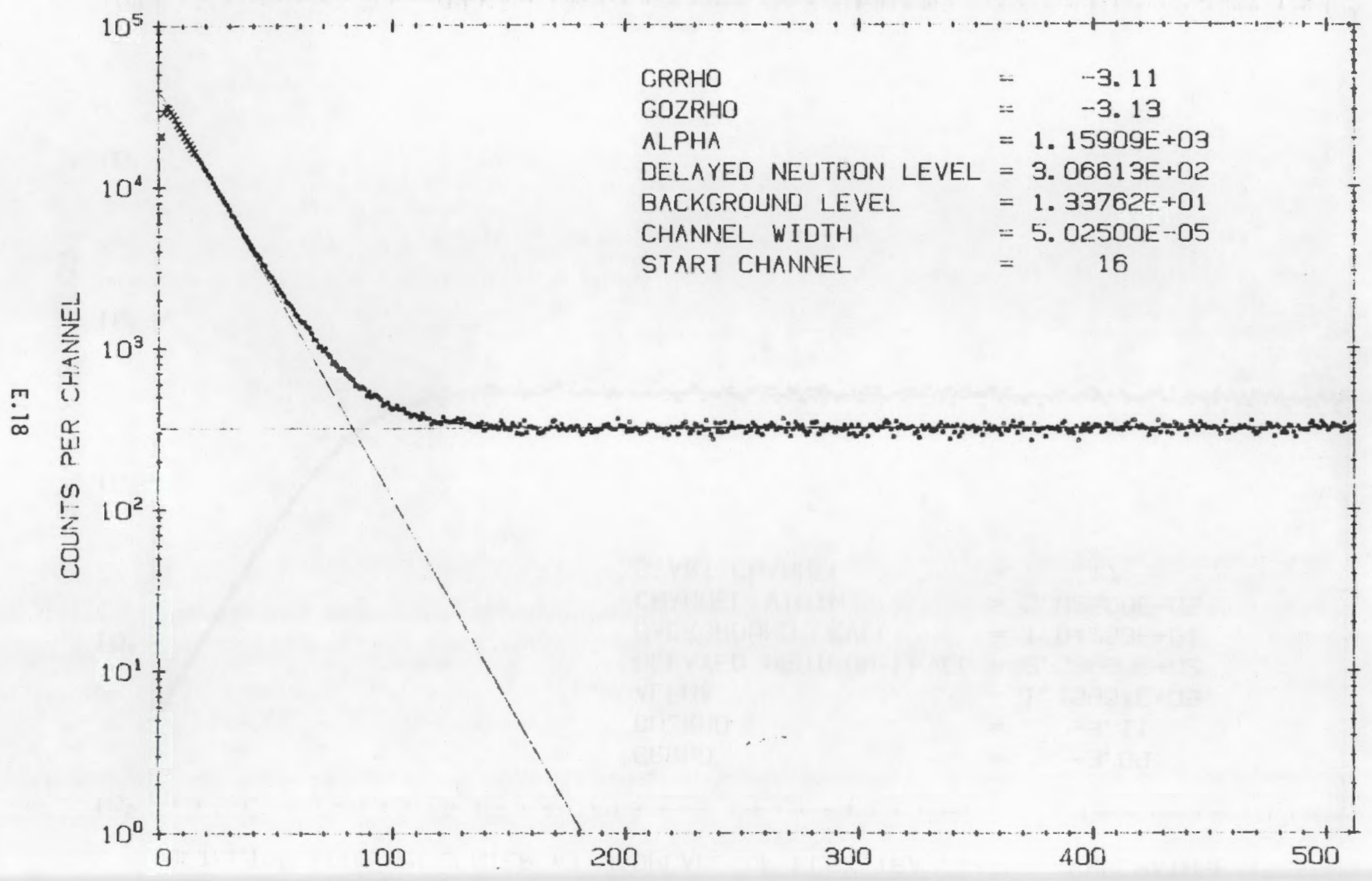

ANALYSER CHANNEL NUMBER 
TTC-4 ASSEMBLY 231 WITH 0. 4515 GB/CM2 AND 306 FUEL RODS. 8APRIL86

DETECTOR FOUR IN CENTER AT MIDPLANE OF FLUX TRAP. WATER TEMPERATURE $20 C$.

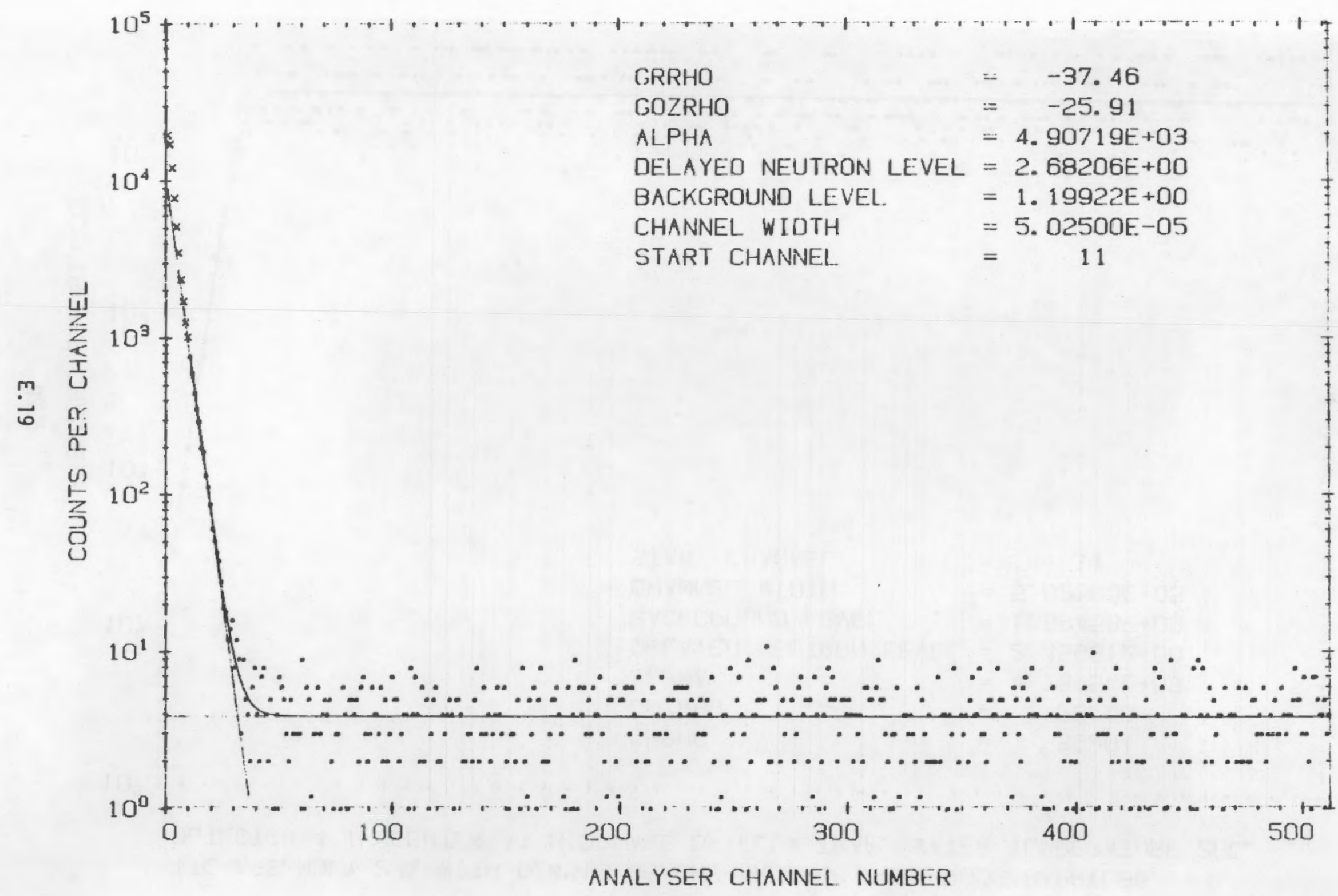


TTC ASSLMBLYY 231 WITH 0. 4515 GB/CM2 AND 306 FUEL RODS. 8APRIL86.

DETECTOR 4 IN CENTER AT MIDPLANE OF FLUX TRAP. WATER TEMPERATURE 2OC.

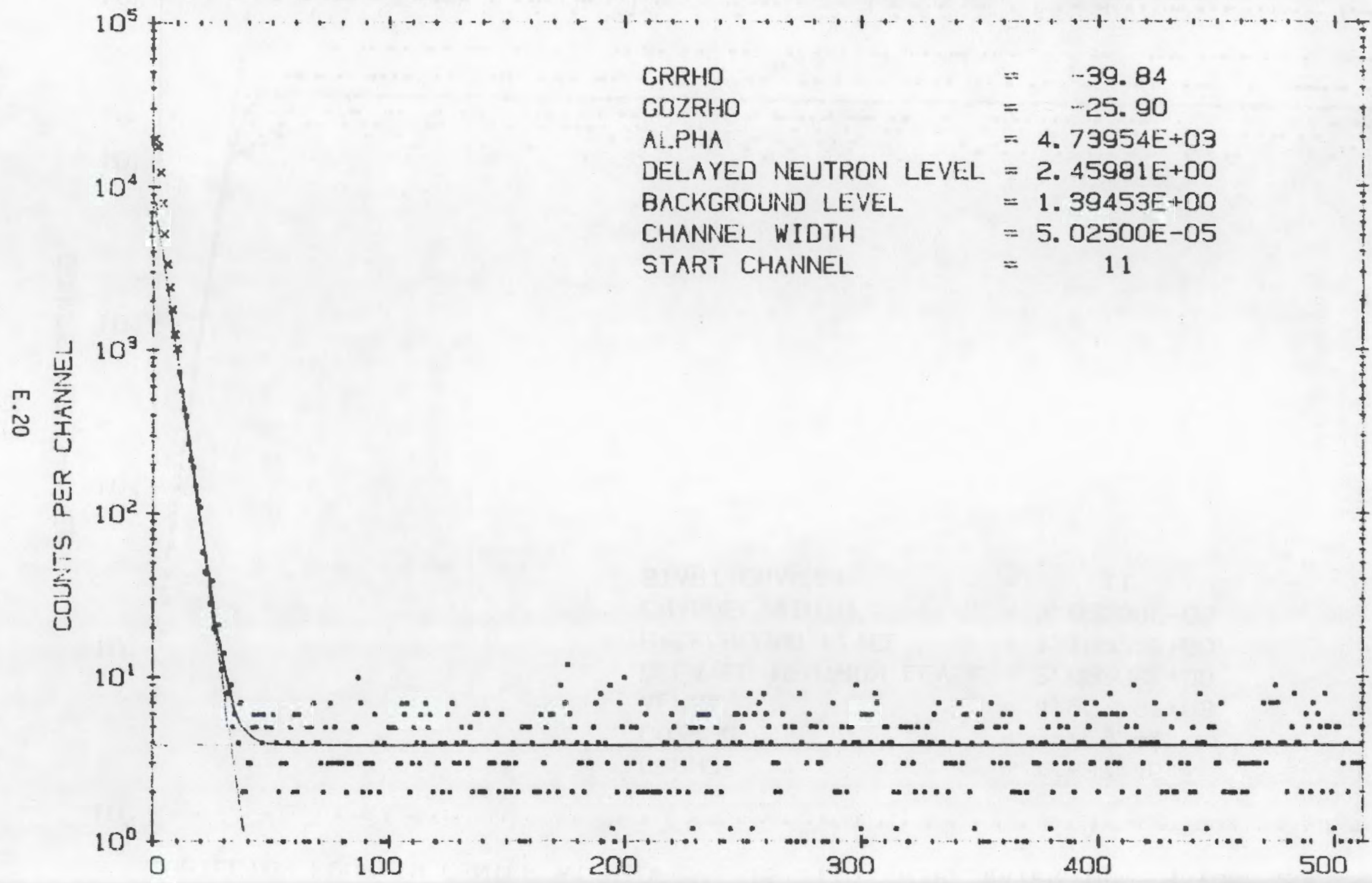

ANAL.YSER CHANNEL NUMBER 
TTC-4 ASSLMBLY 231 WITH 0. 4515CB/CM2 AND 306 FUEL RDDS. 8APRIL.86.

DETECTOR 4 IN CENTER AT MIDPLANE OF FLUX TRAP. WATER TEMPERATURE $2 O C$.

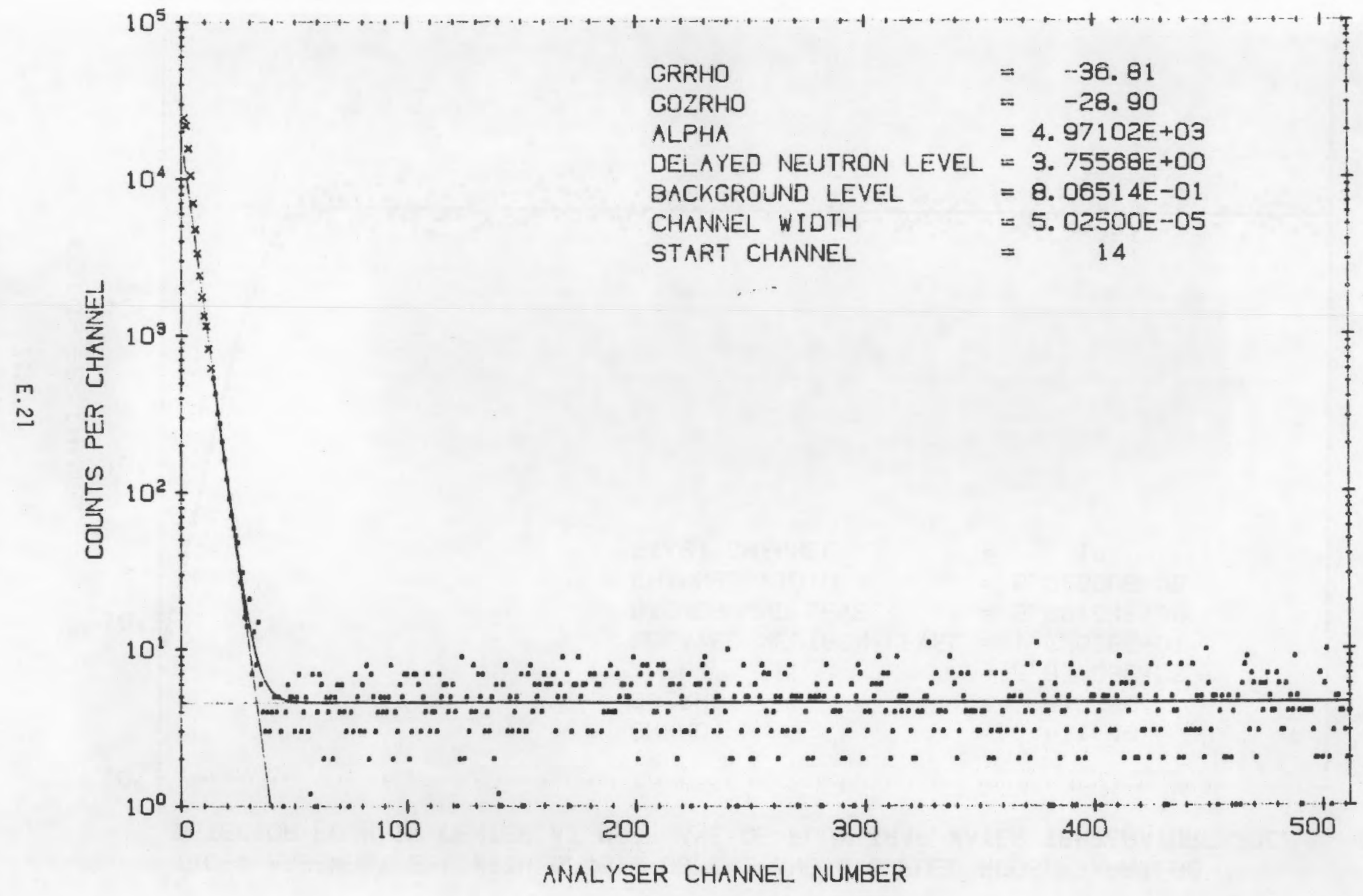


TTC-4 ASSEMBLY 231 WITH 0.4515 GB/CM2 AND 676 FUEL RODS. 7APRIL86

DETECTOR FOUR IN CENTER AT MIDPLANE OF FLUX TRAP. WATER TEMPERATURE $20 C$.

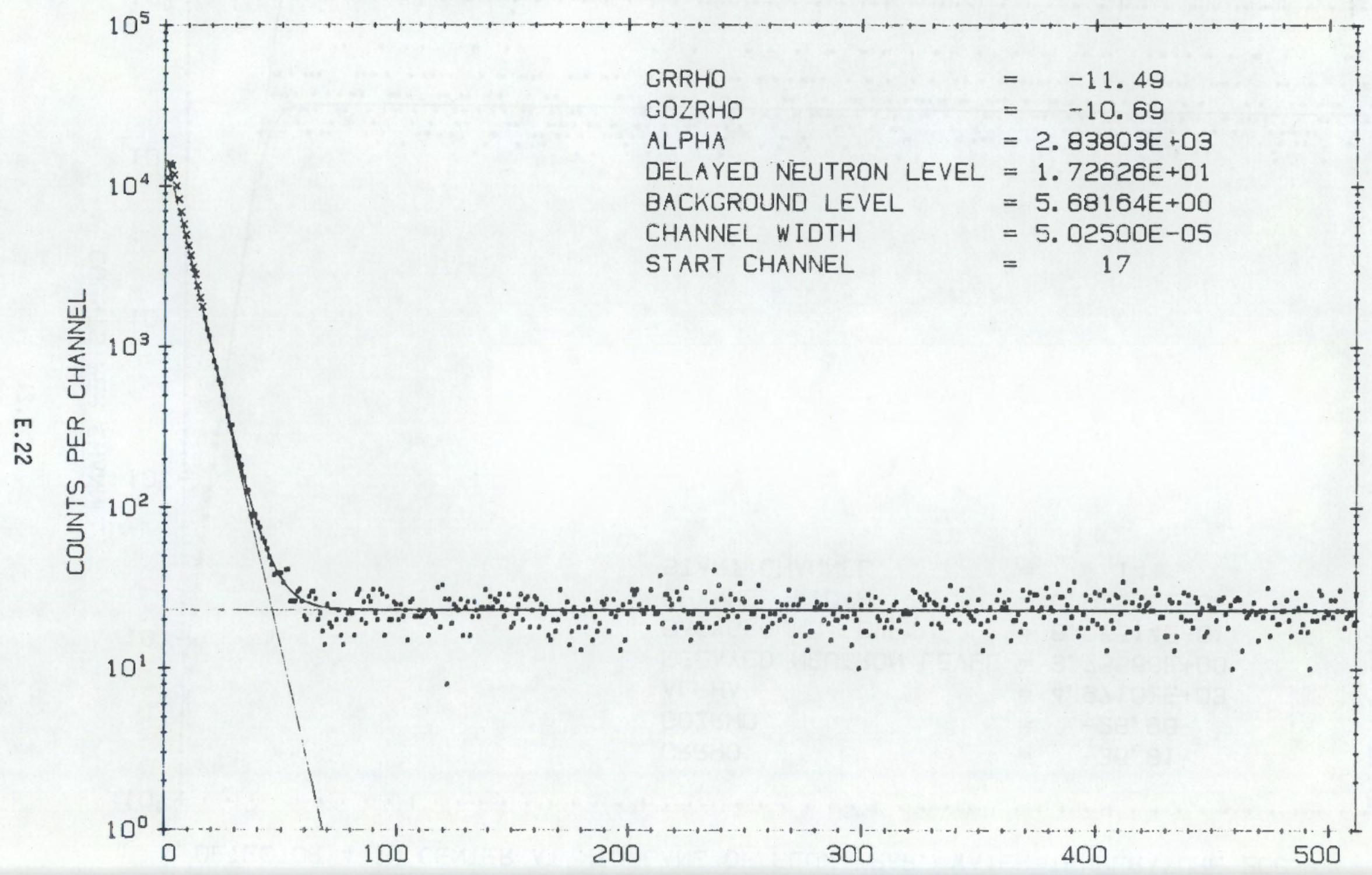

ANAL.YSER CHANNEL. NUMBER 
TTC-4 ASSEMBLY 231 WITH 0. 4515 GB/CM2 ANO 855 FUEL RODS. 4APRILB6. DETECTOR 4 IN CENTER AT MIDPLANE OF FLUX TRAP. WATER TEMPERTURE 14C.

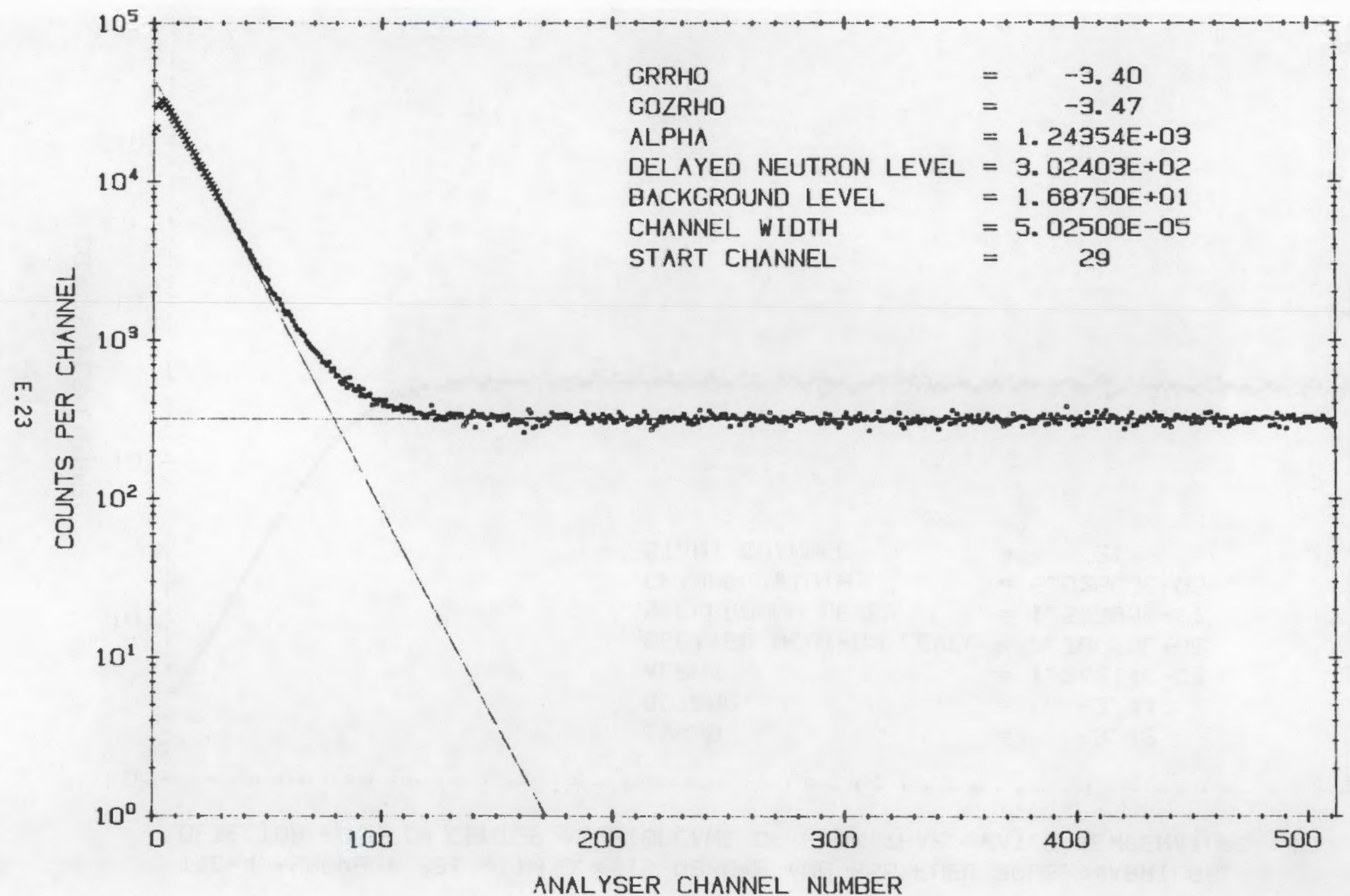


TTC-4 ASSEMBLY 231 WITH 0.4515 GB/CM2 AND 855 FUEL RODS. 4APRIL86.

OETECTOR FOUR IN CENTER AT MIDPLANE OF FLUX TRAP. WATER TEMPERATURE 14 C.

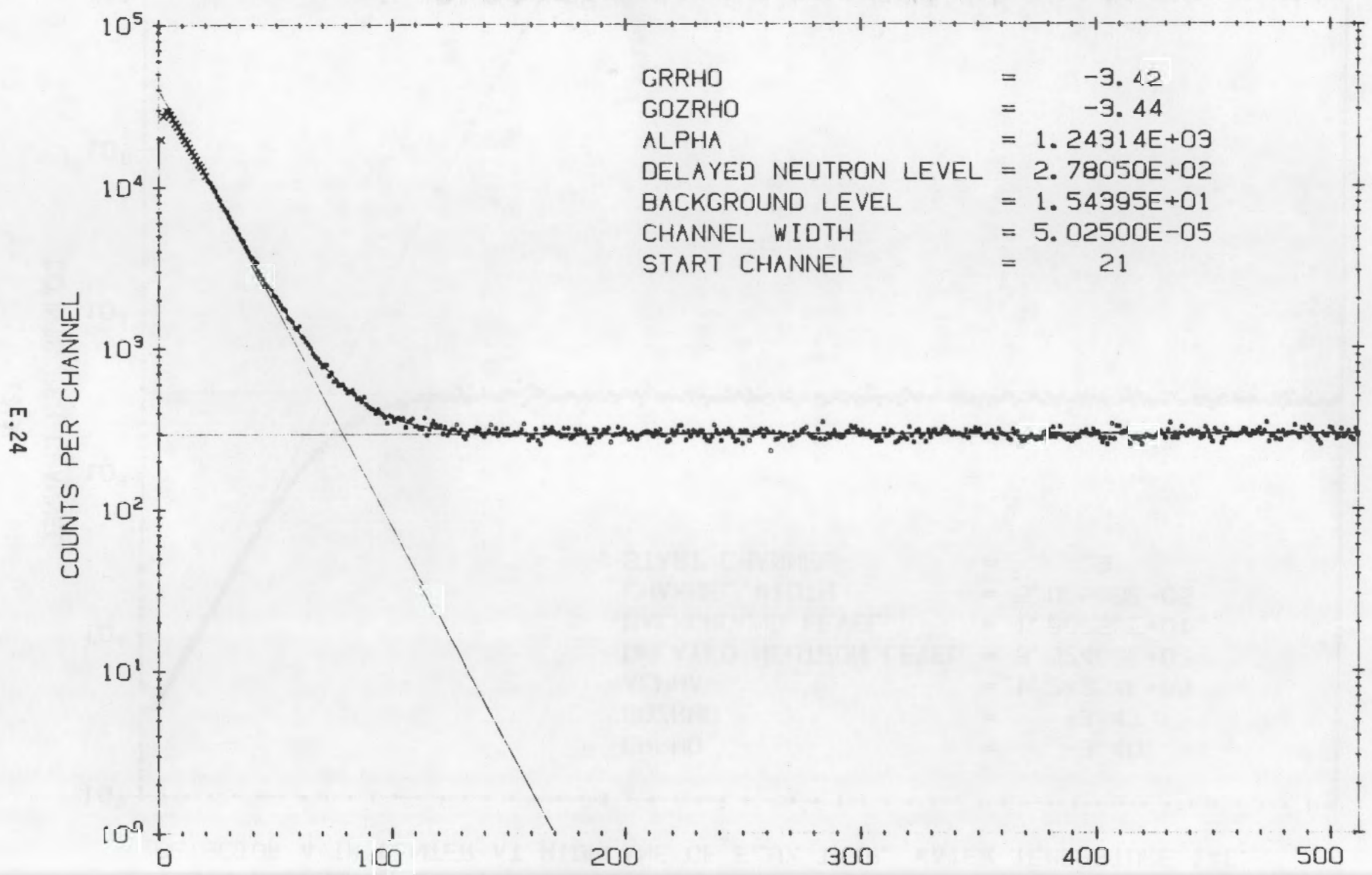

ANALYSER CHANNEL NUMBER 


\section{DISTRIBUTION}

No. of

Copies

\section{OFFSITE}

Frank Falci

DP -123

U. S. Department of Energy

Washington, DC 20545

R. F. Garrison

DP-122, GTN

Department of Energy

Washington, DC 20545

W. Lake

U. S. Department of Energy

RW-33

1000 Independence Avenue, SW

Washington, DC 20585

10 DOE Technical Information

Center

20

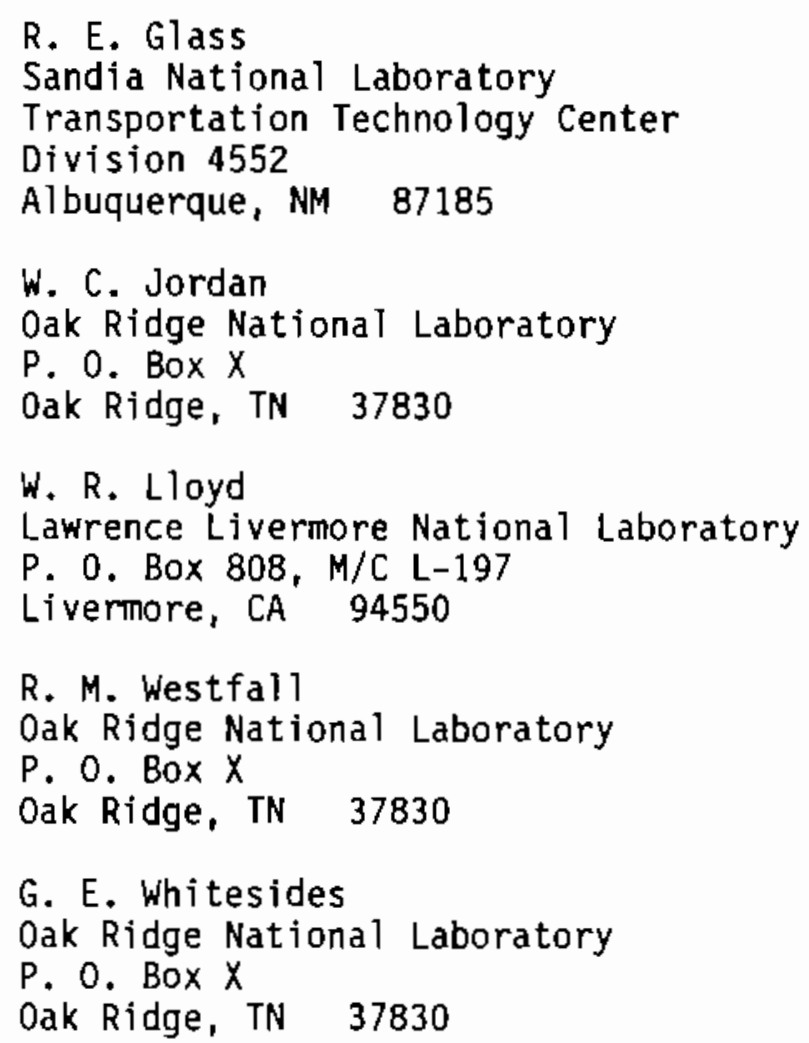

No. of

Copies

\section{ONSITE}

3 DOE Richland Operations office

D. K. Jones

D. C. Langstaff

J. J. Sutey

2 Westinghouse Hanford Company

C. L. Brown

R. D. Carter

27 Pacific Northwest Laboratory

W. W. Ballard

S. R. Bierman (10)

E. D. Clayton

M. A. Covert

A. L. Doherty

R. A. Libby

R. C. Lloyd

J. H. Smith

L. N. Terry: CML Records (2)

H. H. Van Tuyl

Publishing Coordination (2)

Technical Report Files (5) 

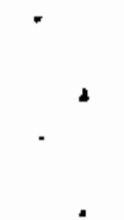

‘ 